\title{
AFCI Options Study
}

R. Wigeland

T. Taiwo

M. Todosow

W. Halsey

J. Gehin

September 2009

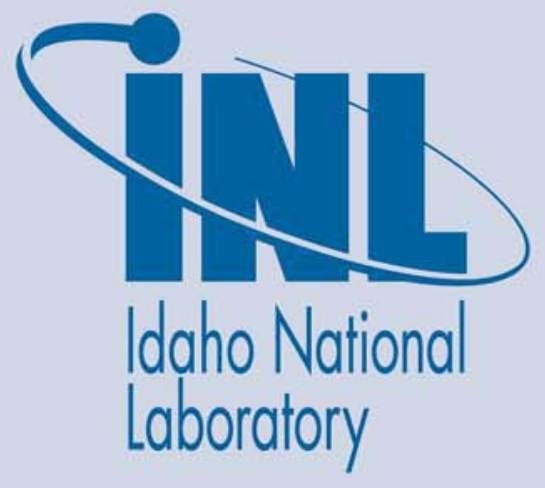

The INL is a U.S. Department of Energy National Laboratory operated by Battelle Energy Alliance 
INL/EXT-10-17639

\section{AFCI Options Study}

${ }^{1}$ ANL

${ }^{2} \mathrm{BNL}$

${ }^{3}$ LLNL

${ }^{4}$ ORNL
R. Wigeland

T. Taiwo ${ }^{1}$

M. Todosow

W. Halsey ${ }^{3}$

J. Gehin ${ }^{4}$

September 2009

\section{Idaho National Laboratory}

Advanced Fuel Cycle Initiative

Idaho Falls, Idaho 83415

http://www.inl.gov

Prepared for the U.S. Department of Energy Office of Nuclear Energy Under DOE Idaho Operations Office

Contract DE-AC07-05ID14517 


\section{DISCLAIMER}

This information was prepared as an account of work sponsored by an agency of the U.S. Government. Neither the U.S. Government nor any agency thereof, nor any of their employees, makes any warranty, expressed or implied, or assumes any legal liability or responsibility for the accuracy, completeness, or usefulness, of any information, apparatus, product, or process disclosed, or represents that its use would not infringe privately owned rights. References herein to any specific commercial product, process, or service by trade name, trade mark, manufacturer, or otherwise, does not necessarily constitute or imply its endorsement, recommendation, or favoring by the U.S. Government or any agency thereof. The views and opinions of authors expressed herein do not necessarily state or reflect those of the U.S. Government or any agency thereof. 


\section{SUMMARY}

The AFCI Options Study has examined the issues with the current use of nuclear power and collected and summarized the extensive results from previous studies for identifying the issues, the root causes, and the evaluation measures to be used for alternative fuel cycle and technology options. The importance of the fuel cycle strategy is discussed, as this directly affects the ability of an alternative fuel cycle to address the issues with nuclear power. The technology options are reviewed for the four major technology areas, fuel type (form and content), reactors and irradiation, processing, and disposal. The general capabilities of each option are summarized with respect to the potential effect that the option could have in addressing the nuclear power issues. The report concludes with a discussion of the decision framework for both nuclear fuel cycle strategies and the associated technology options, recognizing the overall advantages and limitations of various choices.

A number of observations can be made at this stage of the AFCI Options Study. It is seen that the only fuel cycle strategy that can have a significant impact, i.e., an order of magnitude or more change, with respect to the nuclear power issues is continuous recycle of all transuranic (TRU) elements. There may be a special case for near-complete burnup of UNF that could also result in significant impact on the issues, making once-through and limited recycle strategies more attractive, since such an approach is essentially equivalent to a continuous recycle strategy where all TRU is recycled. However, after review of the technical issues, this possibility is considered impractical, maybe even impossible. Deciding the fuel cycle strategy is the important first step in considering alternative nuclear fuel cycle systems.

Technology options exist for many areas of a nuclear fuel cycle. For fuel type, either uranium-based or thorium-based, it is only in the case of continuous recycle where these two fuel types exhibit different characteristics, and it is important to emphasize that this difference only exists for a fissile breeder strategy. The comparison between the thorium/U-233 and uranium/Pu-239 option shows that the thorium option would have lower, but probably not significantly lower, TRU inventory and disposal requirements, both having essentially equivalent proliferation risks. For these reasons, the choice between uraniumbased fuel and thorium-based fuels is seen basically as one of preference, with no fundamental difference in addressing the nuclear power issues. Since no infrastructure currently exists in the U.S. for thoriumbased fuels, and processing of thorium-based fuels is at a lower level of technical maturity when compared to processing of uranium-based fuels, costs and RD\&D requirements for using thorium are anticipated to be higher. The availability and utilization of thorium-based fuels along with the uranium fuel technology in the U.S. would however make available more nuclear fuel resources for future nuclear expansion.

For reactor or irradiation options, thermal and fast reactors could both be used in a once-through strategy with comparable resource needs and UNF characteristics. The same is likely to be true for the limited recycle strategy, since UNF disposal is part of the integrated system. In both cases, incremental improvements such as higher UNF burnup can be used to reduce the volume of UNF requiring geologic disposal, but with little impact on disposal issues. The selected reactor systems can be mature technologies or a more innovative approach with higher technical risk. Cost has not been a major discriminator between thermal reactor options to date, with the developers of all approaches aiming for lower overall costs, and fast reactors are widely considered to be more expensive.

However, with continuous recycle, fast neutron irradiation is seen to be preferable due to the more favorable transmutation environment, i.e., more surplus neutrons, less disturbance to the system due to the introduction of additional TRU, and other beneficial characteristics. Either fast neutron reactors or externally-driven sub-critical systems could be used, but due to the increased size, complexity and cost of the latter, any deployment would likely be limited to specialized applications such as minor actinide (part of TRU) transmutation. Fast reactors are capable of continuous TRU recycle for transmutation, and although sodium-cooled fast reactor technology is mature, it is not without technical risk. Other fast 
reactor options are at a lower level of development with significant technical issues remaining and have higher development risk. Accelerator-driven sub-critical systems and fusion-fission hybrid systems rely on fission reactor technology, both thermal and fast, which adds to the technical risk associated with the external neutron source, requiring truly major development efforts to develop and integrate the external neutron source with neutron fission technologies.

Processing is usually only associated with recycle strategies, although it could also be considered for once-through use if the benefit of having HLW instead of UNF was high enough to offset all of the added costs. At this time, this does not seem likely, so the discussion of processing is confined to recycle strategies in this report. Applicable processing options in any given fuel cycle strategy will be determined by the separations and recovery goals, the types and characteristics of the fuel being processed, relative proliferation risk, and economics. At this time, aqueous-based methods are more technically mature with low technical risk, although some of the alternatives such as electro-chemical processing are also at a stage of development where technical risk could be relatively low.

It is essential to recognize that waste disposal remains a common element for all nuclear fuel cycle strategies, being required for the disposal of highly radioactive materials, whether from fission products alone or including long-lived TRU. All UNF and HLW disposal options face the same issue of demonstrating the required isolation for these materials. There are also non-technical issues such as political and public acceptance that can dominate the decision-making process for siting and licensing such facilities. Continuous recycle appears to be the only practical fuel cycle strategy that can significantly affect waste management issues for UNF and HLW, but only if all of the TRU is recycled, leaving only fission products and residual amounts of TRU in the HLW. 
AFCl Options Study

September 30, 2009 


\section{CONTENTS}

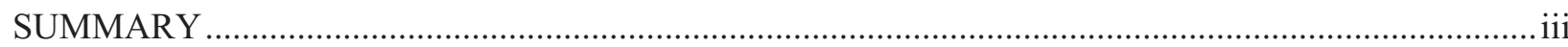

ACRONYMS

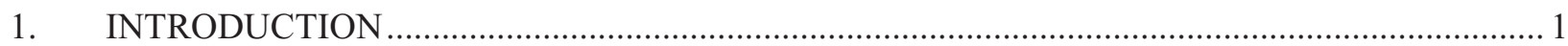

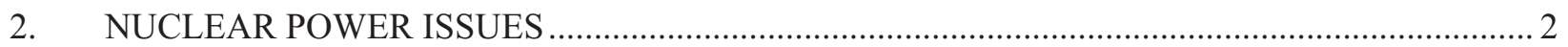

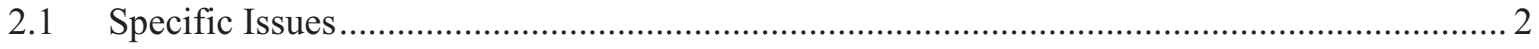

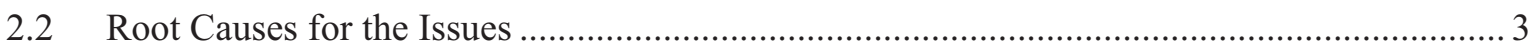

2.3 Evaluation Criteria - Performance Measures................................................................... 4

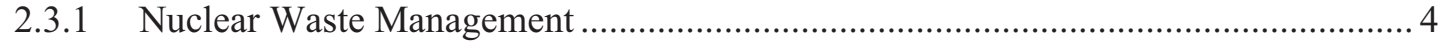

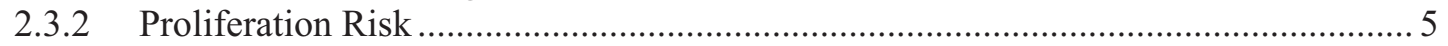

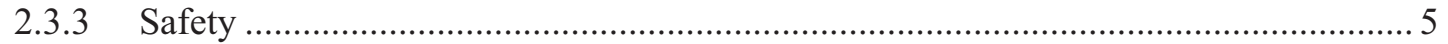

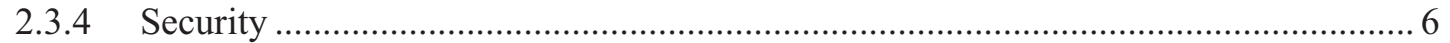

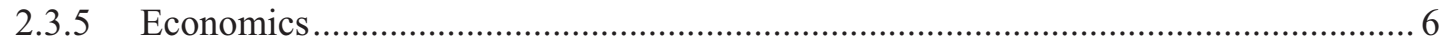

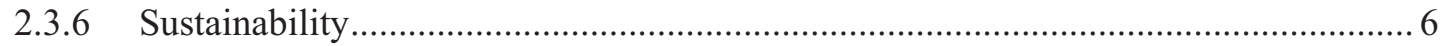

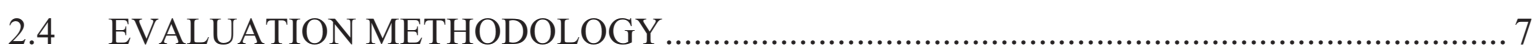

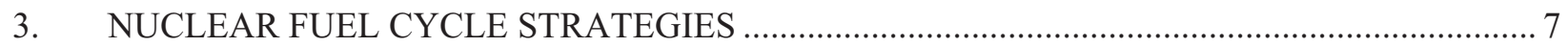

3.1 The Once-through Nuclear Fuel Cycle Strategy …........................................................ 8

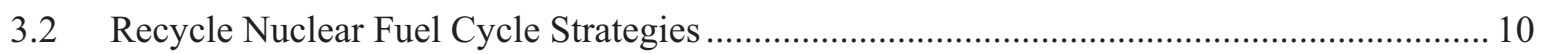

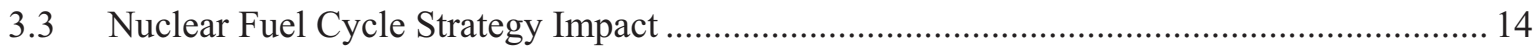

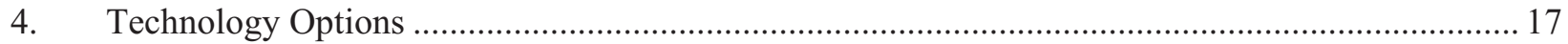

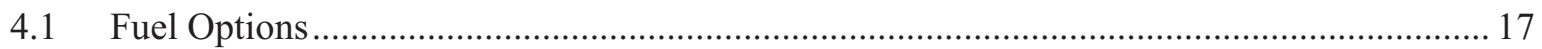

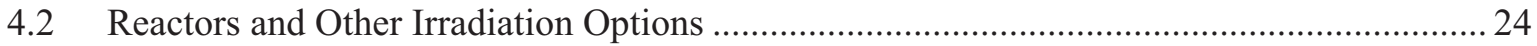

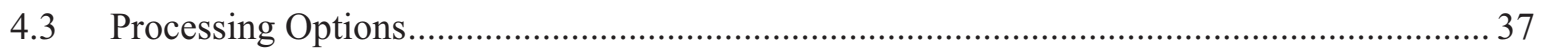

4.4 Disposal Options for UNF and Radioactive Wastes ..................................................... 42

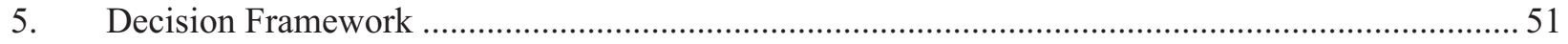

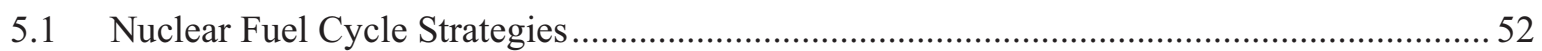

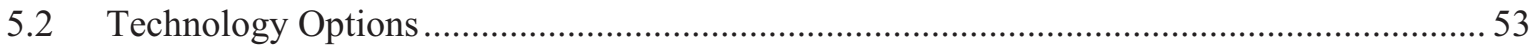

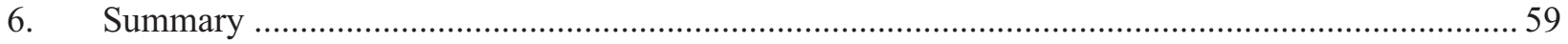

\section{FIGURES}

Figure 1. Schematic of the Once-Through Nuclear Fuel Cycle Using Enriched Uranium [17] ................ 8

Figure 2. A Limited Recycle Strategy Using Enriched Uranium Fuel [17]............................................ 11

Figure 3. A Continuous Recycle Nuclear Fuel Cycle Strategy Using Enriched Uranium Fuel [17]......... 11

Figure 4. A Continuous Recycle Nuclear Fuel Cycle Strategy Using Uranium-Based Fuel Without Uranium Enrichment [17]. 
Figure 5. Neutron Energy Spectra for Fast-Neutron (SFR) and Thermal-Neutron (PWR) Nuclear

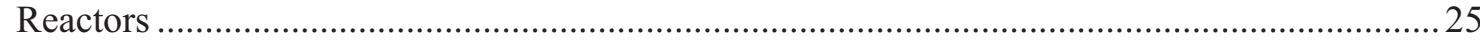

Figure 6. Cross section of a repository in unsaturated volcanic tuff..................................................... 44

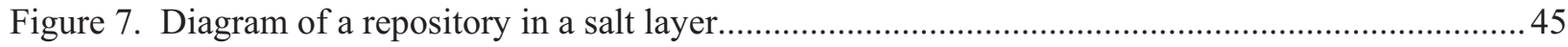

Figure 8. Cross-section detail of used fuel disposal in clay................................................................... 46

Figure 9. Cut-away view of a mined geologic repository in granite .................................................... 47

Figure 11. Decision Framework for Limited Recycle Nuclear Fuel Cycle Strategies.............................55

Figure 12. Decision Framework for Continuous Recycle Nuclear Fuel Cycle Strategies .........................58

\section{TABLES}

Table 1. Relative Impact of Alternative Fuel Cycle Strategies.............................................................. 15

Table 2. Impacts of uranium-based, thorium-based, and transuranic fuel options ................................... 24

Table 3: Important Radionuclides for Long-term Isolation Performance in Representative Disposal Environments for Normal (Undisturbed) Conditions ............................................... 48

Table 4. Dominant Risk and Performance Contributors for UNF / HLW Disposal ................................50 
AFCI Options Study 


\section{ACRONYMS}

\begin{tabular}{ll} 
AAA & Advanced Accelerator Applications \\
AFCI & Advanced Fuel Cycle Initiative \\
Am & Americium \\
ASTM & American Society for Testing and Materials \\
ATW & Accelerator Transmutation of Waste \\
CANDU & Canadian Deuterium Uranium reactor \\
Cm & Curium \\
Cs & Cesium \\
DOE & Department of Energy \\
FFH & Fusion-Fission Hybrid \\
FP & Fission products \\
Gen III & Generation III \\
Gen IV & Generation IV \\
GFR & Gas-cooled fast reactor \\
GNEP & Global Nuclear Energy Partnership \\
GTCC & Greater than Class C \\
HEU & Highly-enriched uranium \\
HLW & High-level waste \\
HTGR & High temperature gas-cooled reactor \\
HWR & Heavy-water reactor \\
IMF & Inert matrix fuel \\
LEU & Low enriched uranium \\
LLW & Low-level waste \\
LFR & Lead-cooled fast reactor \\
LWR & Light water reactor \\
MA & Minor actinides \\
MSR & Molten salt reactor \\
NRC & Nuclear Regulatory Commission \\
NWPA & Nuclear Waste Policy Act \\
PBMR & Pebble Bed Modular Reactor \\
PRPP & Proliferation Resistance - Physical Protection \\
Pu & Plutonium \\
PUREX & Plutonium-Uranium Extraction \\
R\&D & Research and development \\
RD\&D & Research, development and deployment \\
SFR & Sodium-cooled fast reactor \\
SNM & Special nuclear material \\
Sr & Strontium \\
TRU & Transuranic \\
U & Uranium \\
UNF & Used nuclear fuel \\
UOX & Uranium dioxide fuel \\
UREX+ & Uranium extraction \\
VHTR & Very high temperature reactor \\
& \\
\hline HER
\end{tabular}


AFCI Options Study 


\section{AFCI TECHNOLOGY INTEGRATION OFFICE AFCI OPTIONS STUDY}

\section{INTRODUCTION}

The Advanced Fuel Cycle Initiative (AFCI) Options Study is being conducted for the purpose of identifying potential directions for research and development of advanced nuclear fuel cycle options. These options offer opportunities to address the challenges associated with the current implementation and potential expansion of commercial nuclear power in the United States. Issues such as nuclear waste management, especially the increasing inventory of used nuclear fuel and the current uncertainty about used fuel disposal, especially in the long-term, and the risk of nuclear weapons proliferation have contributed to the reluctance to expand the use of nuclear power, even though it is recognized that nuclear power is a proven and reliable method of producing large amounts of electricity with very low emissions of greenhouse gases and other pollutants. In the AFCI Options Study, current, evolutionary, and potentially revolutionary nuclear energy options are assessed against their abilities to address these issues. The goal is to define potential AFCI research and development options based on the desired or achievable resolution of the issues.

Various DOE programs have been conducted in the past that compared advanced nuclear technology capabilities with possible missions for the purpose of providing direction for research and development, especially within the last decade. These included "roadmaps", technology development plans, reports to Congress, and other reports developed as part of the Gen IV nuclear energy systems initiative, Accelerator Transmutation of Waste (ATW), Advanced Accelerator Applications (AAA), Global Nuclear Energy Partnership (GNEP), the Advanced Fuel Cycle Initiative (AFCI) program, and many other efforts.[1-27] However, in all of the previous examples, one or more boundary conditions were imposed that limited the scope of the assessments, such as (1) having the proposed geologic repository at Yucca Mountain as the intended used fuel and high-level waste (HLW) disposal site; (2) by specifying the use of certain nuclear technologies such as light-water reactors (LWRs), fast reactors, gas-cooled reactors, and accelerator-driven sub-critical systems, (3) evaluating only a few separation systems such as UREX+ and electrochemical; or (4) by the desire to move forward quickly with implementation of an advanced nuclear fuel cycle. These previous efforts are used to provide background information while a broader view is taken in this study, without any boundary conditions or constraints, on all aspects of an advanced nuclear energy fuel cycle, including irradiation facilities and disposal options.

In this report, the issues with nuclear power, their root causes, and the evaluation measures for judging the effectiveness of an advanced nuclear fuel cycle are described. This is followed by a discussion of the range of possible nuclear fuel cycle strategies and an assessment of the ability of each strategy to address issues. A strategy is defined in this study as the basic structure of the nuclear energy fuel cycle, such as a strategy based on the once-through use of nuclear fuel followed by direct disposal, or a strategy that would process used fuel and employ continuous recycle of actinide elements with disposal of HLW. Previous studies have indicated that it is the characteristics of the strategy that largely determine how well an advanced nuclear fuel cycle can address nuclear power issues. Any selected strategy can be implemented using one or more nuclear technologies, often with similar results but in many cases with significant differences between technologies that would favor one over another. Due to the large number of variations that are possible, it is important to first consider what one may want to achieve (one or more strategies), and to then focus on the details of how one can do it (the nuclear technologies).

There is then a discussion of the basic technology options and their impact on the issues, which can then be used to support the decision-making process about specific technologies for directing research and 
development efforts. The report concludes with a summary of the decisions to be made and the framework for making the decisions based on the addressing the issues with nuclear power.

\section{NUCLEAR POWER ISSUES}

Today, there are a number of issues ascribed to the use of nuclear power. Although these issues are not new, the relative importance of each of the issues changes with time due to events such as nuclear reactor accidents and nuclear weapons proliferation. The perceived importance of the issues at any given time has been instrumental in past decisions on the directions of nuclear energy research and development (R\&D) in the United States. In the 1960s and 1970s, the perception that uranium resources would be limited prompted R\&D into breeder reactors for providing much larger supplies of nuclear fuel. In the 1980 s and into the 1990s, safety, proliferation risk, and economics focused R\&D on safer, more secure and affordable nuclear energy systems. Later in the 1990s and into the $21^{\text {st }}$ century, the growing issue of nuclear waste and used (i.e., spent) fuel disposition resulted in R\&D being focused on approaches for treating used nuclear fuel to reduce its radiotoxicity and the volume and mass requiring long-term geologic disposal. Looking forward, it is likely that all of these past issues will continue to be relevant, at least to some degree, and all should be considered as nuclear energy R\&D is planned.

\subsection{Specific Issues}

The AFCI Options Study has focused on six general issues as the basis for examining alternatives to the current commercial strategy in the United States of using light water reactors (LWRs) with a oncethrough fuel cycle followed by direct disposal of the used fuel in a repository at Yucca Mountain.

- Nuclear Waste Management - Radioactive wastes such as used nuclear fuel (UNF) and highlevel waste (HLW) represent a significant long-term risk due to the presence of long-lived radioactive isotopes, prompting decisions that the only acceptable disposal path is geologic isolation for hundreds of thousands of years or longer. HLW is defined in NRC regulations to be either spent (used) reactor fuel when it is accepted for disposal or waste materials remaining after spent fuel is reprocessed. Uncertainty about the ability to provide sufficient isolation has prevented implementation of geologic disposal. Risk from most low-level waste (LLW) disposal has been judged to be minimal, resulting in licensed, yet controversial, disposal using near-surface burial, and there is the potential for some 'greater than Class C' (GTCC) LLW that may require geologic disposal.

- $\quad$ Proliferation Risk - Global proliferation risk concerns from an expanding use of nuclear power arising from the connection between the use of civilian nuclear power and the ability to develop nuclear weapons capability. These are plausible concerns, given the required deployment of fuel cycle technologies such as uranium enrichment that could produce weapons-usable uranium, nuclear systems that have the potential to produce weapons-usable materials by neutron irradiation of uranium or thorium, and processing of UNF that provides the ability to extract these materials.

- $\underline{\text { Safety }}$ - All facilities and activities, including reactor operation, processing, transportation and storage may have safety-related risks due to the potential for events or accidents that can disperse radioactive materials.

- $\underline{\text { Security }}$ - The risk that a terrorist attack or sabotage could result in radioactive release from any nuclear power related facility or activity.

- Economics - Cost of nuclear power has been an issue for several decades, primarily due to the large capital investment required for building nuclear power reactors, and affected by uncertainties about licensing, the time required for plant construction prior to operation, permission to operate the plant once constructed, and cost recovery once the plants have been approved for operation. 
- $\quad$ Sustainability - The ability to sustain nuclear power depends on resolving existing issues and will also depend on the availability of resources in the future. Overall environmental impact of nuclear power and its fuel cycle may be an issue if the impact is judged to be significant.

All of these issues have been acknowledged in the past and the nuclear power infrastructure in the United States includes features that have been implemented to address these concerns.

- The Nuclear Waste Policy Act (NWPA) of 1982 and subsequent amendments defined an R\&D strategy for disposing of UNF and HLW, resulting in the Yucca Mountain project.

- The United States continues to discourage processing that recovers separated plutonium.

- The Nuclear Regulatory Commission (NRC) was created in 1974 to provide oversight of the nuclear power industry, and developed a system of regulations for licensing of nuclear facilities.

- Nuclear power plant security has been significantly increased since 9/11/2001.

- New simplified nuclear power plant designs with the promise of lower construction costs along with a more efficient licensing process developed by the NRC provide a greater assurance of plant operation and cost recovery.

- Exploration and development of new uranium resources for fuel

Conditions continue to evolve due to technical, economic, and political realities such that the directions for nuclear energy R\&D must be periodically reevaluated to ensure appropriateness and relevance. A major purpose of the AFCI Option Study is to assess what can be done within the context of the existing once-through strategy and with alternate strategies to address these issues.

\subsection{Root Causes for the Issues}

There are one or more characteristics of the nuclear power system that contribute to creating the issues with nuclear power discussed above, as follows:

- The root cause of the waste management issue is mainly the hazard posed by UNF and HLW due to the presence of fission product and transuranic (TRU), some of which are long-lived. They are produced as part of the nuclear fission process and are a fundamental characteristic of UNF and HLW. Addressing the issue of UNF and HLW disposal requires either siting an acceptable geologic repository that provides sufficient isolation or using treatment methods to remove and modify the hazardous TRU and fission products to sufficiently reduce the hazard prior to disposal. Using alternative fuels and irradiation technologies to reduce the content of hazardous materials in the UNF and HLW may mitigate the problem, but the disposal issues would still remain. Another aspect concerns the LLW, which although representing very low risk, still requires disposal.

- The root cause of concerns about nuclear weapon proliferation is that fissile materials such as $\mathrm{Pu}-$ 239, U-233, and U-235 are usable in nuclear weapons, i.e., special nuclear materials (SNM), and the creation of such materials is an unavoidable fundamental property of the nuclear fission process. Addressing the issue requires approaches that would eliminate the opportunities to obtain SNM, or ensure detection of attempts to acquire SNM for nuclear weapons.

- The root cause of safety concerns is that nuclear power creates and uses significant amounts of highly radioactive materials. Current nuclear reactors operate at high temperatures and pressures that are required for efficient electricity production, with potential accident conditions possibly resulting in dispersal of the radioactive materials. Processing and transport of the UNF and HLW also offer opportunities for accidents to result in release of radioactive materials. Addressing this issue requires the use of facilities and activities with sufficient safety features and operational procedures to minimize or eliminate the likelihood of such events. 
- The root cause of security concerns is the existence of highly radioactive materials at reactor and other facilities that may be dispersed through terrorist acts or sabotage. Addressing this issue requires sufficient reduction in the amounts of such materials or eliminating the potential for such acts to occur.

- The root causes of concerns about economics are the large and complex nature of nuclear reactor systems, the corresponding operational conditions required to satisfy safety, security, and electricity production requirements, and natural resource requirements, all of which contribute to costs. The complexity results in a complicated and uncertain licensing process that is another cost contributor. Addressing this issue requires development of less complex or alternative systems and activities that cost less initially, cost less to operate, and are more amenable to safety evaluation to facilitate the licensing process.

- The root cause of sustainability concerns is the uncertainty about the availability of natural resources required to support nuclear power, including adequate disposal space, fuel supply, and materials. Addressing this issue requires developing systems that need less disposal space, less fuel, and less material for construction and operation, or alternatively, more attractive disposal options, additional fuel supplies, and other material choices.

The important observation to be derived from the root causes is that many of the issues arise due to the unavoidable presence of hazardous and weapons-usable materials in UNF and to the ability to provide safe and secure disposal for such materials. The importance of UNF content and the required disposal is used to structure the decision-making process for identifying research and development opportunities.

\subsection{Evaluation Criteria - Performance Measures}

Assessment of the ability of alternate nuclear fuel cycle strategies to address the root causes of the nuclear power issues requires the establishment of measures to be used as a basis of comparison. There has been a substantial amount of work done related to all of the root causes, as used in the earlier assessment reports [1-27] and possible measures are available for each of the issues. These measures have been selected since they are high level measures, suitable for understanding the implications of alternate nuclear fuel cycle strategies and advanced technology options. More detailed measures could be specified, but given the immature nature of many advanced technologies, credible information would be difficult to provide, and is not essential to inform the decision-making process. The measures have been listed under the major issue where the measure has the most effect, although many of the measures impact more than one of the issues. At this time, in conducting the initial stages of the AFCI Options Study, data for some measures may only be preliminary while for some others data may even not exist. Statements for these measures may not be possible and indicate where additional information may be needed to support evaluation of a particular fuel cycle strategy or technology.

\subsubsection{Nuclear Waste Management}

Measures for nuclear waste management provide insight into the ability to either provide the required isolation or to alter the waste characteristics to reduce the hazard, as described in Section 2.2.

- Estimated peak dose rate - estimate of the peak dose rate, usually for a member of the general population, that would result from the existence of the repository; provides a measure of the geologic isolation potential and the risk for undisturbed repository conditions for UNF and HLW disposal

- Radiotoxicity of disposed materials - reflects the radiological hazard of the disposed materials and provides a measure of the hazard at any given time from contact with the disposed materials; measures the risk for disturbed repository conditions such as human intrusion 
- UNF, HLW, and LLW - the mass of hazardous radionuclides requiring disposal in the environment, on a per unit of energy generated basis; the volume and mass of the specific form of UNF, HLW, and LLW would also need to be considered for detailed planning of the disposal paths

- Interim (decay) storage - storage used as part of a fuel cycle strategy to allow shorter-lived radionuclides to decay, affecting radiation and decay heat; interim storage in spent fuel pools or dry casks can favorably impact UNF handling and processing as well as UNF, HLW, and LLW disposal requirements

- Heat load - the decay heat at the time of disposal for UNF and HLW; mainly an engineering issue that provides a measure of the repository space required for waste disposal

\subsubsection{Proliferation Risk}

Measures for proliferation risk allow judgments to be made as to the relative increase or decrease in proliferation risk as a result of nuclear fuel cycle activities that may alter the amount and availability of SNM, or change the detection probability of attempts at acquiring SNM for weapons use. The measures were developed in recognition of more detailed proliferation risk assessment analysis methodologies and measures, such as in the Gen IV Proliferation Resistance - Physical Protection initiative, and capture the major contributors to proliferation risk. [28]

- Inventory of weapons-usable materials (SNM) - the amount of SNM present in the fuel cycle as in-process materials, UNF and HLW; provides an indication of the availability of SNM that in principle could be diverted to weapons use given suitable technologies and that needs physical protection

- Material attractiveness - a measure of the difficulty of handling and using the SNM; provides a measure of the availability and usefulness of the SNM present in the fuel cycle as in-process materials, UNF and HLW; recent examples are given in Ref. 29 and 30

- Need for Uranium Enrichment - uranium enrichment technology is capable of producing SNM without the need for reactors or other irradiation environments; need for uranium enrichment provides a measure of the extent to which this technology must be used, if at all

- Safeguardability - a measure of the ability to implement safeguards technology for detecting attempts to acquire SNM using nuclear fuel cycle facilities and materials; provides a measure for detecting diversion, misuse, or theft, and includes intrinsic and extrinsic features of the technologies

\subsubsection{Safety}

Safety requirements have been defined by the NRC so that the operation of nuclear reactors, facilities using nuclear materials, and transportation of nuclear materials can all be utilized without posing a significant risk to public health and safety. Addressing safety concerns requires the use of reactors, facilities, transportation and activities with sufficient safety features and operational procedures to minimize or eliminate the likelihood of catastrophic events that pose a significant risk to workers and the general public such that all parts of the nuclear fuel cycle are suitable for being licensed.

- Level of difficulty in licensing the facilities and operations, including the potential for introducing new safety issues with alternative fuel cycle strategies and technologies - a qualitative estimate of the relative difficulty of developing a licensable facility for a new technology based on experience; provides a measure of the inherent hazards associated with the technology 
In this report, it is assumed that any of the technologies can be licensed, in principle. Further determination is not possible at this evaluation level given that safety is greatly influenced by design and operational details as well as the required activities, including transportation.

\subsubsection{Security}

Addressing security concerns requires reduction in the amounts of hazardous radioactive materials or minimizing the potential for terrorist and sabotage acts to occur.

- Inventory of radioactive materials - a measure of all of the materials that could be used for exposing workers or the general population to radioactive materials; provides a measure of the potential risk

- Ability to provide physical security - terrorist actions and sabotage are physical actions taken by workers or outsiders; measures the ability to eliminate outsider access to facilities where hazardous radioactive materials are stored

These measures are not treated separately in the discussions that follow, but are used to provide the basis for the any qualitative statements in the report.

\subsubsection{Economics}

The economic impact of an alternative fuel cycle strategy depends on similarities to the existing infrastructure as well as the number and complexity of alternative facilities and activities, including direct costs and costs from required activities such as licensing and operations.

- Similarity to existing infrastructure - a qualitative estimate of the differences; provides a measure of the new supporting infrastructure what would be required with an alternate fuel cycle

- Capital at risk - a estimate of the financial impediments to implementation

- Technical maturity - a qualitative measure indicating the investment that would be needed to develop the technology to the level of commercial deployment

- Technical risk - a qualitative measure of the level of scientific development that would be needed before an option can be developed, providing insight into potential additional cost

- Development time - an estimate that is provided for background information; results from the estimated technical risk and maturity and based on experience with technology development

- Life-cycle costs - a quantitative assessment identifying the added costs expected for technology development, number of facilities and activities, and operations supporting the fuel cycle, and decommissioning balanced by the avoided costs for parts of the fuel cycle where reductions could be expected

In this study, information on these measures is combined into overall statements reflecting the additional facilities required or avoided, along with qualitative information about technical maturity and risk.

\subsubsection{Sustainability}

Some of the previous measures also have an impact on the sustainability of nuclear power. The measures in this section specifically address issues that have not already been covered.

- Fuel resources - the quantity of new fuel resources per unit of energy generated; a measure of the need for new natural resources, uranium and / or thorium, to support the fuel cycle and indicative of the efficiency with which the resources are utilized 
- Disposal needs - a qualitative assessment on the relative required disposal space on an energygenerated basis; provides an estimate of the utilization of disposal capabilities.

No determination is made as to the potential availability or uranium or thorium resources in this report, only information on the relative resource requirements between fuel cycle and technology options.

\subsection{EVALUATION METHODOLOGY}

For the purposes of assessing the ability of advanced fuel cycle strategies to address the issues with nuclear power, the approach is to compare the relative change in the measures with respect to a reference nuclear fuel cycle, which for this study is the current nuclear power implementation in the United States, represented as follows:

- Mining, milling, and enrichment of uranium to support the current and planned evolutionary Gen III LWRs, e.g., AP-1000, ABWR, etc.

- Once-through use of uranium-based nuclear fuel in LWRs for electricity production

- On-site storage of UNF for several decades

- Direct disposal of UNF.

It should be emphasized that this nuclear fuel cycle strategy is only used for reference purposes in the comparisons and represents current "business as usual", i.e., the existing infrastructure as well as known planned installations. It is important to recognize that disposal of highly-hazardous radioactive materials is always required regardless of the nuclear fuel cycle strategy. Studies to date have shown that both fission product and actinide content in UNF and HLW contribute significantly to the risk from disposal, as illustrated by Ref. 31-33.

The nuclear fuel cycle strategy options are analyzed first since the strategies have a large impact in determining what can be accomplished in affecting the issues of waste management, proliferation risk, and sustainability. Then technology options for each component of a fuel cycle strategy are reviewed. This organization can be viewed as a "top-down" approach, focusing first on the larger question of the overall nuclear fuel cycle strategy, and then discussing the specific technology options, where the intention has been to include all realistic alternatives. This approach supports the purpose and objectives of the AFCI Options Study to provide the framework for understanding the capabilities of advanced nuclear fuel cycles, identifying where information may be needed, and making decisions both about nuclear fuel cycle strategies and the candidate technologies for research and development.

\section{NUCLEAR FUEL CYCLE STRATEGIES}

Evaluating any alternative nuclear fuel cycle strategy to augment or replace the current nuclear energy infrastructure in order to resolve the issues with nuclear energy requires consideration of the entire integrated nuclear energy system, including natural resources, facilities and their operation, and the ultimate disposition of any and all waste materials. Conceptually, this approach allows one to take advantage of synergistic features among the components of the integrated system, resulting in better coordination of technologies and operation, reducing waste production and optimizing disposal. Since, as discussed in Section 2, many of the issues with nuclear power arise from the actinide and fission product content in UNF, there are two basic strategies to the use of nuclear power differentiated by the management of the UNF, 'once-through' and 'recycle'. For the purposes of evaluating the potential of nuclear fuel cycle strategies, the focus is on the issues of nuclear waste management, proliferation risk, and sustainability. The other issues, such as safety and security, are also dependent on the technology options used in each part of the fuel cycle strategy and discussion of these issues is deferred until Chapter 4 where technology options are discussed. In the following discussion, the term 'fissionable' is used to 
describe materials that can be fissioned to produce power, instead of using more technical terms such as 'fissile' or 'fertile' that require reference to specific irradiation conditions.

\subsection{The Once-through Nuclear Fuel Cycle Strategy}

The once-through nuclear fuel cycle strategy consists of fabricating nuclear fuel made from naturallyoccurring material, using it once in a nuclear reactor, usually followed by direct disposal of the UNF, typically in a deep geologic repository. As discussed in Chapters 1 and 2, the high level of radiation associated with UNF requires isolation from the biosphere for hundreds of thousands of years to allow time for radioactive decay. This is currently the nuclear fuel cycle being pursued in the United States, and is shown schematically in Figure 1 for the use of uranium-based fuel, giving the flow of materials from one part of the fuel cycle to the next, leading to final disposal. Uranium enrichment is also shown as this is required for most once-through fuel cycles, for operability, efficient fuel utilization, or both, although the depleted uranium byproduct is not shown. For once-through fuel cycles, depleted uranium may be reusable for further enrichment processing, but eventually would not be reusable and becomes waste.

There are only 3 major components of the once-through fuel cycle strategy, the new nuclear fuel, the power plant, and disposal, with this simplicity being one of its attractive features. Transportation requirements are not shown in Figure 1, but would occur between most steps in the fuel cycle. Disposal of HLW and LLW in addition to the UNF also needs to be considered as part of the once-through strategy. Interim storage is also shown prior to disposal because it is a potential option for any oncethrough fuel cycle. It provides benefits for the planning and logistics of waste management due to the added time delay and to UNF handling and disposal due to the reduced radiation from radioactive decay, although there are also costs for including interim storage. Due to the simple nature of the once-through fuel cycle, there are relatively few opportunities for options and the use of advanced technologies to affect the content of UNF and the other issues as discussed in Section 2.2, many of which are interdependent.

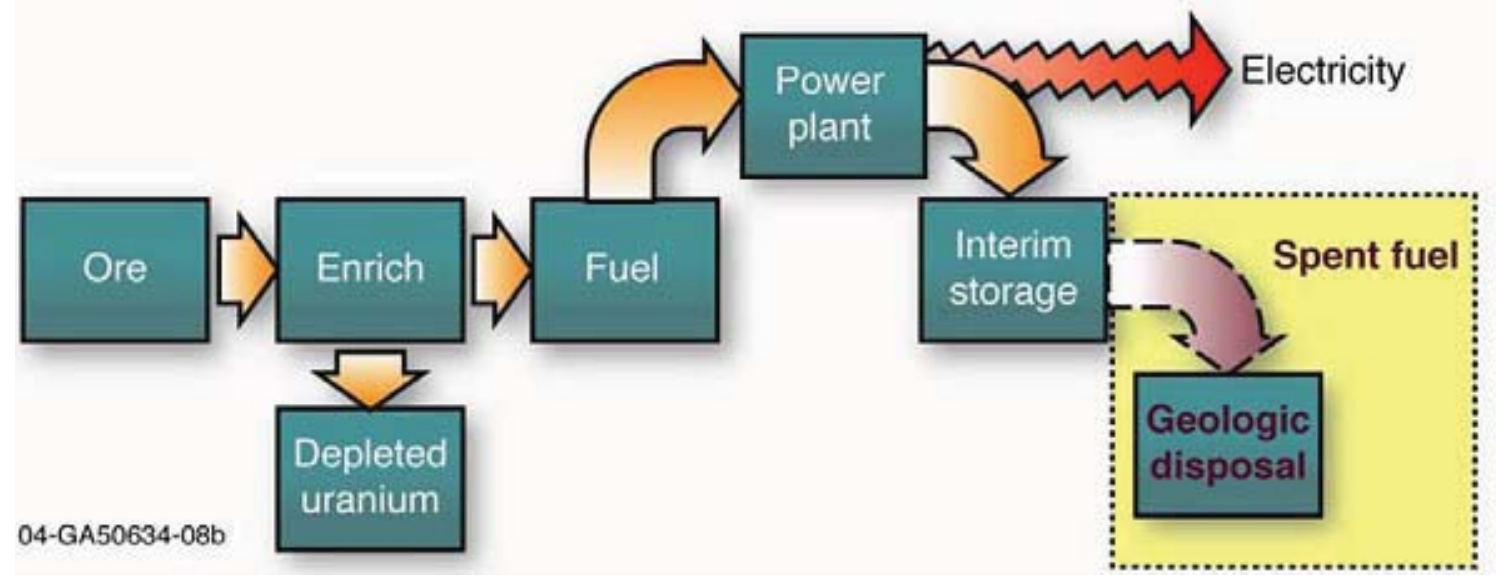

Figure 1. Schematic of the Once-Through Nuclear Fuel Cycle Using Enriched Uranium [17]

\section{Fuel Options and Enrichment}

In a once-through strategy, there is no processing of fuel either during or after irradiation. As a result, the fission product and actinide content of UNF are primarily affected by the type of fuel and the discharge burnup, i.e., the extent to which the fuel has been consumed. In order for a nuclear reactor power plant to operate and produce power, the reactor must contain fissionable materials. In the once-through strategy with reactors, there must be a naturally-occurring supply of fissionable (fissile) material for making new nuclear fuel, of which uranium-235 is the only one that occurs in any significant amount in nature. For this reason, only uranium or thorium-uranium are usable in the once-through fuel cycle strategy utilizing 
nuclear reactors since thorium by itself is not capable of sustaining a fission chain reaction. In the case where an external source supplies neutrons, in principle one could also start with thorium-only fuel but the plant would not produce power until sufficient U-233 has been created in the fuel. Similarly, natural or depleted uranium-based fuel could be used with an external neutron source but significant power would not be produced until sufficient $\mathrm{Pu}-239$ has been created.

It is possible to use natural uranium for new fuel, as in heavy-water- or graphite-moderated reactors, although fuel usage may be inefficient, requiring frequent refueling of the reactor and generating large amounts of UNF per unit of energy produced. For many reactor technologies, the uranium needs to be enriched in U-235 content in order to sustain the nuclear chain reaction. Enrichment allows fuel to be used longer before discharge, thus reducing the quantity of used fuel per unit of energy produced and altering the amounts and proportions of fission products and actinide elements.

A by-product of the uranium enrichment process is the depleted uranium tails that could be used again in the enrichment process depending on the U-235 content, but depleted uranium will ultimately be a waste stream requiring disposal in a once-through fuel cycle strategy. Uranium enrichment is generally limited to less than $20 \%$ U-235 due to proliferation concerns, placing an upper limit on burnup in reactors. Consideration of higher enrichment would allow higher burnup. If near-complete burnup of the fuel in reactors is an objective, then, the system must have very high uranium enrichment (possibly beyond $90 \%$ ). This would make the system impractical from safety and operations viewpoints, and the use of HEU is not considered for commercial power production. On the other hand, externally-driven subcritical systems, such as the fusion-fission hybrid system, do not require uranium enrichment to achieve high burnup, and are being promoted by the developers for near-complete burnup of the fuel. The system would build in and consume fissile material, but it is not likely that such systems will be able to achieve complete burnup of the fuel in practice due to the long irradiation time that would be required at typical neutron flux levels.

If uranium enrichment is required, gaseous diffusion or gas centrifuge technology is typically used today for this purpose. Laser isotope separation and other advanced enrichment options are being developed. Currently, in the U.S., enriched uranium fuels are also obtained from the down-blending of weaponsgrade highly-enriched uranium to low-enriched uranium.

In evaluating the importance of fuel resources in a nuclear energy strategy, it should be recognized that the largest environmental impacts and public health effects from nuclear energy arise in the front end of the fuel cycle, in particular from the mining and milling of uranium ore to obtain the uranium needed for fuel. As stated in Ref. 34, an increased awareness has been observed in all countries of the need for environmental protection of all steps of the nuclear fuel cycle, but in particular for uranium mining and milling since the release of uranium daughter products from mines and tailings results in a general dose to workers and the general population that exceeds the impacts from both reactor operations and waste management, for both once-through and recycle approaches.

\section{Nuclear Power Plants - Reactors and Other Irradiation Environments}

There are many irradiation technology options that can be proposed for a power plant in an advanced nuclear fuel cycle, including conventional nuclear reactors, although all options can be classified in one of two categories, either neutron-based or non-neutron-based. For neutron-based irradiation, the first option involves using a self-sustaining nuclear reactor, where the operating reactor is said to be "critical" when it is capable of achieving the self-sustaining neutron fission chain reaction. A second option is by using a "sub-critical" system, one that does not sustain the neutron fission chain reaction by itself, but is driven by neutrons from an external source, such as a proton accelerator driven spallation neutron source, or the fusion driver in a fusion-fission hybrid. Other irradiation approaches include the use of non-neutron elementary particles (like protons, electrons, ions, and photons) to induce nuclear fission and other 
reactions, but these are considered expensive and impractical for power production or material transmutation, as they have low efficiencies and low intensities. Whether a critical or externally-driven sub-critical system is used for irradiation, the nuclear materials in the fuel are either fissioned or transmuted into other elements, and therefore there is no significant difference in the UNF characteristics.

The need for enrichment is determined by the characteristics of the irradiation option and the desired fuel usage. The burnup of the nuclear fuel at discharge is the measure of the amount of fuel that has been fissioned. The remaining fuel in UNF is either unchanged from the original fuel when it was loaded into the reactor, or is the product of initial uranium transmutation into heavier TRU elements such as plutonium, neptunium, americium and curium. As a result, discharge burnup can alter UNF content, but the UNF will always contain fission products in proportion to the power generated and higher actinide elements in significant quantities unless the fuel is completely consumed (impossible in practice using a once-through fuel cycle strategy). If an externally-driven subcritical system is not required to produce power from the fission component, it might be possible to achieve much higher burnup than reactors that are self-sustaining, i.e., critical. However, there would still be substantial TRU and fission product content at discharge. Reactors operating on HEU fuel can also achieve high burnup, but as mentioned above, proliferation concerns discourage the use of HEU, and the UNF also contains significant TRU along with the fission products.

\section{Disposal Environments for Waste Management}

The once-through nuclear fuel strategy generates substantial amounts of highly-radioactive UNF, which is by definition the only HLW produced with a once-through cycle. Any LLW that is created in the fuel cycle will require disposal. Since there most likely would be no treatment of these materials prior to disposal, the UNF and some GTCC LLW require long-term isolation from the biosphere to allow time for radioactive decay to reduce the radiological hazard. Developing a convincing scientific basis that a disposal approach would provide the required isolation for such large quantities of hazardous materials has proven to be challenging due to the very long times over which performance is required and the large uncertainties concerning the potential for release of the radioactive materials. Due to the much lower radiological hazard, the LLW does not require such isolation, but is managed to provide the required level of isolation based on applicable regulations.

\section{Economics of the Once-Through Fuel Cycle Strategy}

The economics of the once-through fuel cycle strategies are determined by the costs for each component in the strategy. Costs for construction of the irradiation facilities and the UNF/HLW disposal sites are usually large, costs for resource acquisition and uranium enrichment (if needed) are moderate, and fuel fabrication costs are typically the smallest component. Operational costs are generally low, contributing to the current state where nuclear power is among the lowest-cost generators of electricity. As a result, relative cost comparisons between once-through options would likely be dominated by differences in costs for irradiation facilities and disposal, although future fuel resource acquisition may also become a significant difference depending on the availability of natural resources, and complex approaches could substantially increase operational costs.

\subsection{Recycle Nuclear Fuel Cycle Strategies}

In recycle nuclear fuel cycle strategies, at least some UNF is processed for recovery of certain elements for further transmutation into less hazardous or shorter-lived materials, substantially altering the characteristics of materials destined for disposal. Recycle strategies that include the disposal of UNF and HLW are termed "limited recycle", since disposal of UNF indicates the limit of the recycling activities, an example of which is shown in Figure 2. Recycle strategies that only have disposal of HLW, with processing of all UNF for recycle, are termed "continuous recycle" since the recycling activities continue 
without limit. A schematic of the continuous recycle strategy is shown in Figure 3 when enriched uranium is used for fuel in at least part of the system. Figure 4 shows a schematic of the continuous recycle strategy when uranium enrichment is not needed.

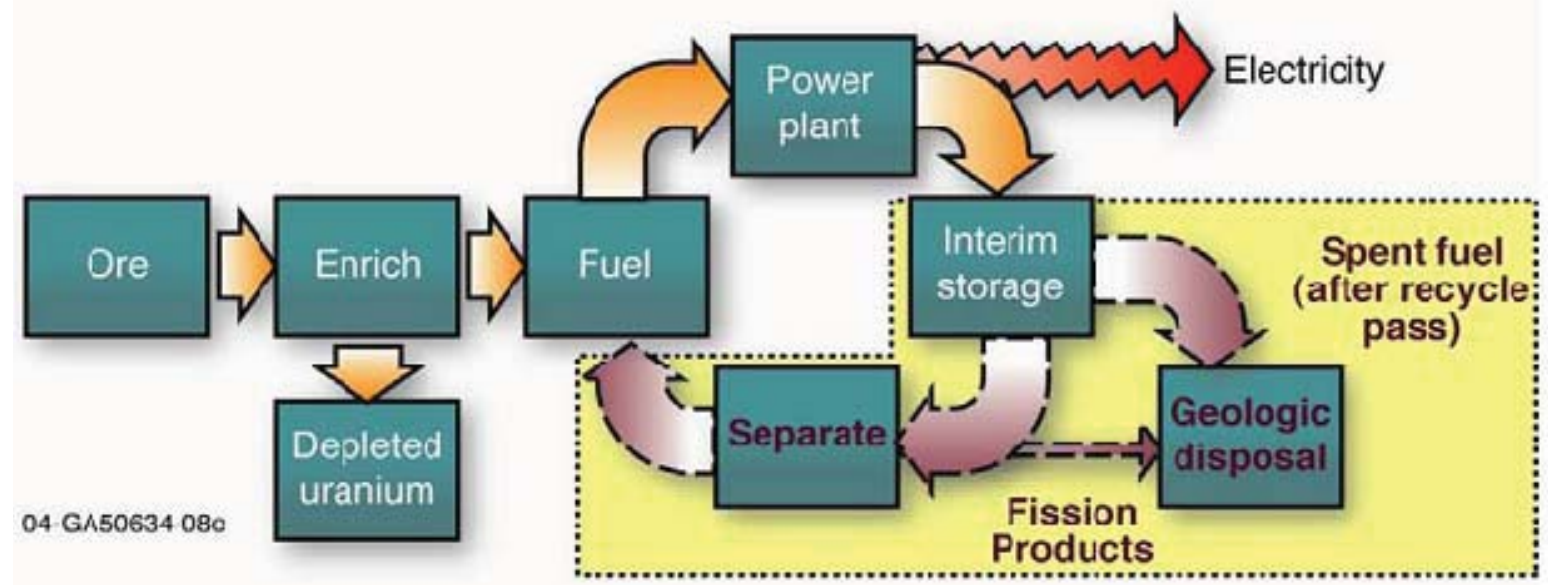

Figure 2. A Limited Recycle Strategy Using Enriched Uranium Fuel [17]

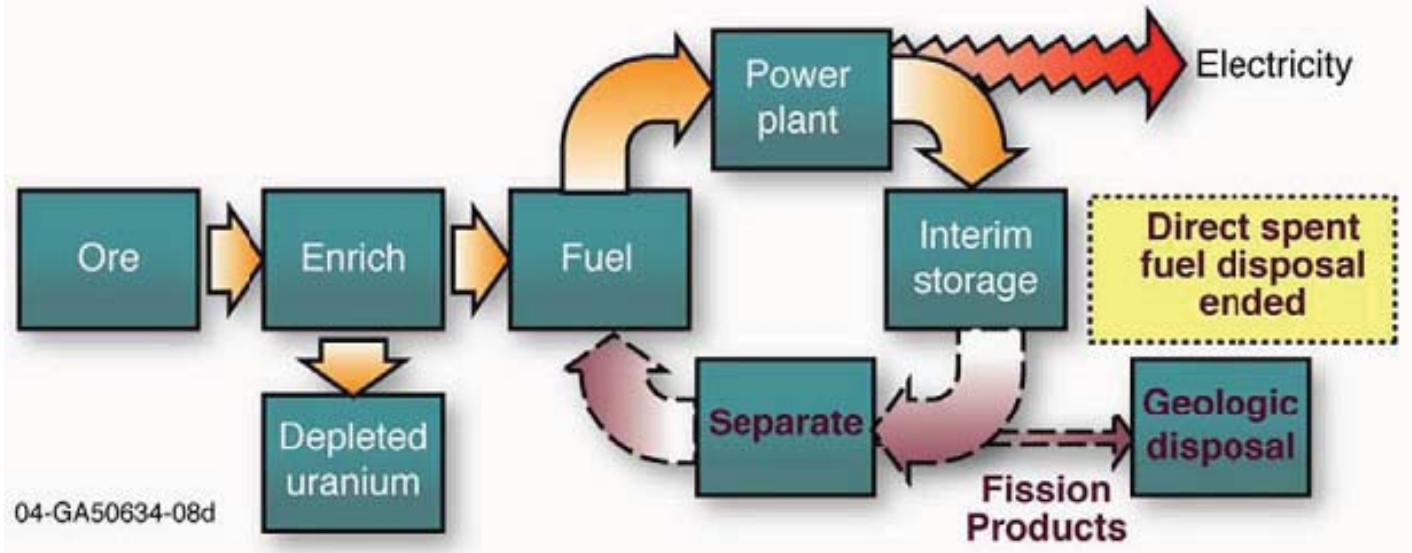

Figure 3. A Continuous Recycle Nuclear Fuel Cycle Strategy Using Enriched Uranium Fuel [17]

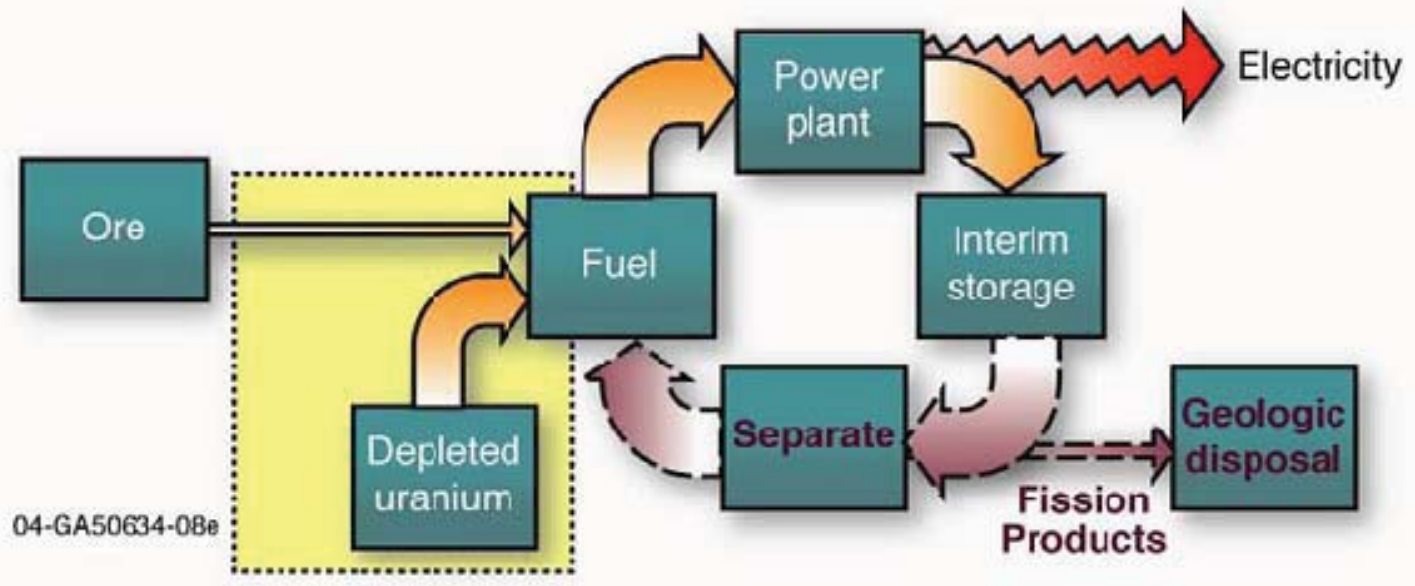

Figure 4. A Continuous Recycle Nuclear Fuel Cycle Strategy Using Uranium-Based Fuel Without Uranium Enrichment [17] 
In contrast to the once-through strategy, there are more major components and operations with recycle strategies. In addition to the fuel, the power plants, and disposal, the new components are UNF processing, fabrication of recycle fuel, and the irradiation facilities for transmutation of the recovered materials in recycle fuel. The irradiation facilities are also shown schematically as power plants but the power plants using recycle fuel may or may not be the same power plants using the new nuclear fuel, or may not be power plants at all, depending on the technology choices and the detailed structure of the nuclear fuel cycle. Transportation requirements are also not shown in Figures 2, 3 and 4, but would occur between most steps in the fuel cycle, although specific technology choices may dramatically change transportation requirements between some parts of the fuel cycle. Interim storage can be used in the same manner as in once-through strategies with the same potential benefits to planning and logistics for waste management. In addition, since there are more scientific and technological issues with recycle strategies, there is the benefit of providing the time needed for identifying, developing, and demonstrating the desired technologies. There can also be a significant benefit to processing UNF with lower radiation due to radioactive decay. However, radioactive decay can also change elements from ones that are easily recycled into ones that are more difficult, e.g., fissile $\mathrm{Pu}-241$ decays to Am-241, and the SNM may have higher attractiveness. The usefulness of interim storage needs to be considered for the specific recycle conditions being proposed, and there are the additional costs and risks to be considered.

Disposal of LLW also needs to be considered as part of recycle strategies, especially since the new components and operations have the potential for substantial LLW creation. Recycle strategies are more complex than once-through strategies, and while recycle may involve similar mining and enrichment steps as the once-through fuel cycle, the additional components in a recycle strategy are designed to offer opportunities to significantly change the contents of UNF and HLW prior to disposal and for addressing the issues with nuclear power by implementation of advanced technologies.

\section{Fuel Options and Enrichment}

In a recycle fuel cycle strategy, one may have the same new fuel, enrichment, and irradiation approaches as for the once-through strategy, creating UNF. However, recycle fuel contains the materials recovered in UNF processing, requiring the use of different fuels, fuel fabrication facilities, and possibly irradiation facilities, all of which can be complex operations. Recycle also enables consideration of novel approaches for nuclear fuel, even fuel dissolved in the reactor coolant and processed continuously instead of as UNF.

Recycle fuel usually contains one or more of the TRU elements, such as plutonium. Since the TRU elements are highly radioactive, the fuel fabrication process is more complex, requiring shielding and remote handling as determined by the activity of the TRU. Some fission products may also be included. A recycle fuel strategy enables many more options for the use of nuclear materials, including using thorium for producing U-233 and uranium for producing Pu-239 for use as fissile isotopes in fuel, a capability that can make uranium enrichment unnecessary as part of the fuel cycle.

Since there is only disposal of HLW from processing with continuous recycle, the actinide content of the UNF may not be relevant for waste management, depending on what is being recycled. Fuel burnup desired at discharge can be important, since burnup determines the frequency of processing where HLW is generated. The need for new fuel resources in the recycle fuel strategy may be significantly reduced depending on the details of the implemented technologies.

\section{Processing of UNF}

Recycle nuclear fuel cycle strategies require UNF processing, whether limited or continuous recycle is being used. UNF processing includes separations, also known as reprocessing, used since the beginning of the nuclear age, initially to produce weapons-usable materials and more recently for recovery of usable 
fuel materials. Research on the potential for recycle nuclear fuel strategies to favorably impact waste management issues has prompted development of new processing technologies to recover actinide and fission product elements from UNF, keeping them out of the wastes destined for disposal and offering the possibility of improved waste management using waste forms that could have better performance in disposal environments. Processing also includes technologies for reconstituting nuclear fuel to allow higher burnup in cases where other constraints such as cladding lifetime limit fuel usage. Overall, the goals of a recycle strategy will define the processing that is needed, whether to separate and recover certain chemical elements from UNF or for other purposes, and determines the impact the recycle strategy will have on the issues discussed in Section 2.1.

\section{Nuclear Power Plants - Reactors and Other Irradiation Environments}

The nuclear power plants in the recycle nuclear fuel strategy can have various functions depending on the details of the strategy. However, since it is not necessary for all irradiation facilities in a recycle strategy to use recycle fuel, and therefore would be using new fuel, all of the irradiation characteristics discussed for the once-through use of nuclear fuel in Section 3.1 would apply to those facilities. The difference for the recycle strategy is in the ability to potentially transmute the recovered actinides and fission products. With a recycle strategy, actinide recycle allows consideration of more types of irradiation environments since the reactors are no longer limited to fuels that are derived only from naturally-occurring materials, and the entire system can be optimized for achievement of whatever goals are selected, including waste management and proliferation risk benefits.

\section{Disposal Environments}

The disposal environment options for the recycle strategy are the same as those available to the oncethrough strategy. The difference for a recycle strategy is the content of the materials to be disposed and the amounts and forms of the waste materials. If a limited recycle strategy is used, there is still direct disposal of UNF, but the UNF will have characteristics that are significantly different than those of UNF from a once-through strategy. The HLW will be mainly produced from processing, with the content dictated by the recovered elements, i.e., everything in UNF that is not recovered will remain in the HLW. With continuous recycle, only HLW is produced, and there is no disposal of UNF. In this case, it is the difference in content between the UNF for once-through and the HLW from recycle that will determine any potential waste management benefits for the recycle strategy. Since proving that disposal will have sufficient isolation is challenging due to the very long times and large uncertainties concerning the potential for release of the radioactive materials, recycle strategies that reduce the content and lifetime of the radioactive materials can reduce the importance of these uncertainties depending on the planned disposal amounts at any given site. Generation of LLW is affected by the technologies chosen for processing, and is discussed in Chapter 4.

\section{Economics of Recycle Fuel Strategies}

The economics of the recycle strategies are determined by the costs for each of the components in the strategy. Some of the major costs may be similar to those for the once-through strategy, including costs for fuel resources, costs for construction of irradiation facilities if the same technologies are used, and costs for developing and operating disposal sites. However, recycle strategies will have added major costs for the construction of UNF processing facilities, and costs for the construction of recycle fuel fabrication facilities and the irradiation facilities for recycle fuel. On the other hand, recycle strategies may avoid major costs depending on the need for fuel resources, uranium enrichment, and the utilization of the disposal sites. As a result, the relative cost of a recycle strategy compared to the reference oncethrough strategy depends on the balance between the added costs of recycling and the avoided costs of disposal and supplying new fuel. 


\subsection{Nuclear Fuel Cycle Strategy Impact}

Using the evaluation criteria in Section 2.3, it is possible to evaluate the relative abilities of various nuclear fuel cycle strategies to address some of the issues identified in Section 2.1. In this discussion, the focus is on identifying where 'significant' improvements, i.e., an order of magnitude or more, are possible instead of those where impacts only result in an incremental change based on review of prior studies, as compared to the reference nuclear fuel cycle defined in Section 2.4. Evaluations of the oncethrough strategy in this Section do not reflect the theoretical possibility for complete burnup with externally-driven subcritical systems or reactors operating on HEU due to the speculative nature of such systems given many practical constraints, as discussed in Chapter 4 for the specific technology options.

\section{Nuclear Waste Management}

The effect on nuclear waste management depends on the materials that need to be disposed. For all oncethrough systems, the fission product content of UNF is proportional to the power generated and the TRU content also increases with higher burnup, at least for the range of burnup that is currently considered practical, but the amount of TRU per unit of energy generated generally decreases with increasing burnup. For these reasons, there is no significant change from the reference fuel cycle with alternative once-through cycles or limited recycle on radiotoxicity, and only continuous recycle that keeps the bulk of the hazardous radioactive materials, e.g., TRU, out of the waste stream may have a significant effect, as summarized in Table 1. However, the characteristics of the disposal environments will determine whether or not actinide recycle can be effective in reducing the estimated peak dose rate. Alternative disposal options can have a significant impact on estimated peak dose rate but cannot be used to discriminate between fuel cycle strategies since the disposal options can be used and are needed with any fuel cycle strategy.

As noted in Section 3.1, near complete consumption of natural uranium is being contemplated using externally-driven subcritical systems, such as the fusion-fission hybrids. If such an approach becomes practical, then the waste management requirements for the UNF would be limited to those for the large quantity of fission products and the remaining amount of highly radioactive actinides. Such systems would have waste management characteristics similar to those of the continuous recycle system where the TRU is recycled. However, achieving such a once-through system without processing of any kind depends completely on the availability of fuel-cladding material that can maintain integrity for the very long residence time required in such systems.

Both UNF and HLW require geologic disposal. However, higher burnup of the fuel results in less UNF per unit of energy generated, and there is a greater mass of fission products and TRU in the UNF. For once-through and limited recycle strategies, this means less UNF disposal. For recycle strategies, since more power is generated before discharging the fuel with higher burnup, processing is less frequent and the HLW generated by processing would be proportionately lower. However, for limited recycle in comparison to once-through, there is a decrease in UNF disposal even for the same burnup, since at least some UNF is processed, and higher burnup would make the reduction even greater. When compared to a once-through strategy, although processing generates HLW, when the smaller amount of UNF is combined with the greater HLW from processing, the total amount of UNF and HLW can be lower. For continuous recycle, there is no UNF disposal, and while HLW will be greater than for once-through due to processing, the total amount requiring geologic disposal will be lower. It is important to recognize that the reduction in the amount of hazardous radioactive materials going to waste disposal in the HLW depends on the elements being recycled and the recovery efficiency in processing.

For LLW, higher burnup with a once-through strategy will lower LLW from fuel fabrication in proportion to the higher energy generation, although higher enrichment requirements could mitigate improvements. With both limited and continuous recycle, more LLW will be produced due to processing. 
Table 1. Relative Impact of Alternative Fuel Cycle Strategies

\begin{tabular}{|c|c|c|c|}
\hline $\begin{array}{l}\text { Nuclear Fuel Cycle } \\
\text { Strategy }\end{array}$ & $\begin{array}{l}\text { Alternate Once- } \\
\text { Through }\end{array}$ & Limited Recycle & Continuous Recycle \\
\hline \multicolumn{4}{|l|}{ Nuclear Waste Management } \\
\hline $\begin{array}{l}\text { Estimated Peak Dose } \\
\text { Rate }\end{array}$ & $\begin{array}{l}\text { No change due to UNF } \\
\text { disposal }\end{array}$ & $\begin{array}{l}\text { No significant change } \\
\text { due to UNF disposal }\end{array}$ & $\begin{array}{l}\text { Possibly significantly } \\
\text { lower with actinide } \\
\text { (TRU) recycle and HLW } \\
\text { disposal }\end{array}$ \\
\hline $\begin{array}{l}\text { Radiotoxicity of } \\
\text { Disposed Materials }\end{array}$ & $\begin{array}{l}\text { No change due to UNF } \\
\text { disposal }\end{array}$ & $\begin{array}{l}\text { No significant change } \\
\text { due to UNF disposal }\end{array}$ & $\begin{array}{l}\text { Significantly lower with } \\
\text { actinide (TRU) recycle } \\
\text { and HLW disposal }\end{array}$ \\
\hline $\begin{array}{l}\text { UNF \& HLW for } \\
\text { Disposal }\end{array}$ & $\begin{array}{l}\text { Same UNF and HLW } \\
\text { content; less UNF with } \\
\text { higher burnup }\end{array}$ & $\begin{array}{l}\text { Less combined UNF \& } \\
\text { HLW content due to } \\
\text { recycle }\end{array}$ & $\begin{array}{l}\text { No UNF; TRU content in } \\
\text { waste is significantly } \\
\text { lower due to TRU } \\
\text { recycle }\end{array}$ \\
\hline LLW Disposal & $\begin{array}{l}\text { Less LLW in proportion } \\
\text { to higher burnup }\end{array}$ & $\begin{array}{l}\text { Possibly significantly } \\
\text { more LLW due to } \\
\text { processing }\end{array}$ & $\begin{array}{l}\text { Possibly significantly } \\
\text { more LLW due to } \\
\text { processing }\end{array}$ \\
\hline Effect of Interim Storage & $\begin{array}{l}\text { Lower near-term } \\
\text { radiotoxicity and heat } \\
\text { load for UNF and HLW }\end{array}$ & $\begin{array}{l}\text { Lower near-term } \\
\text { radiotoxicity and heat } \\
\text { load for UNF and HLW }\end{array}$ & $\begin{array}{l}\text { Lower near-term } \\
\text { radiotoxicity and heat } \\
\text { load for UNF and HLW }\end{array}$ \\
\hline Heat Load & $\begin{array}{l}\text { No change due to UNF } \\
\text { disposal }\end{array}$ & $\begin{array}{l}\text { No significant change } \\
\text { due to UNF disposal }\end{array}$ & $\begin{array}{l}\text { Significantly lower with } \\
\text { actinide (TRU) recycle, } \\
\text { Cs/Sr management, and } \\
\text { HLW disposal }\end{array}$ \\
\hline \multicolumn{4}{|l|}{ Proliferation Risk } \\
\hline SNM Inventory & No significant change & $\begin{array}{l}\text { Higher in the fuel cycle } \\
\text { inventory, lower for } \\
\text { waste disposal }\end{array}$ & $\begin{array}{l}\text { Higher in the fuel cycle } \\
\text { inventory, significantly } \\
\text { lower for waste disposal }\end{array}$ \\
\hline Material Attractiveness & No significant change & $\begin{array}{l}\text { Technology dependent; } \\
\text { may be lower or higher }\end{array}$ & $\begin{array}{l}\text { Technology dependent; } \\
\text { may be lower or higher }\end{array}$ \\
\hline Uranium Enrichment & $\begin{array}{l}\text { Technology dependent; } \\
\text { may be lower or higher }\end{array}$ & $\begin{array}{l}\text { Technology dependent; } \\
\text { may be lower or higher }\end{array}$ & $\begin{array}{l}\text { Technology dependent; } \\
\text { may be lower or higher }\end{array}$ \\
\hline Safeguardability & No change & No change & No change \\
\hline \multicolumn{4}{|l|}{ Sustainability } \\
\hline Fuel Resources & No change & Lower with recycle & $\begin{array}{l}\text { Significantly lower with } \\
\text { actinide recycle }\end{array}$ \\
\hline Disposal Needs & No change & No significant change & $\begin{array}{l}\text { Significantly lower with } \\
\text { actinide recycle }\end{array}$ \\
\hline
\end{tabular}

Green: $\quad$ Significant favorable impact from the strategy

Green/white: Potential for significant favorable impact may exist but is technology dependent

White: No significant change

Red/white: Potential for significant unfavorable impact may exist but is technology dependent

Red: $\quad$ Significant unfavorable impact from the strategy 
The effect of interim storage is comparable for all once-through strategies and limited recycle strategies due to the similarity in decay heat for the combined UNF and HLW. Interim storage allows time for decay of shorter-lived isotopes, both fission products and TRU that can have a beneficial impact by lowering the radiotoxicity and decay heat of the materials in storage, which would facilitate handling, any potential processing, and disposal, but which would also increase the attractiveness of the SNM either in process or in the UNF/HLW. However, long-term radiotoxicity and decay heat that can be important to the disposal options are unaffected by interim storage. When interim storage is part of an implemented strategy, it is also important to recognize that there are costs and licensing issues to be considered. At this time, interim storage can also be used while decisions about advanced nuclear fuel strategies and the associated technologies are being considered, and for any subsequent development. However, there may be uncertainty about any detrimental effects from interim storage of UNF significantly beyond current experience.

The UNF and HLW decay heat can affect the required disposal space, although addressing this issue is not the same for all disposal options and the benefit of any approach to alter the decay heat needs to be considered in combination with the specific disposal option. Interim storage is the only option available with a once-through strategy. Substantial reductions in decay heat relevant for geologic disposal are only possible with continuous recycle if the major decay heat producers, TRU and $\mathrm{Cs} / \mathrm{Sr}$, are separated and recovered for recycle or for treatment independent of HLW disposal

\section{Proliferation Risk}

There is SNM in all UNF due to the presence of plutonium generated from uranium during irradiation and the presence of U-235, and even with the use of thorium fuel due to the generation of U-233 and other uranium isotopes. For the once-through fuel cycle strategy, there may be differences in SNM content, but much less than an order of magnitude regardless of the technology option selected. With limited recycle, there can be some reduction in the amount of SNM sent to disposal, but processing can also make the SNM contained in the fuel cycle more attractive since the fission products providing most of the radiation barrier are separated from the SNM as is most of the uranium. With continuous recycle, there can be a substantial reduction in the amount of SNM in materials sent for disposal, but again there is significant SNM contained in the fuel cycle, and processing can make this SNM more attractive as well by separating the fission products and uranium. However, a determination on material attractiveness is not possible on strategy alone since it depends on technology options and implementation, but in general interim storage can increase material attractiveness with the decreasing radiation of UNF due to radioactive decay.

Achieving complete burnup with once-through externally-driven subcritical systems would be an attractive option, since the UNF would contain essentially no SNM. If the burnup were only nearly complete, about $99 \%$ to $99.9 \%$, the residual SNM in the UNF could make such an approach comparable to continuous recycle for the measures driven by SNM content in the materials sent to disposal. However, it is noted that any intermediate burnup in such systems would result in the availability of UNF with high SNM content. This is the case for some of the recent reactor concepts that have proposed very high burnup (and/or long-life) cores. Typically, these systems utilize driver assemblies having enriched uranium fuel $(\sim 5-15 \%)$ and possibly blanket assemblies, projected to have burnups as high as $30-40 \%$. Both driver and blanket assemblies would have a significant SNM content with higher material attractiveness.

The need for uranium enrichment as part of a fuel cycle strategy also has an impact on proliferation risk. Uranium enrichment technology can be used by itself to obtain SNM in the form of HEU, and the same technology that is used to provide LEU can also be used to make HEU. However, for fuel cycles that may not require uranium enrichment, either they operate on natural uranium as in heavy-water or graphite-moderated reactors, or the fissionable materials must be created within the fuel cycle by breeding and obtained from UNF by processing. These materials are also SNM, such as Pu-239 and U-233. One 
needs to consider the specific features of the technologies being used to determine if there is an impact on proliferation risk from eliminating the need for uranium enrichment.

As a consequence, the main concern for any fuel cycle is whether or not the SNM can be adequately safeguarded. Safeguardability is possible for all of the fuel cycle strategies, although the safeguards approaches will be different when processing and recycle are used.

\section{Sustainability}

The fuel resources required for once-through are affected by the discharge burnup due to higher enrichment requirements by critical systems, but there is essentially no change in the amount of raw materials required for fuel on a per unit energy generated basis. For externally-driven sub-critical systems, the fuel requirements are determined in principle by the discharge burnup and whatever enrichment is required to achieve the desired degree of criticality in the externally-driven subcritical blanket. With limited recycle, the recycle of fissionable materials can displace some of the need for new resources. Similarly with continuous recycle, reuse of the fissionable materials is beneficial. In principle, if the continuous recycle technologies are used to breed new fissile materials, the need for resources can be substantially decreased.

A once-through strategy with near-complete burnup of the fuel could also be quite attractive, in the same manner as continuous recycle, since fuel resources are used to the maximum extent. However, such systems are considered impractical as discussed above.

Overall, it is seen that the use of recycle strategies can favorably impact the issues of waste management and sustainability, but as discussed above, there are costs and other issues as well, especially with respect to the proliferation risks, which are discussed further in Chapter 4.

\section{Technology Options}

Within the context of the nuclear fuel cycle strategies as mentioned above, there are numerous technologies that can be used. In this Chapter, both conventional and advanced options are reviewed for their applicability in once-through and recycle nuclear fuel cycle strategies and their potential to impact the nuclear power issues discussed above based on available results. Evaluations for the measures discussed in Section 2.3 are provided to the extent possible, although for many less-researched options, reliable information can be sparse or non-existent.

\subsection{Fuel Options}

Nuclear reactors require fissionable materials, whether using a critical system or an externally-driven subcritical system. As discussed in Section 3.1 for once-through strategies, only uranium or thorium / uranium fuels can be used, while for recycle strategies discussed in Section 3.2, other fuels can be used, including plutonium.

\section{Physical Fuel Form}

The fuels used for the once-through and recycle options can have different physical forms depending on the nuclear irradiation, fuel fabrication, and processing system chosen. The physical form of the fuel has significant implications on the entire fuel cycle system in terms of the means of manufacture of the fuel, the achievable burnup during irradiation, the processes used to recycle the fuel, and the ultimate disposal.

The conventional fuel forms used in operating reactors consist of a solid fuel material in various chemical forms (typically oxides, but could also be metals, nitrides, carbides) contained within a cladding material to separate the coolant from the fuel and the highly radioactive fission products resulting from irradiation. 
The cladding facilitates handling and to provide a barrier to the release of highly radioactive fission and other transmutation products during and after irradiation. Metallic cladding, typically an alloy of zirconium is currently used in LWRs and steel alloys are used in fast reactor systems. Fuel can also be manufactured with ceramic cladding, as with TRISO fuel particles used in high-temperature gas-cooled reactors where layers of pyrolytic graphite and silicon carbide surround the fuel. In many cases it is the cladding performance of the fuel that limits its lifetime in the reactor core. Additional research being performed in the development of advanced claddings with higher strength and more irradiation tolerance is necessary to support higher burnup fuels.

In addition to solid fuels, liquid fuels have also been proposed and demonstrated in so called "homogenous" experimental reactors. In these cases, the fuel can be contained in aqueous solutions, organic solutions, molten metals, or molten salts. When in liquid form the fuel could be circulated through critical or externally-driven subcritical core region and directly used as the coolant and heat transfer mechanism. The use of liquid fuels also allows the option of performing chemical processing online during the operation of the reactor to add new fuel and to remove fission products or other materials that are unfavorable for the operation of the irradiation system. Liquid fuels do not have cladding so there are no lifetime irradiation limits imposed by cladding as in the case of solid fuel. However, retention and control of fission products and interactions with the reactor structural materials must be considered. Several liquid-fueled reactors have operated as experimental systems.

Another distinguishing feature of the nuclear fuels is the manner in which they are used within the reactor system. The fuel can either be fixed in place at the time of loading, or it can be mobile and allowed to be loaded and unloaded from the reactor during operation. The use of a solid-form fixed fuel implies a batch mode operation in which the fuel is loaded into the reactor, the reactor is operated for some length of time, and the fuel is removed either for storage and disposal for once-through fuel cycles or processed to fabricate new fuel for the recycle fuel cycles.

A mobile fuel approach has fuel moving during irradiation. Mobile fuel allows on-line and perhaps continuous loading of the fuel supporting multiple-passes through the reactor core for some designs. The mobile fuel could be solid, such as CANDU fuel bundles or pebbles as in the pebble-bed modular reactor (PBMR), and separated from the coolant primarily to support on-line fueling and defueling operation. Alternatively the mobile fuel can be in liquid form dissolved in the reactor coolant, such as fuels dissolved in a molten salt allowing online chemical processing in addition to online fueling, as small particles suspended in the coolant, or as molten fuel separate from the coolant.

Once-through systems generally need to use solid fuel that is either fixed as in the case of LWRs or prismatic high temperature gas-cooled reactors (HTGR), or mobile as the case for CANDU and HTGR pebble-bed systems. The choice of fixed or mobile fuel is system dependent based on reactor design and operation decisions. The long-term integrity of the solid fuel form and cladding can have important implications on the long term retention of the radioactive hazardous materials in the ultimate disposal location. For recycle the fuel must be compatible with approaches for chemical processing allowing separation and fabrication of new recycle fuels. The use of solid fuel forms requires unloading of the fuel from the reactor core and chemical processing and fabrication either in a centrally-located or a co-located facility. The fuel form would not necessarily be required to withstand long-term storage environments as the chemical processing allows for alternative waste forms. The use of liquid fuels in recycle allows the chemical processing to be performed in a directly integrated manner with the irradiation system by having the liquid fuel flow through a chemical processing system. In this case, the processing can directly use the fuel form and there is no re-fabrication of new fuel required. Fission products can also be removed on-line in such systems to facilitate high burnup while maintaining sufficient fissile material to operate the reactor, either by internal breeding or by adding new fissile materials. 


\section{Uranium-Based Fuels}

Uranium-based fuels have been utilized or are being considered for most nuclear energy systems under the once-through and recycle strategies. These systems include thermal reactors (e.g., the LWRs), fast reactors, and subcritical systems driven by externally-produced neutron sources, such as in fusion-fission hybrid and accelerator-driven systems. These fuels are obtained by mining and milling of uranium ore. Natural uranium has two isotopes, U-238 the fertile isotope (predominant) and U-235 the fissile isotope (about $0.7 \%$ of the natural uranium mass). Both natural uranium and enriched uranium fuels have been considered for nuclear systems. Besides natural uranium, depleted uranium from the enrichment process and uranium extracted from LWR UNF have been employed or are considered for reactor fuels.

\section{Once-Through Nuclear Fuel Cycle Strategy}

For the once-through strategy, it is possible to use natural uranium for fuel, such as in the heavy-water- or graphite-moderated reactors, although fuel usage may be inefficient, requiring frequent refueling of the reactor and generating large amounts of UNF per unit of energy produced. Recent once-through concepts considering near-complete burnup of fuel materials have also been proposed to use non-enriched uranium fuels. For many reactor technologies, however, such as the LWRs, the uranium needs to be enriched in its U-235 content in order to sustain the nuclear chain reaction. Enrichment allows fuel to achieve high burnup, thus reducing the quantity of used fuel per unit of energy produced. Uranium enrichment produces a substantial quantity of depleted uranium tailings which must be managed.

For both the natural and enriched uranium fuels, the irradiation of the fuel produces plutonium, including $\mathrm{Pu}-239$, and higher actinide elements. In current LWRs, more than $25 \%$ of the reactor power is produced by fission of plutonium. Typical UNF for an LWR has a burnup of about $5 \%$ and contains about $94 \%$ unused uranium, $\sim 5 \%$ fission products, and $\sim 1 \%$ TRU including plutonium. The U-235 content of such UNF is less than $1 \%$, approaching the naturally-occurring value of $0.7 \%$. For the heavy-water reactor, like the CANDU system that uses natural uranium, the U-235 content at discharge is about $0.1 \%$ and $\mathrm{Pu}-$ 239 content is about $0.25 \%$.

Uranium-based fuels can also be used in fast reactors in a once-through strategy. In this case, enriched uranium is required, with the enrichment level depending on the system design goal. Most of the system designs have limited this uranium enrichment to less than $20 \%$ to satisfy the non-proliferation requirements for low-enriched uranium fuel. To achieve ultra-high burnups (e.g. 30-40\%), however, the reactor concept would need much higher uranium enrichment level or need to be designed for the in situ production and burning of fissile plutonium. Separate assemblies containing natural-uranium based fuel (blankets) have been used for this purpose or conversely lower enrichment fuel could be used throughout the core.

For the purposes of the AFCI Options Study, it is only important to recognize the need for uranium enrichment due to the proliferation risk, and the level of enrichment that is required. As discussed above, the specific enrichment technology does not affect resolution of the issues described in Section 2.

\section{Recycle Nuclear Fuel Cycle Strategy}

The two issues of waste management and resource extension/effective utilization (sustainability) have driven the need for advanced fuel cycles, involving fuel recycle. These have led to the development of reactor concepts based on fast and thermal systems for these purposes. One approach that has been taken by European countries (primarily France) and Japan, is the use of a uranium-plutonium mixed oxide (MOX) fuels in LWRs; the plutonium is recovered from LWR UNF and the uranium could be depleted uranium from the enrichment process, natural uranium, or uranium recovered for recycle from the processing of used nuclear fuels. Proliferation concern, associated with the potential availability of 
separated plutonium during the reprocessing stage, is one reason why MOX fuel has not been generally accepted in the U.S.

A single-recycle of the MOX fuel is currently practiced internationally for power production. At the end of irradiation, the used MOX fuel assemblies remain and have radioactive content that is more hazardous than in used uranium-oxide fuel assemblies from current U.S. LWRs. Although a fraction of the original plutonium has been consumed, the consumption is not sufficiently high to make a significant impact on the repository space required for UNF, on an energy production basis. For this reason, approaches have been proposed for multi-recycle of the plutonium in LWRs in order to reduce the amount of plutonium and higher actinides that need to be passed to the repository as high level waste. The conclusions have been that such multi-recycling would need enriched uranium support and that the fuel gets progressively problematic to handle due to the creation of higher actinides that are more radioactive than uranium and plutonium. Also, if uranium resource extension is an issue, this approach is not sustainable, due to the enriched uranium requirements. Consequently, continuous recycle has generally been considered to be attractive only in fast systems for advanced fuel cycles.

Natural, depleted, recycled and enriched uranium fuels have also been considered for use in fast reactor recycle strategies. Enriched uranium could be used to startup the fast reactors and enrichment less than $20 \%$ have been considered for this purpose in the U.S., though some fast reactors have used high enrichments in the past (e.g., EBR-II fuel was greater than 60\%). Mixed uranium-plutonium (or other TRU) fuels in the oxide and metallic forms have also been considered along with other forms such as carbide and nitride fuels. For the blanket assemblies of fast reactors systems, non-enriched uranium fuels are typically employed. Due to the spectrum of these systems, the used blanket fuels of the fast reactors contain SNM, possibly with high attractiveness for weapons use. This is one reason why some of the $\mathrm{AFCI}$ fast reactor designs do not contain blanket regions, which is possible if conversion ratio of about 1.0 or less is the design goal.

The fast reactor could be configured for the management of plutonium and minor actinides extracted from LWR UNF. In what is termed a "single-tier" system, the TRU is directly recovered from uranium-dioxide (UOX) UNF. In a "double-tier" strategy, the TRU is obtained from fuel derived from an intermediate tier system (e.g., the MOX UNF from an LWR-MOX core). For the fast reactor systems, the TRU content would have to be low to get a breeding core design and significantly high to get a burner core design. In the double-tier system, the higher actinides could bypass the intermediate tier system (which uses U-Pu fuel only) and would have to be consumed in the fast spectrum system. This would be the case for a fuel cycle strategy that relies on current commercial UOX fuel separation processes for recovering material for the production of conventional U-Pu MOX fuel. Alternatively, advanced separation processes have been proposed for extracting all the transuranic elements in the MOX fuel for use in the fast reactor, but this is not yet practiced at the commercial scale. While the utilization of all transuranics in the fast reactors is attractive, the existing or previously operated fast reactors have only employed U-Pu fuel and consequently additional development is required before these fuels can be deployed for industrial use.

\section{Thorium-Based Fuels}

Thorium has been considered as an option to uranium-based fuel since the earliest days of the nuclear industry, initially based on considerations of resource utilization (thorium is approximately three times more plentiful than uranium), and more recently as a result of concerns about proliferation and waste management (e.g., reduced production of plutonium and higher actinides, improved physical and nuclear properties for reactor and potential waste management applications). Since there are no naturallyoccurring thorium isotopes that can fission under reactor conditions, thorium is only useful as a resource for breeding new fissile materials, in this case U-233, which can be done in either thermal or fast reactors. Consequently, an isotope such as U-233, U-235, or Pu-239 must be present in sufficient quantities for the reactor to operate. Thorium can be used in both once-through and recycle options, and in both thermal 
and fast systems. The thorium-uranium system allows breeding of U-233 (breeding ratio greater than unity) in both types of systems, although the ability to breed in a thermal spectrum generally would require specially designed systems that are different from current commercial LWRs. Since U-233 has similar properties to $\mathrm{Pu}-239$ it presents a similar proliferation risk, even with the other uranium isotopes that may be present. The production of U-232 and its associated decay products accompanying the production of U-233 cause radiation hazards in handling, but methods exist to overcome these hazards so that this may not prevent the use of the U-233 in nuclear weapons. Options have therefore been proposed where sufficient uranium is added to the thorium in the initial fuel composition so that all the U-233 and U-235 is diluted with U-238 so that SNM can only be obtained with isotopic separation, greatly reducing proliferation concerns, although the addition of uranium leads to the creation of more TRU in the UNF, diminishing the difference between uranium-based and thorium-based fuel systems. In considering the thorium-based fuel system, it is essential to recognize the need for fissile material such as U-233, enriched uranium or plutonium to operate the reactor.

\section{Once-Through Nuclear Fuel Cycle Strategy}

Using thorium can only be done along with enriched uranium to ensure criticality and desired cycle length. The uranium must be more highly enriched than in a conventional UOX-fuelled system (e.g., $10 \%-20 \%$ instead of $<5 \%$ in a PWR). This will require significant modifications to the existing fuel fabrication and handling infrastructure (e.g., shipping casks) to address the higher enrichments and criticality issues, in addition to those associated directly with the thorium. This results in a uranium resource requirement that is basically equivalent to using uranium-based fuel. As such, the thorium-based UNF characteristics are similar to uranium-based UNF, with the major difference being reduced plutonium production, and the isotopic mix contains a higher fraction of heat and spontaneous neutron producing isotopes thereby making it less attractive for potential weapons use relative to the plutonium contained in uranium-based UNF. However, the radiotoxicity is comparable to that of uranium-based UNF. Since differences relative to uranium-based fuels are generally well below the order of magnitude improvement desired for "significant" improvements (Section 3.3), uranium- and thorium-based UNF are effectively comparable for a once-through strategy.

\section{Recycle Nuclear Fuel Cycle Strategy}

If recycling of used nuclear fuel (UNF) is considered, the two main options are U-233/Th and/or Pu/Th. Initial scoping studies suggest that sufficient U-233 cannot be generated in a conventional PWR to make it self-sustaining on a pure U-233/Th cycle, and enriched LEU or Pu from UNF would be required. If the objective is a complete avoidance of the need for natural uranium and uranium enrichment, sufficient quantities of U-233 for the U-233/Th variant need to be produced. This would require a pre-breeder dedicated to this mission to support the remaining reactors. An extensive study of a potential U-233/Th PWR economy performed by the Bettis Atomic Power Laboratory (BAPL) under the Advanced Water Breeder Applications (AWBA) program envisioned "pre-breeder reactors" based on the Light Water Breeder Reactor (LWBR) Shippingport reactor to serve this purpose.[35] Options for this purpose also include fast reactors, and systems based on the Molten Salt Reactor, FFH, or ADS (which could be thermal or fast systems).

In addition to the proliferation concerns discussed above, there are issues associated with processing thorium-based fuel/blankets which in an oxide form are inherently more difficult to process than UOX because of the greater stability of $\mathrm{ThO}_{2}$. While the THOREX process is available, additional development would be needed to address potential implementation scenarios.

While most of the implementation scenarios have considered solid "conventional" fuel forms (e.g., oxide fuel pellets, TRISO particles), liquid fuel concepts have also been explored, notably the molten salt reactor (MSR) developed at ORNL in the 1950s, through the mid 1970s. The MSR was intended to 
operate as a thermal breeder on the thorium-uranium cycle as a complement to the sodium-cooled fast reactor uranium-plutonium cycle. The reactor concept has a molten-salt fuel that also serves as the reactor coolant along with a graphite moderator. The use of a molten-salt containing fuel optimizes the overall breeding ratio by continuously processing the fuel to remove fission product poisons that lower the breeding ratio as well as allowing the intermediate $\mathrm{Pa}-233$ isotope to be located in regions of low flux or outside of the core to minimize neutron capture that would lower the production of U-233. The fuel processing was fundamentally based upon the fluorination of thorium-containing blanket salts to remove the U-233, which is subsequently used in the fuel salt although some designs had a much more sophisticated processing system to remove Pa-233. Alternative designs with a single fluid breeder (no blanket salt), a converter (conversion ratio $<1$ ), and with a once-through, denatured configuration (U-238 was added to the salt to keep the fissile uranium enrichment below $12 \mathrm{wt} \%$, which prevent the system from being a true breeder) were also explored. Technical challenges with this reactor included corrosion of the metallic components, on-line operation of the fuel salt chemical processing, and tritium migration. The MSR has also been investigated in a fast reactor configuration without graphite moderator and as transuranic and minor actinide burners.

Recent examination of thorium-based fuels in fast spectrum systems has been relatively limited, with most of the available information dating back to earlier studies.[36,37] Thorium blankets can be used to breed U-233 analogous to breeding plutonium in a "conventional" fast breeder reactor. The reactor spectrum may have to be tailored to maximize U-233 production since a softer spectrum is more desirable for this application. Alternatively, thorium can be used as the matrix material in place of uranium in homogeneous or driver/target transmutation fuels along with TRU elements to limit production of new TRU. If additional uranium is added to address the proliferation risk from U-233, this will negatively affect achievement of this objective.

In summary, the use of thorium-based fuel cycles alters the nature of the issues with respect to uraniumbased fuel cycles. This is most evident in the classic "true thorium continuous recycle - U-233/Th" where the production of higher actinides is significantly reduced, affecting the HLW waste management issue, and the nuclear and physical characteristics of U-233/Th can be utilized to greatest advantage, although it must be recognized that this is directly comparable to the $\mathrm{Pu}-239 / \mathrm{U}$ approach in terms of proliferation risk. However, as noted above, thorium can be implemented in a number of other variants which tend to reduce the potential waste management benefits while eliminating the proliferation risk that may be associated with U-233. For example, the need to supply fissile material initially for the oncethrough approach requires the use of $\sim 20 \%$ enriched LEU, and if denaturing is employed to reduce the proliferation risk, additional uranium must be added and both of these introduce a source of higher actinides as in conventional uranium based fuel, although in smaller amounts. Similarly, if plutonium or TRU is used to provide fissile material, this also acts as initial material from which higher actinides are created. In addition, there are several other issues associated with potential large-scale utilization of the Th cycle in the U.S. These include:

- Development of a fuel fabrication infrastructure and development of a fuel separation infrastructure in recycle scenarios to extract the U-233 or other actinides to address potential implementation scenarios (e.g., burning plutonium and other TRU elements) that introduce cost, licensing, and $\mathrm{RD} \& \mathrm{D}$ requirements.

- If the objective is a complete avoidance of the need for uranium and uranium enrichment, sufficient quantities of U-233 for the U-233/Th variant need to be produced requiring a U-233 breeder infrastructure.

\section{Transuranic Fuels - Transmutation Fuels}

Transuranic fuel, characterized as fresh fuel containing TRU, is a key element of recycle options, and is used to transmute the TRU into less hazardous fission products. As described in Section 2, some of the 
TRU elements are responsible for many of the issues with waste management, and some are usable in nuclear weapons and therefore the utilization of TRU fuels is the primary target for transmutation. There are no naturally-occurring TRU materials, but they are produced from neutron irradiation of uranium or thorium as described in the previous sections. The most common option for transmutation fuel is to combine one or several TRU elements with uranium, although it is also possible to consider TRU contained in an inert matrix or combined with thorium to avoid or limit the creation of additional TRU by the irradiation of uranium. Since all reactors currently use uranium-based fuels, they also operate with TRU fuel that is created once irradiation begins, although the TRU content is much lower than is envisioned for transmutation fuel where the TRU is included in the fresh fuel. As a result, there is little experience with the use of TRU transmutation fuel, with the majority of the experience related to the use of mixed uranium-plutonium fuels, as discussed above.

The use of full-TRU transmutation fuels will require remote fabrication and handling. It is also possible to consider using TRU "targets," where one or more TRU elements are fabricated into fuel pins or assemblies for irradiation in a heterogeneous core configuration consisting of "driver" fuel regions and target regions. TRU targets are typically proposed with a much higher content of TRU and accommodate the higher content by operating at lower power. However, significant amounts of helium gas may be produced during irradiation which must be accommodated in the design of the fuel. Due to the characteristics of TRU, including that they may produce significant amount of radiation and heat through radioactive decay, there are many issues with fuel fabrication and handling of these new fuels that are not encountered with once-through use of uranium-or thorium-based fuels.

\section{Impacts of Fuel Options}

The uranium-based, thorium-based, and transuranic fuel options discussed above have various impacts on the fuel cycle. The impacts in the areas of waste management, proliferation risk, and sustainability, relative to the once-through fuel cycle used in the U.S., are summarized in Table 2. For waste management measures, the only significant difference between the use of uranium-based fuels and thorium-based fuels is with continuous recycle, where TRU that is predominantly plutonium needs to be recycled with uranium-based fuels while predominantly uranium is recycled with thorium-based fuels, although the uranium is predominantly U-233. On the subject of proliferation risk, there is no significant difference between uranium-based fuels or thorium-based fuels, either for once-through (due to plutonium) or recycle (due to U-233) strategies.

Considering the safety and security measures listed in Section 2.3, there does not appear to be any significant difference between any of the options in that licensable systems meeting NRC safety and security requirements could be designed using any of the fuel options. However, this is not to say that all options are equally attractive or at a comparable stage of development. Additional evaluation of economic impacts is needed, but development is needed for the use of thorium-based, TRU, or near-complete burnup fuels, and for handling fuels (including transportation) in some strategies that would be much more radioactive. 
Table 2. Impacts of uranium-based, thorium-based, and transuranic fuel options

\begin{tabular}{|c|c|c|c|}
\hline Issues & U-based & Thorium-based & Transuranic \\
\hline Fuel Cycle & Once-through, Recycle & Once-through, Recycle & Recycle \\
\hline $\begin{array}{l}\text { Waste } \\
\text { Management }\end{array}$ & $\begin{array}{l}\text { - UNF contains significant } \\
\text { TRU and fission products } \\
\text { (FP) in a once-through or } \\
\text { limited recycle strategy; } \\
\text { UNF directly disposed } \\
\text { - Once-through near- } \\
\text { complete-burnup systems } \\
\text { limit UNF TRU content } \\
\text { - A continuous recycle } \\
\text { strategy allows TRU and } \\
\text { FP recovery; FP and } \\
\text { unrecycled TRU in HLW }\end{array}$ & $\begin{array}{l}\text { - UNF contains significant } \\
\text { TRU and FP in a once- } \\
\text { through or limited recycle } \\
\text { strategy; UNF directly } \\
\text { disposed } \\
\text { - Once-through near- } \\
\text { complete-burnup systems } \\
\text { limit UNF TRU content } \\
\text { - For a continuous recycle } \\
\text { strategy, mainly uranium } \\
\text { is recycled; FP and } \\
\text { unrecycled TRU in HLW }\end{array}$ & $\begin{array}{l}\text { - Predominantly used } \\
\text { with uranium-based } \\
\text { fuels, although could be } \\
\text { used with thorium-based } \\
\text { fuels } \\
\text { - Only used with recycle } \\
\text { systems; no UNF } \\
\text { disposal } \\
\text { - FP and unrecycled TRU } \\
\text { (TRU losses) in HLW }\end{array}$ \\
\hline $\begin{array}{l}\text { Proliferation } \\
\text { Risk }\end{array}$ & $\begin{array}{l}\text { - UNF contains SNM in } \\
\text { useful quantities unless } \\
\text { burnup is nearly complete } \\
\text { - UNF has significant } \\
\text { radiation levels } \\
\text { - TRU recovered in } \\
\text { processing contains useful } \\
\text { SNM quantities with lower } \\
\text { radiation protection } \\
\text { - Recycle may reduce or } \\
\text { eliminate the need for } \\
\text { uranium enrichment and } \\
\text { reduce SNM inventories }\end{array}$ & $\begin{array}{l}\text { - UNF contains SNM in } \\
\text { useful quantities unless } \\
\text { burnup is nearly complete } \\
\text { - UNF has significant } \\
\text { radiation levels } \\
\text { - Uranium recovered in } \\
\text { processing contains useful } \\
\text { SNM quantities with } \\
\text { lower radiation protection } \\
\text { - Recycle may reduce or } \\
\text { eliminate the need for } \\
\text { uranium enrichment and } \\
\text { reduce SNM inventories } \\
\end{array}$ & $\begin{array}{l}\text { - UNF contains SNM in } \\
\text { useful quantities } \\
\text { - UNF has significant } \\
\text { radiation levels } \\
\text { - TRU recovered in } \\
\text { processing contains } \\
\text { useful SNM quantities } \\
\text { with lower radiation } \\
\text { protection } \\
\text { - Recycle may reduce or } \\
\text { eliminate the need for } \\
\text { uranium enrichment and } \\
\text { reduce SNM inventories }\end{array}$ \\
\hline Sustainability & $\begin{array}{l}\text { - Uranium resources } \\
\text { required; highest for once- } \\
\text { through, dependent on } \\
\text { plutonium breeding for } \\
\text { recycle strategies } \\
\text { - UNF disposal for once- } \\
\text { through and limited } \\
\text { recycle strategies } \\
\text { - HLW disposal with } \\
\text { continuous recycle }\end{array}$ & $\begin{array}{l}\text { - Thorium and uranium } \\
\text { resources required for } \\
\text { once-through; dependent } \\
\text { on U-233 breeding for } \\
\text { recycle strategies } \\
\text { - UNF disposal for once- } \\
\text { through and limited } \\
\text { recycle strategies } \\
\text { - HLW disposal with } \\
\text { continuous recycle }\end{array}$ & $\begin{array}{l}\text { TRU fuel requires TRU } \\
\text { from UNF, whether } \\
\text { uranium-based or } \\
\text { thorium-based } \\
\text { - HLW disposal with } \\
\text { continuous recycle }\end{array}$ \\
\hline
\end{tabular}

\subsection{Reactors and Other Irradiation Options}

In the United States, the commercial nuclear power sector has focused on the use of nuclear technology for electricity generation, which contributes about $20 \%$ of the total electricity supply. This sector relies on light water reactors (LWRs) for this purpose. The LWRs and other nuclear energy systems could also be used for the purpose of burning hazardous radionuclides while still generating power. The nuclear system options that have been considered for both purposes (power and transmutation) are discussed in this section with a few examples of the systems presented. The discussion covers:

- Neutron-based irradiation, as general introduction 
- Critical system using fast and thermal spectrum

- Externally-driven sub-critical systems using fast and thermal spectrum

- Non-neutron transmutation.

The discussions on the critical and externally-driven systems include considerations for the once-through and recycle strategies.

\section{Neutron-Based Irradiation}

There are many neutron-based irradiation environments that can be proposed for the mission of transmuting the TRU in UNF. They include critical reactors that achieve a self-sustaining neutron fission chain reaction, and subcritical systems that are not able to sustain the neutron fission chain reaction, but are driven by neutrons from an external source such as fusion-fission hybrids (FFH) and acceleratordriven systems (ADS). The systems can produce power and be an integral part of the electric grid, or be dedicated, non-power producing burners targeted at specific isotopes. Systems that are expected to be reliable sources of power are subject to more constraints than dedicated burners since they must compete in the marketplace, be licensable by the US NRC, etc. . Other irradiation approaches include the use of non-neutron elementary particles (like protons, electrons, ions, and photons) or systems based on lasers and other non-particle systems to induce nuclear fission or other nuclear reactions, but these are considered expensive and impractical for power production or material transmutation, as current technologies have low efficiencies and low intensities relative to neutron-based systems.

For neutron-based irradiation, the first distinction is based on the neutron energy spectrum. Figure 2 shows the two main classes, which are termed 'thermal' and 'fast', based on the predominant energy of the neutrons causing fission in the system. This difference is essential to understanding the performance of nuclear reactors and how the highly-radioactive actinide and fission product elements are created and destroyed during the course of irradiation.

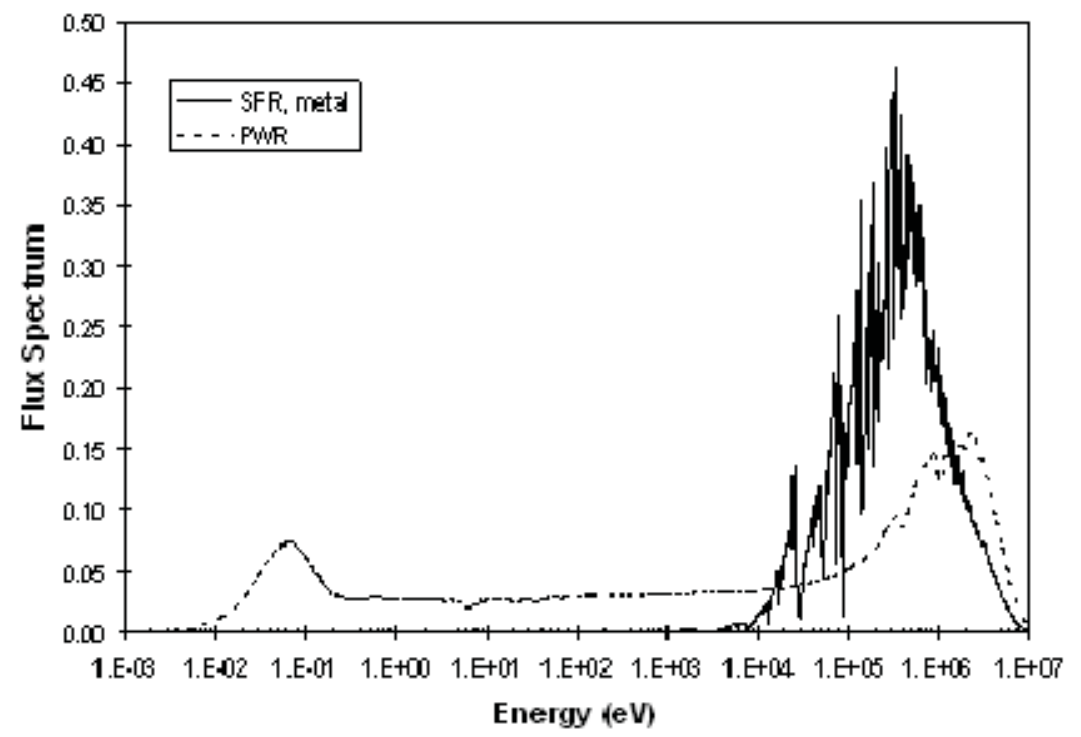

Figure 5. Neutron Energy Spectra for Fast-Neutron (SFR) and Thermal-Neutron (PWR) Nuclear Reactors

Actinide transmutation envisioned as part of a recycle system can be done with either a thermal or a fast neutron spectrum system. A thermal neutron spectrum provides for a greater transmutation rate at a given 
neutron flux due to the generally higher probability of fission or capture for thermal neutrons (higher cross sections). However, a thermal system is more adversely impacted by the poisoning effect of fission products which serve to parasitically capture neutrons that would otherwise be available to transmute the TRU. Therefore, the neutron balance in a thermal spectrum system which must satisfy criticality requirements, and account for parasitic capture and leakage is such that there are very few excess neutrons available for transmutation of actinides. This is in contrast to the availability of excess neutrons in a fast spectrum system which allows the inclusion of actinides for transmutation in the fast reactor with less negative impact to the system characteristics. Fast spectrum systems are less affected by fission products, and have a higher flux which partially compensates for the reduced probability of fission or capture. In addition, the relative probabilities of fission and capture are such that the actinides are much more likely to undergo fission rather than capture reactions with fast neutrons. Therefore, transmutation in a fast spectrum is more efficient. Also, the capture reactions with thermal neutrons create higher actinide elements that are highly radioactive and complicate fuel handling, processing, and fabrication, while the lower capture rate with fast neutrons suppresses the buildup of these higher actinide elements. As a result, fast reactors are preferred for transmutation, but the desirability of using thermal neutrons to increase the transmutation rate has led to some interesting proposals such as the use of moderated targets in a fast spectrum reactor. In principle, both thermal and fast spectrum systems can be considered for TRU transmutation.

The burnup of the nuclear fuel at discharge from the system measures the amount of fuel that has been fissioned. The remaining fuel is either unchanged from the original fuel loaded into the reactor, or it has been transmuted into heavier TRU elements, including plutonium, neptunium, americium and curium. The isotopes of TRU elements are important contributors to the radiological hazard of UNF. For current thermal reactors such as LWRs and CANDU, the discharge burnup is typically in the range of 1-6\%, which corresponds to a fission product content of 1-6\%. The TRU elements comprise approximately $0.5-$ $1.5 \%$ of the mass of UNF, with the remainder being uranium with $0.1-0.9 \%$ U-235 (from an initial enrichment of $0.7-5 \%$ ). For fast reactors used in a recycle strategy, the fissile content of tend to be much higher to sustain the fission reaction in the compact reactor, and the TRU content of the UNF is much higher, but since the fuel is reprocessed in recycle strategies, this is not an issue. A fast neutron irradiation environment might be effectively used in a system with an external source of neutrons since the fission reaction is driven by a separate device.

Recently, several systems have been proposed that claim the ability for near-complete burnup of the fuel in situ without the need for any processing or recycling. These systems present formidable, perhaps even practically insurmountable, challenges in materials and the fuel performance and integrity required, that are well beyond current or projected capabilities. While it may be possible to configure such systems if a high intensity external neutron source is available, it is unlikely that they would be viable candidates for power production, or feasible in a critical reactor.

\section{Critical Systems - Nuclear Reactors}

Critical reactor systems have been used for power production and can be used for the transmutation of nuclides. A variety of reactor types (thermal or fast spectrum) and fuel types (uranium-based and thoriumbased fuels) have been considered for both the once-through and recycle strategies, and systems for both limited and continuous recycle have been proposed. With fuel processing, the transmutation of minor actinides in irradiation targets becomes an option to direct disposal of MA or use of MA in recycle fuel containing all of the TRU ("homogeneous" recycle).

The amount of the actinide nuclides destroyed by fission for a given reactor power level is the same for all reactor designs, since power production is primarily from the fission process. Designs can be constructed to preferentially destroy some nuclides at a higher rate relative to the others by using a different neutron spectrum or nuclear fuel composition. Studies have shown that plutonium nuclides can 
be destroyed or utilized for fuels in both thermal and fast reactors. As discussed in the previous section, fundamental physics indicates that fast reactors have more surplus neutrons that can be used for transmutation than thermal reactors. The fast reactors can additionally be used for more efficient burning of the minor actinides because they have significantly higher probability for the fission reaction than for capture leading to higher actinide creation. Evaluation of the required neutron consumption for a recycled nuclide, defined as the number of neutrons required to pass from the initial nuclide to a stable nuclide, indicates that it is always possible to have actinide nuclides transmuted into stable lower mass nuclides in a fast spectrum, but this is more difficult in a thermal spectrum due to the stronger competition between neutron capture and fission, as well as poisoning (absorption) by fission products.

Different designs have been developed for transmuting the problematic nuclides with only one recycle in fast reactor systems in order to eliminate the need for reprocessing the used fuel containing the recycled materials. Some of these designs have included the use of special "target" pins containing the problematic nuclides Am and Cm ("heterogeneous" recycling), or the use of fuels that include such problematic nuclides along with the all of the other TRU nuclides ("homogeneous" recycling). Other designs have included special destruction 'zones' for certain nuclides within the reactor, such as specialized thermal zones in fast spectrum systems for enhanced nuclide destruction using the surplus neutrons that are available in fast reactors. Some designs have considered not using uranium in the target fuel pins to reduce the production of plutonium in the nuclear system and associated radiotoxicity. Such pins are referred to as inert matrix fuels (IMF), since the matrix materials are essentially inert with respect to neutron irradiation. Others have considered the use of thorium for reducing plutonium production, although production is not eliminated as it is with inert matrix fuel. All these studies have however concluded that it is impossible or impractical to have a complete destruction of the TRU elements with only one recycle due to considerations of neutron availability to sustain a steady power generation and fuel/cladding performance.

\section{Once-Through Nuclear Fuel Cycle Strategy with Thermal Reactors}

Once-through systems require fabrication of nuclear fuel, use it once, and dispose of it without recycle. Common attributes include mining of uranium, fuel fabrication, utilization and disposal. Most include uranium enrichment and used fuel storage prior to disposal. Efficiency of uranium utilization and the characteristics of the UNF become the primary differentiators in once-through systems. In all oncethrough systems the UNF contains all the fission products and minor actinides generated during irradiation, and rely on the fuel form to also serve as the disposal form.

All current or historic once-through systems use thermal spectrum reactors in which a moderator such as water, graphite or heavy water $\left(\mathrm{D}_{2} \mathrm{O}\right)$ slow the fission neutrons with an average energy of $\sim 2 \mathrm{MeV}$ to near thermal equilibrium energies of about $1 \mathrm{eV}$. Typical fuel is uranium oxide enriched to several percent $\mathrm{U}$ 235. Alternative fuels include uranium metal alloy and coated particle fuels. Systems with graphite or $\mathrm{D}_{2} \mathrm{O}$ moderators may operate on natural uranium without the need for uranium enrichment. However, the final burnup achievable varies directly with the initial uranium enrichment.

Examples of thermal systems for the once-through strategy include the commercial LWRs that operate in the U.S., the HWR-CANDU reactor system used in countries like Canada, Romania, and partially in South Korea and China. HWR reactors are also deployed India. Graphite moderated reactors have been used in the U.S. and Europe, and were also employed in the military material production reactors in most countries (along with heavy-water moderated reactor systems). The advanced gas-cooled reactors (AGRs) operating in the U.K. use graphite as moderator.

LWRs and other thermal reactors have been considered for extended burnup and deep-burn of the nuclear fuels. One of two technical considerations might limit the burnup level. The first pertains to the fact that current materials of construction of nuclear fuels (e.g., its cladding or assembly duct or spacer grids) have 
limited endurance for the harsh temperature and radiation environment of the nuclear system and consequently have to be removed before irradiation damage to the fuel assembly, corrosion, and other chemical and mechanical interactions with the coolant and fuel become a safety concern. This issue can be overcome by developing materials that have better nuclear irradiation performance, controlling coolant conditions, and improved fuel designs to prolong fuel residence time in the reactor. The second issue pertains to the fact that nuclear reactors must sustain and control the nuclear chain reaction to ensure reliable power production. This issue could be addressed by using higher enrichment for the fuel, use of burnable poisons, or by using designs that allow the creation of fissile materials in situ during reactor operations to prolong the sustained nuclear interaction.

An example of LWR with extended burnup is illustrative. By increasing the enrichment of the pressurized-water reactors (a class of LWRs) to about $8 \%$, the burnup could be increased to $100 \mathrm{GWd} / \mathrm{t}$ from the current value of $\sim 50 \mathrm{GWd} / \mathrm{t}$. This would halve the fuel loading and UNF in the system. However considerations must be given to the cost of the higher enrichment, the unavailability of fuel assembly construction material that can perform to the higher burnup level, and the fact that the resulting UNF is more radioactive. It is noted that by using much higher enrichments in this system, burnups as high as 20$25 \%$ might be obtained. Proliferation risk considerations limit initial fuel enrichment to $20 \%$, thus limiting the maximum burnup that can be attained with enriched uranium fuel. The LWR industry in the United States has been increasing the burnup of nuclear fuels due to associated fuel cycle cost benefits, and will most likely continue to do so. However, economic and licensing constraints will likely be the determining factor in arriving at an "optimum" burnup.

As noted earlier, using thorium can only be done along with enriched uranium to ensure self-sustaining nuclear reactions and desired cycle length. The uranium must be more highly enriched than in a conventional UOX-fuelled system (e.g., 10\%-20\% instead of $<5 \%$ in a PWR). Two basic implementation scenarios have been considered for PWRs. In the "homogeneous" approach, the fuel rods in a standard fuel assembly are replaced with LEU plus thorium. In the "heterogeneous" approach the thorium plus some LEU to generate power before sufficient U-233 is built up and to denature the bred U-233 to keep it below the "proliferation limit" [38] is located in a blanket which can be a separate assembly, or a separate zone in a standard assembly. An LEU driver ("seed") assembly or zone is also required to supply neutrons to the blanket regions. The seed regions are always supercritical (k-eff $>1.0$ ), and the blanket regions are always subcritical. Use of separate zones allows a separate fuel management approach to be followed for the seed and blanket to optimize performance. This approach has shown some improvements relative to conventional UOX-fuelled LWRs in terms of reduced plutonium production and quality, and reduced waste per unit of power generation. However, high power production in the seed region and high burnups in both the seed and blanket required to satisfy cycle length objectives and optimize performance present challenges.

The nuclear fission reactors are the most mature of the possible technologies for fuel burnup and utilization.

\section{Recycle Nuclear Fuel Cycle Strategy with Thermal Reactors}

The UNF with the associated plutonium, minor actinides and fission products are currently being accumulated at nuclear power plants all over the United States. It is estimated that the legislative limit established for UNF and defense waste at the Yucca Mountain site (70,000 tons) would be reached by 2010. Since the UNF have reached their designed lives the options available for their long-term management are a challenge. The fuels could be entombed in disposal sites, held indefinitely at reactor sites as long as permitted by the Nuclear Regulatory Commission, or reprocessed and recycled using existing or advanced nuclear fuel cycles and reactor designs. If one of the first two options is chosen, then ultimately, disposal sites must be selected, characterized and deployed. While a disposal site is required for the third option, it however permits the potential to use nuclear systems to significantly reduce the 
mass, radiotoxicity, and heating, associated with the UNF in the repository. Alternatively, it would allow a repository to accommodate the wastes of nuclear fuel processing associated with a much higher nuclear power generation capacity than that which could be accommodated with a once-through fuel cycle.

Different nuclear systems have been proposed for the recycle infrastructure, but there are only two basic options to be considered as discussed in Chapter 3. These are the limited recycle option or the continuous recycle option. In the limited recycle approach, the fuel is reprocessed to extract one or more transuranics that are subsequently used for making fuel that can be recycled in a reactor system or another irradiation system. Recycle is only done once or a few times, but eventually there will be UNF that is not processed further, and is sent to disposal instead. On the other hand, in the continuous recycle approach, the fuel material is continuously recycled, with only the wastes from the reprocessing step being passed to the disposal site.

Just like in the once-through discussion above, different nuclear systems and system architecture can be used for fuel recycle, but the technical maturity levels of the candidate systems vary. Both limited and continuous recycle concepts have been considered for LWR systems. Currently, an example of limited recycle is the LWR-MOX concept used in Europe and being instituted in Japan since there are no facilities available for processing and recycling materials from the used LWR-MOX fuel. In this technically-mature approach, the LWR-UOX UNF is reprocessed and the plutonium is used to make U$\mathrm{Pu}$ mixed oxide fuel that is used to run a LWR. This LWR could be the same system in which the plutonium was produced or a different LWR. Options for partial core loading of MOX fuels or full-core loading of MOX fuels have been proposed, but the former is currently used in commercial reactors. These considerations rest on the reactor safety characteristics of the system. Similarly, innovative concepts using inert matrix fuels have been proposed for deep-burn of UNF in LWRs. Typically, burnup as high as 50$60 \%$ has been projected. However using whole-core loading of the IMF fuel is not practical from a safety viewpoint and only fractional-core loading of the material is realistic. The repository performance of limited recycle in LWRs is similar to that for the once-through low burnup system, and as such they are not of much of interest when the intent is to fundamentally change the characteristics of the waste confinement time from a geologic time scale (hundreds of thousands of years to millions of years) to an engineered time scale $(<1,000$ years).

LWR concepts have also been proposed for the multi-recycle of plutonium only or of all the TRU elements. However, proliferation concerns might preclude the use of plutonium-only fuel. Additionally, the fuel cycle concept must have a solution for the minor actinides that are not utilized in the nuclear system. This has led to the proposal for the continuous recycle of all the TRU in the LWR. In this case, the fissile quality of the fuel becomes progressively worse and the fuel radioactivity increases with each recycle, which makes fuel handling (particularly fabrication) difficult and expensive. The use of extended decay storage for LWR UNF (for $>30$ years) has been proposed to allow radioactivity and decay heat to decrease, facilitating UNF processing. The longer decay time also reduces the buildup of higher actinide elements with recycle by allowing the curium isotopes to decay. Pu-241 also decays to Am-241, which results in $\mathrm{Pu}-238$ through transmutation and decay, instead of using $\mathrm{Pu}-241$ which can transmute into $\mathrm{Pu}-$ 242 and higher Am and $\mathrm{Cm}$ isotopes. In order to have a self-sustaining critical system based on multirecycle of TRU in thermal reactors, it is also necessary to add enriched uranium to the fuel. This is unattractive if scarcity of uranium resources becomes constraining to nuclear utilization in the future. In that case, a nuclear system that could be used for breeding additional fuel would be attractive.

The use of other thermal reactors has been proposed for limited recycle. Some examples include the VHTR for the deep-burn of TRU from LWR UNF. This approach was originally proposed by General Atomics and is being investigated under the DOE Generation IV program. It was also proposed that following the deep-burn ( $\sim 60 \%$ burnup) the UNF could be directly disposed due to the favorable characteristics of the ceramic graphite fuel (TRISO coated fuels in graphite). This recycle approach suffers from the limited benefits to the repository due to the limited recycle. 
Systems using liquid fuels are in a different class because of the possibility that the fuel could be continuously recycled on-line. The molten-salt reactor is grouped as part of this class of reactors. Different fuel types could be used to startup the system. This could include U-235/U- or U-233/Th-based systems. In either case, the fissile U-235 is used to support the internal conversion of uranium or thorium for the creation of fissile $\mathrm{Pu}$ or U-233. Due to the creation of fission products, additional U-235 or U-233 might be necessary to ensure that a self-sustaining chain reaction is maintained. One concept proposed that the fuel mass in the system will continue to grow while maintaining criticality. As the system volume limit for fuel is reached, portions of the core material could be transferred to start-up another system. Mechanisms for the transfer of the fuel and any storage requirements need to be developed. Independent confirmation of the approach is required and issues with material performance limits in a toxic environment would have to be resolved. Alternatively, the fission products could be removed to limit or eliminate the need to add additional fissionable material if a self-sustaining MSR was used. However, generally, the liquid fuel systems offer the potential for high burnup of fuel materials including keeping the problematic fission products out of the repository. Coupled systems with liquid fuel fission blanket and external neutron source have also been proposed

Th based fuels may also be used in limited recycle systems with the creation of fissile U-233. Minor actinides may be incorporated into recycle fuel or separated for disposal or partial transmutation in irradiation targets. Several studies have considered the use of $\mathrm{Pu} / \mathrm{Th}$ fuel to more efficiently burn the $\mathrm{Pu}$ (plus potentially other MA) in UNF from conventional UOX fuel. Studies for a PWR confirmed a significant increase in net $\mathrm{Pu}$ consumption relative to MOX. However, there is still a significant production of TRU, although less than with conventional MOX.

To summarize, thermal systems can generally be divided into:

- Thermal with single $\mathrm{U} / \mathrm{Pu}$ recycle

- Thermal with single U/Pu recycle plus MA targets

- Thermal multi-recycle U/Pu

- Thermal multi-recycle U/Pu plus MA targets

- Variants of the above with thorium fuels.

Continuous recycle systems are designed to achieve the highest possible resource utilization and to produce minimum waste. This could be achieved through nearly complete burnup of fissionable material resulting in just fission products with minimal minor actinides in the HLW stream. Continuous recycle with critical systems can be done with fast reactors to avoid generation of higher actinides, although this constraint may be removed with long-term interim storage prior to recycle in thermal reactors.

\section{Once-Through Nuclear Fuel Cycle Strategy with Fast Reactors}

Fast reactors have generally been associated with the recycle fuel cycles. This is because the early fast reactors were designed for fissile material breeding, recovery via processing, and re-use in reactors. More recently however, once-through fast reactors have been proposed using naturally-occurring fuel materials (uranium and thorium). In these systems, it is planned to use driver assemblies containing low enriched uranium fuel and blanket assemblies containing uranium or thorium. The driver fuel is planned to be irradiated to burnups of 30-40\%, while the burnup of the blankets would be lower, though designs with $\sim 20 \%$ blanket burnup have been proposed. While the driver assemblies are initially supporting the core criticality at the beginning of core life, the blankets play a major role at the end of cycle, generating most of the reactor power. To achieve high-burnup and the long core residence that are planned, the core power density is derated, thus resulting in larger core sizes than traditional fast reactors. Operated with a conversion ratio near unity, fast reactor systems can achieve burnup limited only by fuel and cladding 
lifetime. Achieving near complete burnups in these once-through systems in a fast reactor appears impossible without the use of high uranium enrichment fuel.

\section{Recycle Nuclear Fuel Cycle Strategy with Fast Reactors}

Fast reactors have typically been designed for the recycle of plutonium. Recent evaluations have indicated that the system could also be used for the recycle of TRU. However, beyond the demonstration with a few fuel pins and assemblies, TRU recycle has not been practiced in previously operated or currently operating fast reactors. Because the fuel cycle operations for the fast reactors have been designed to be done remotely, the additional transmutation of the minor actinides is assumed to be feasible in such systems.

Fast reactors have been designed primarily for TRU burning under the AFCI program. This is to provide a special niche for them in the current U.S. nuclear infrastructure that relies primarily on light water reactors for commercial power production. Designs in the range from very low conversion ratios $(0.0$ to $0.25)$ to traditional values $(>0.5)$ have been considered in the program. The initial motivation for the low conversion ratio core was to developed designs that could provide nearly the same burning capabilities as the accelerator-driven systems (while meeting safety goals), after it was found that the latter systems would be very expensive (maybe as much as a factor of two) and were not ready for continuous power production, which would be needed to offset the higher cost of the advanced transmutation systems. Fast reactors in the traditional conversion ratio range were assumed to cost about $25 \%-50 \%$ more than light water reactors and therefore some effort in the AFCI program has been devoted to investigating approaches to make their cost comparable to or lower than for the LWRs.

The burner fast reactors would be quite useful if the primary mission of the advanced nuclear enterprise is minimization of UNF and HLW. The reactors would be used for transmuting the TRU generated by LWRs systems. If on the other hand, effective uranium resource utilization is a primary focus for the fuel cycle, the fast reactors could be run with high conversion ratios $(>1.0)$ for the production of additional fissile material for the overall nuclear infrastructure. Studies have shown that the same reactor vessel could be used to contain cores with conversion ratios in the 0.75 to 1.0 range. Higher conversion ratios might however be required for a sustainable nuclear infrastructure.

In the U.S., based on proliferation and waste management considerations, it is attractive to recycle all the TRU as a group in the reactor fuel (homogeneous recycle), rather than separating the plutonium and minor actinides, and using the plutonium in driver fuels and the minor actinides in target pins for transmutation (heterogeneous recycle). The initial fuel of the homogeneous recycle approach has higher radiation-emission and heating rates than the driver fuel containing just plutonium. The target pins would however be much hotter (radioactivity and heat) than these fuels. However, by separating the streams into the different pins, it might be possible to start the transmutation mission using the plutonium fuels and allow time for the development of fuels containing TRU.

Different types of fast reactor designs have been considered in U.S. nuclear energy programs in recent years. These have included sodium-cooled fast reactors (SFR), gas-cooled fast reactors (GFRs), and leadcooled fast reactors (LFRs). These different systems have been studied because of their distinct features. For example, the GFR was considered because of its potential for high temperature operation that could permit designs of systems with high thermal efficiencies and systems for hydrogen and process heat production. In addition, the ability to inspect the core offered operational benefits. From a TRU transmutation and management viewpoint the performance of these fast reactors are quite similar. The systems however differ in their characteristics. For example, the GFR tends to be larger to get a lower power density that could be removed by the gas coolant (helium and carbon-dioxide being leading coolants that have been considered) which is less effective as a heat transfer medium than sodium, especially in the case of accidents. Coolant operation considerations also make the LFR bigger than the 
SFR (in this case the LFR has to be operated at relatively lower velocity than sodium to prevent the scaling of an oxide layer that needs to be present to prevent corrosion).

The SFR is the most mature fast technology that has been used for test and demonstration scale reactors internationally (some of which are power producers like the Russian BN-600). This was a primary reason why the advanced recycling (or burner) reactor being considered under the AFCI and GNEP program assumed sodium as the coolant. It is noted that the Russians have a wealth of knowledge on lead-cooled systems because military reactors have been operated with this coolant. Due to the fact that sodium has been used for most fast reactor designs, particularly the breeder designs, it is common to attribute this coolant with proliferation risks associated with the breeder reactors. In fact, breeding characteristics for the sodium cooled fast reactor are similar to those of the GFR and LFR.

Different fuels have been considered for the fast reactors, including oxide and metallic fuels. Others include carbide and nitride fuel. Fuel pin and coated particle fuels in a matrix have been considered along with other fuel forms. Fuel compatibility with the coolant or the matrix is a significant consideration for reactor design. This is why nitride fuel has been considered as the leading candidate for the LFR and carbide fuels for the GFR. Most SFRs have been run using oxide fuels, but metallic fuels have also been perfected and utilized by the U.S. program, offering safety advantages. Some foreign programs (India and China) are now considering transitioning to metallic fuels.

Thorium fuel could be used in fast reactor systems for resource extension and for minimizing the amount of highly radioactive minor actinides in used fuel. Fissile support from enriched uranium or plutonium fuel is however required as thorium has no naturally-occurring fissile nuclide. Following irradiation, U-233 which is fissile is produced. This U-233 could either be used in situ or recovered in the used thorium fuel by the reprocessing process. As noted earlier, a concern with this re-processing is that the U233 which is an attractive fissile material might increase the proliferation risk of the fuel cycle. The used fuel material however contains $\mathrm{Pa}-232$ that is a strong gamma emitter that makes fuel handling and utilization difficult. Additionally, designs have been proposed for denaturing the thorium fuel such that the composition of the uranium constituent makes the isolation of U-233 difficult. Thorium can be used as the matrix material in place of uranium in homogeneous or driver/target transmutation fuels along with TRU elements to limit production of new TRU. If additional uranium is added to address the proliferation risk from U-233, this will negatively affect achievement of this objective.

\section{Multiple Reactor Types in a Recycle Nuclear Fuel Cycle Strategy}

It is potentially possible to minimize the amount of material to be passed to the repository to get benefits similar to the complete burnup proposal discussed under the once-through systems above. This is achieved by having a continuous recycle system as the final tier in a symbiotic fuel cycle containing two or multiple tiers. Because the advantages of the fast spectrum systems discussed above, they are generally considered for the final tier, and could be reactors, or ADS or FFH or mixtures. A thermal system could be proposed, but it has the problem that the higher actinides content grows with recycle, making fuel handling relatively more difficult.

In the single-tier architecture, UNF from the commercial tier (tier 0 ) is reprocessed to recover the transuranics that are then used for fuel in a fast spectrum system. The fuel is then continuous recycled in the fast spectrum system. The advantage of the continuous recycle system is that the limitation imposed by irradiation damage can be eliminated by recycling the fuel material when such limits are reached.

Since current perceptions from an economics viewpoint is that the fast reactor systems are more expensive than the LWRs (and most other thermal systems), multi-tier approaches have been proposed for the continuous recycle architecture. In this case, an intermediate thermal burner is introduced between the commercial sector LWRs and the fast spectrum system. Since these systems could be used to effectively consume the plutonium either in a single pass or few passes in the system, the remaining fuel would be 
lower and would reduce the number of the fast spectrum systems required. Thus, the overall fuel cycle architecture cost could potentially be reduced. Both uranium-based and non-uranium fuels (or IMF) have been considered for the intermediate tier.

The strategic utilization of the intermediate tier has been proposed as a means of reducing the overall cost when the ADS or FFH system is used in the final tier of the multi-tier nuclear architecture. In this case, the plutonium is completely or mostly burned and the remaining fuel contains primarily the minor actinides and the higher plutonium isotopes. By so doing, fewer final tier system machines are required in the fuel cycle architecture. This has been promoted as competitive or cheaper than using fast reactors in the fuel cycle, but the fact remains that the fast reactor system has a higher technical readiness level than the FFH and ADS, and there is need for consistent comparison of the systems for a given mission.

In summary, it is noted that different combinations of reactors with or without externally-driven subcritical systems could be used in a recycle strategy. In these considerations it is cautioned that TRU fuels have not been used in commercial or experimental systems and need additional development for nuclear system applications (including reactors, though the experience base at lab scale is for reactors). The cost of utilizing these fuels in the fuel cycle is expected to be high until technology is perfected for their handling due to the high radioactivity of the fuel materials. Regarding maturity, reactors have a much higher readiness level than the ADS and FFH systems. The addition of fast spectrum systems in combination with thermal systems in limited recycle permits additional improvements in both resource utilization and waste minimization. While $\mathrm{Pu}$ could be optionally recycled in thermal systems, both $\mathrm{Pu}$ and MA can be effectively used in fast spectrum fuel. Enrichment requirements may be reduced for the entire system, in proportion to the fissile recycle. Fast spectrum reactors may be used primarily as burners at lower conversion ratio to minimize MA waste, or at higher conversion ratio to produce greater fissile recycle. Limited recycle systems may be divided into:

- Thermal with single U/Pu thermal recycle plus FR U/Pu

- Thermal with single U/Pu thermal recycle plus FR U/TRU

- Thermal multi-recycle U/Pu plus FR U/TRU

- Thermal with single U/Pu recycle plus FR IMF

- Thermal with multi-recycle U/Pu plus FR IMF

- Thermal with single U/Pu recycle plus MA targets and FR TRU

- Thermal multi-recycle U/Pu w/MA targets plus FR U/TRU

The use of fast spectrum systems in combination with thermal systems can result in large improvements in both resource utilization and waste minimization. Enrichment may be used to fuel thermal spectrum systems, and the recycled fissile from this fuel used in fast spectrum systems. Fast spectrum systems with high conversion ratios can produce excess fissile for use in thermal spectrum systems without enrichment. Continuous recycle in general will require a preponderance of fast spectrum reactors. Continuous recycle systems may be divided into:

- Thermal single cycle with plus continuous FR U/TRU

- Thermal with single U/Pu thermal recycle plus continuous FR U/TRU

Thorium could also be used in place of the uranium in these systems, but the development and use of these fuels would entail additional research and development which would only be warranted if significant improvements could be achieved relative to the use of uranium. 


\section{Externally-Driven Sub-critical Systems}

The need to self-sustain the nuclear chain reaction while maintaining system safety could limit the ability of reactors to achieve complete burnup. Consequently, the requirement of a self-sustaining nuclear fission reaction has been relaxed for some of the nuclear systems that have been proposed for near-complete burnup of fuel materials (enriched uranium or uranium ore). This class of systems would require an external neutron source to ensure a sustained neutron interaction. Examples of these externally-driven sub-critical systems include accelerator driven systems (ADS) and fusion-fission hybrids (FFH). These systems have been proposed from nearly the start of the nuclear era, and they have been resurrected in recent times for the purpose of effective material utilization, UNF consumption, and fissile nuclear material production. In the context of the once-through fuel cycle, these systems are attractive as long as the external neutron source device (accelerator-driven spallation neutron or fusion neutron) can be sustained and the neutron multiplication in the fission blanket can be used to produce neutrons to drive the high burnup.

Both inertial confinement and magnetic fusion devices are two fusion approaches that have been considered for providing external neutron sources for coupled nuclear systems, along with the ADS. The DOE fuel cycle program focused on ADS in the early 2000s. Issues with these externally-driven, subcritical systems are the overall system cost (higher than reactors), reliability of continuous operations, fractionally higher energy neutrons that accelerate neutron irradiation damage, the need to regulate the neutron source strength, and low technology readiness level. Different concepts are being developed to alleviate some of these issues.

\section{Once-Through Nuclear Fuel Cycle Strategy}

A variety of sub-critical systems driven by an external neutron source have been proposed, although none have been built for commercial energy generation. The two primary drivers for these systems are accelerator driven spallation and D-T fusion sources. Both produce neutrons with higher energy than fission reactors, and the degree of moderation can be optimized. For once-through use the increased cross sections and reduced material damage make a thermal neutron system attractive. In addition, the external neutron driven systems allow the possibility to start the system with natural or depleted uranium and build up fissile materials over the lifetime of the system to achieve a sustained power level. Such systems have been proposed to drive the fuel to near complete burnup by the end of life to provide waste reduction benefits. As previously discussed, the challenge for these systems is the burnup limitations posed by the materials used.

\section{Recycle Nuclear Fuel Cycle Strategy}

With limited recycle, the use of sub-critical systems driven by an external neutron source provides additional options. In most proposed systems, a combination of thermal reactors are supported by driven systems primarily for waste transmutation in lieu of fast spectrum reactors, and variations are primarily in the division of recycle in critical versus driven systems. With sufficient external neutron source strength, it may be possible to use a driven system alone with limited recycle and no enrichment needed. Either fusion fission hybrid (FFH) or accelerator driven systems (ADS) may be used. Systems may be divided into:

- Thermal reactor with single Pu recycle and fast FFH/ADS TRU burner

- Thermal reactor with multi Pu recycle and fast FFH/ADS TRU burner

- Thermal reactor plus fast reactor $(\mathrm{Pu})$ and FFH/ADS actinide burner

- Thermal reactor and mixed spectrum FFH/ADS UNF burner

- FFH breeder plus thermal once-through (no enrichment) 
- FFH stand-alone.

For continuous recycle, the use of sub-critical systems driven by an external neutron source provides additional options. Either thermal reactors or a mix of thermal and fast reactors are supported by driven waste transmutation systems. With sufficient external neutron source strength, it may be possible to use a driven system alone with continuous recycle or even in a single cycle to complete burnup, if fuels and materials can be developed to enable such high burnup. Either fusion fission hybrid (FFH) or accelerator driven systems (ADS) may be used. Systems may be divided into:

- Thermal reactor plus fast FFH/ADS TRU burner

- Thermal reactor plus fast reactor $(\mathrm{Pu})$ and FFH/ADS actinide burner

- FFH stand-alone.

\section{Non-Neutron Transmutation}

Beyond the use of neutrons, non-neutron elementary particles could be used for the deep or complete transmutation of nuclear fuels. Such systems have typically been restricted to scientific studies due to their very low transmutation efficiency. They include: (1) charged particle systems - protons, electrons, ions, etc., to directly impact materials to be transmuted; (2) photon-based systems - where intense highenergy photons are used to induce photo-nuclear reactions. New sources of mono-energetic photons may enable transmutation of select isotopes that are difficult to treat with other processes; (3) electromagnetic radiation (EM)-based systems - systems that directly transmute individual isotopes by exciting nuclei with intense narrow-band EM radiation to pre-defined energy levels prompting enhanced $\beta$-decay to more stable, less hazardous isotopes or stable elements. Source of EM radiation can be lasers and rf-fields.

Significant research and development is required before these approaches can be practically used for the transmutation mission. For example, it is conceptually possible to use gamma radiation for transmutation of the TRU to stable or shorter-lived nuclides by inducing fission, or raising the nucleus to an energy level that then decays via neutron or beta emission, resulting in a lower mass nuclide or a different element. High photon energies (several $\mathrm{MeV}$ ) are generally required to initiate these reactions. Currently, photons are generally produced with an electron accelerator via Brehmstraulung on a heavy metal target, resulting in a continuous photon energy spectrum ranging downward from the maximum energy of the electron. However, most of the photons are produced below the desired $\mathrm{MeV}$ range, which when coupled with the relatively low (compared to neutrons) interaction probability results in a low transmutation rate. Technologies capable of producing high flux, mono-energetic photons are currently being studied, and if the RD\&D is successfully demonstrated these may overcome the deficiencies described above.

Similarly, transmutation based on direct nuclide interaction with protons does not appear to offer any advantages relative to neutron-based systems. It is likely not cost-effective, as it requires a highenergy/high-current proton accelerator $(1-2 \mathrm{GeV}, 100 \mathrm{~s}$ of $\mathrm{mA})$ to overcome the Coulomb barrier and needs a sufficiently high proton flux to have a useful transmutation capability (quantity of material transmuted in reasonable timescale). In addition, the energy required to produce such high-power proton beams would make these systems net user rather than generators of power. The high gas production in any actinide containing targets and associated embrittlement of cladding/structural materials introduces addition complexities that need to be addressed. Note that the high-power proton beam would also generate neutrons in the irradiated material via spallation, and it not clear without further study whether the protons or the neutrons are the most effective in transmuting the material. If the neutrons are more effective, then the classic ADS system described above would be preferred. 


\section{Impacts of Reactors and Other Irradiation Options}

Neutron irradiation in nuclear reactors is currently the most developed and cost-effective approach for using fission to produce energy or to transmute elements. Neutron irradiation can be implemented using nuclear reactor systems, externally-driven sub-critical systems, or other non-neutron elementary particles to induce nuclear fission. A variety of such systems has been proposed in the United States and internationally.

Employing LWRs for the purpose of transmutation (addressing waste management and proliferation concerns) uses existing infrastructure and familiar technology, although additional infrastructure for reprocessing and recycling, transportation, MA-containing fuels and targets, and appropriate safeguards would be required. An example of the approach is MOX fuel utilization in LWRs, which is known technology practiced extensively in countries such as France. It is noted that even in those countries, MOX fuel utilization is only viewed as one component of a continuous recycle strategy, where advanced fast reactor systems are planned for more effective management of TRU. As discussed above, fast reactors are better suited for the destruction of most transuranics, and have surplus neutrons that could be used for this purpose. Fast reactors may also impact sustainability of nuclear power by extending resources through breeding of fissionable materials, whether from uranium or thorium. These features are also attributable to externally-driven sub-critical fast spectrum systems.

Generally, it has been assumed that the fast reactors would be about $25 \%$ to $50 \%$ more expensive than LWRs, although this cost differential is apparently the subject of continuing debate as evidenced by the studies cited in Chapter 2. Countries such as Japan, Russia and India have indicated that estimated costs for advanced fast reactors systems are potentially lower than for comparable operating water-cooled systems.

All reactors could theoretically be configured to support near-complete burnup in the once-through and recycle strategies discussed in Section 3, although this may not be practical with a once-through fuel cycle. They are however much better configured for the continuous recycle strategy due to material performance limitations. Achieving critical reactor states could also be problematic and could require such periodic replacement of cladding materials. Additionally, even if a mix of reactor systems are used in the fuel cycle strategy, the systems physics consideration suggests that fast reactors would be needed for the final transmutation in the overall system.

The molten fuel reactor systems attempt to resolve these issues by combining features that allow continuous online reprocessing of the fuel and no cladding material that could limit fuel performance. However, as discussed in Section 4.1, while these systems have some attractive features, operations and maintenance issues are substantial.

Based on assessments from the ATW, AAA, and AFCI programs, externally-driven sub-critical systems are certainly more costly than reactor options due to the complexity and size of the systems. However, such systems may offer additional options for UNF and waste management, since it might be more advantageous to use the systems for the transmutation of minor actinides, fission products, and other hazardous radionuclides. It is noted in this regard that from a transmutation viewpoint none of the externally-driven sub-critical systems currently being proposed do not appear to have any advantage over the reactor systems that could also be configured for similar missions. This is because externally-driven sub-critical systems use significant multiplication of neutrons in the fission component of the system to accomplish transmutation, facing exactly the same constraints as reactors. Compared to reactors, externally-driven sub-critical systems introduce new safety concerns due to the independence of the neutron generation in the external source and the response of the fission component of the system, which supplies reactivity feedback to maintain control of the system. 
Proliferations risk concerns apply to all nuclear systems, with no significant difference due to the reactor type or other irradiation environment since all will produce SNM. Safeguards have been established to counter this potential and provide an effective way to reduce the proliferation risks, while at the same time allowing nuclear technology to contribute to energy security. From a proliferation risk viewpoint, the best nuclear system would be one that loads and fissions (burns) naturally-occurring nuclear material (uranium and thorium) completely, to essentially $100 \%$ burnup. However, such a system does not, and may not ever exist because of extreme material requirements, criticality considerations and requirements that the system be a stable power producer.

Non-neutron systems for nuclear power production are ineffective due fundamental physics limitations, low intensity of particles, and cost of the system, resulting in more power being required to operate them than is produced, and such systems would be impractical to be considered as part of a power production system, being relegated to use as scientific instruments where efficiency is not relevant.

\subsection{Processing Options}

By definition, processing technologies are only relevant for recycle strategies. The concept of processing UNF has been the subject of repeated changes in legal and political standing. [39] As discussed above, UNF processing is defined as any change to the form of the UNF that allows access to the fuel materials. Processing can range from a simple reconstitution into new fuel for further irradiation to complete separation of the chemical elements for waste management and fabrication into recycle fuel. Historically, the term 'reprocessing' has been applied to describe the case of chemical separation of plutonium and uranium from UNF, although reprocessing can describe any processing of used fuel. In the broader context, processing is designed to separate UNF into chemical elements or groups of elements, with some destined for transmutation and others to be discarded as waste. Reprocessing was first used to recover plutonium for military purposes in the U.S. and is the reason that there is an associated proliferation concern with the concept of UNF processing. In the commercial sector, reprocessing recovers plutonium for reuse in reactors as a method of extending supplies of nuclear fuel. More recently, processing has been studied for the potential to address nuclear waste management concerns, which were discussed in Chapter 2. The following discussion summarizes UNF processing technologies and their applicability to recycle strategy goals.

\section{Separations Processing Technologies}

Depending on the desired characteristics and products of the separations systems, many approaches have been developed, and can be grouped into two categories.

\section{Aqueous-Based Systems}

Aqueous-based systems use single or multi-phase processes where at least one phase is water-based in order to separate and recover the desired elements in product streams from UNF. Waste streams are also generated and include gaseous releases and solidified waste products for eventual disposal as solid waste. The aqueous-organic two-phase technologies (PUREX, UREX, co-extraction, etc.) include many options for separating uranium, plutonium, minor actinides, fission products, and other elements, individually or in groups, using a solvent extraction approach with specially-designed chemical extractants.

\section{Non-Aqueous-Based Systems}

Non-aqueous-based technologies are single or multi-phase approaches that do not use any phases with water and that can recover the desired elements in product streams from UNF. Waste streams are generated as a result of processing and may include gaseous releases and solidified waste products for eventual disposal. Examples of non-aqueous technologies are as follows: 
- Ionic Liquids / Electrochemical $(\mathrm{LiCl} / \mathrm{KCl}, \ldots)$ - include options for group separation of elements as well as the potential to recover individual elements using either the ionic liquids as part of a solvent extraction process or using electrotransport from an anode to a cathode.

- Gaseous (Fluoride volatility, ...) - converts oxide fuel to fluorides and separates based on gaseous and solid fluoride phases, followed by distillation of the gaseous compounds. The process is capable of uranium, plutonium, and neptunium recovery in the presence of a few of the fission products, with the remaining minor actinides and fission products being collected as solids.

- Supercritical Fluids $\left(\mathrm{CO}_{2}, \ldots\right)$ - uses a supercritical fluid as a substitute for an organic phase in the carrier for the extractant molecule(s). The process can be used directly for the recovery of uranium and plutonium when TBP (the PUREX extractant) is the extractant from either solid UNF or from liquid acidic solutions containing dissolved UNF (reverting to an aqueous-based twophase system).

- Plasma (Archimedes process, ...) - used fuel is ionized in a small accelerator in the presence of a rotating magnetic field for mass separation. The process uses the difference in precession to cause element/isotope separation. In principle, the process may be used for gross separation by mass or fine separation by isotope, and may also be suitable for enrichment as well.

- Laser (AVLIS, MLIS, ...) - more suited to isotope separation or enrichment, but is capable of separating materials and recovering individual elements or isotopes depending on the laser wavelength.

- Thermomechanical - processes such as oxidation/reduction cycles that release volatile fission products and prepare the remaining fuel and fission products for refabrication, typically as fuel for further irradiation.

\section{Performance and Capabilities of Processing Technologies}

In principle, many of the processing technologies can be structured to separate and recover any desired set of elements, either singly or in groups, for waste management purposes, while others have strictly limited application, especially those confined to use in limited recycle strategies. For those processing approaches with a general separations capability, there would appear to be no difference between the specific processing technologies in the capability to address waste management and other issues. All of the processes result in some level of proliferation concern, although the risk may be greater for those technologies where weapons usable elements are routinely separated. However, all of the more general separations processes appear to have the capability to be misused for the production of weapons-usable materials, so there may not be a significant difference in proliferation risk between any of the technologies. In principle, proliferation risk may be judged as lower for technologies where the fission products are intended to remain with any weapons usable materials, making the materials less attractive, although it also appears that these intentions can be circumvented.

The additional cost of any processing facility in a recycle fuel strategy must be factored into the overall fuel cycle cost, and not be treated as a consideration in itself since recycle may have the potential for substantial avoided disposal costs. Analyses have shown that these costs would not typically be a large fraction of the overall cost of electricity. The increased number of waste streams that result from processing must also be addressed, partly by comparison to the UNF that would be disposed if processing were not done, and in recognition that there are opportunities to tailor the contents of each waste stream for compatibility with the disposal environments. In general, processing could potentially reduce HLW waste volume, hazard, and decay heat, depending on the HLW composition. However, processing would also increase the amount of LLW from the nuclear power system, but this should also be viewed in the context of LLW generation from all sources, including those outside of the integrated nuclear power system. 


\section{Aqueous-Based Systems}

The processes to be used for separation of selected elements of UNF in advanced fuel cycles will be chosen to meet the criteria of waste minimization, cost effectiveness, and reduction of proliferation risk while maintaining safety for people and the environment,. The separations steps chosen will likely include a combination of aqueous-based dissolution, solvent extraction, and ion exchange, with other supporting steps leading to product and waste form production. Development has focused on the separation and recovery of actinide elements due to the long-lived radiological hazard and the usefulness of some actinides such as plutonium as reactor fuel.

The aqueous-based, continuously-operated solvent extraction using tri-butyl phosphate in an organic diluent, also known as the PUREX process, has been used effectively in all current industrial-scale plants, primarily because of the capability to process hundreds of tons per year of fuel containing predominantly uranium. The process is highly efficient in separating fission product wastes from the uranium, plutonium, and neptunium components. Modifications to aqueous-based systems have been designed to prevent separation of pure plutonium with the intention of reducing the proliferation risk, such as in UREX+ and other co-extraction processes. Smaller-scale solvent extraction, ion exchange, or precipitation processes may be included to separate the smaller amounts, (still tons per year in commercial-sized facilities) of americium and curium from the fission product wastes. The product conversion processes to make the recovered materials usable in nuclear fuel must be co-conversions of uranium, plutonium, neptunium, and possibly, americium and curium, depending on the recycle approach, but always with the intent of having the plutonium mixed with other elements. In principle, it is possible to design an aqueous-based system to recover either individual elements or groups of elements by using the appropriate processing steps. In this manner, aqueous-based systems should have the flexibility sufficient to meet virtually any processing goal. Waste streams are generated from processing and may include gaseous releases and solidified waste products for eventual disposal as solid waste, including both HLW and LLW.

\section{Non-Aqueous-Based Systems}

Single or multi-phase systems that do not use any phases with water and that can recover the desired elements in product streams from UNF include dry pyrochemical processes and electrochemical processes. As with aqueous-based systems, waste streams are generated from processing and may include gaseous releases and solidified waste products for eventual disposal as solid waste, including both HLW and LLW.

Ionic Liquids / Electrochemical ( $\mathbf{L i C l} / \mathbf{K C l}$, etc.) - These technologies include options for group separation of elements as well as the potential to recover individual elements using either the ionic liquids as part of a solvent extraction process or using electrotransport from an anode to a cathode. The pyroprocessing example studied in the AFCI program is based on using the differences in the free energy of formation of chloride compounds for the constituents of used fuel. WIth $\mathrm{LiCl} / \mathrm{KCl}$ salt, which operates at $500^{\circ} \mathrm{C}$ in a vessel as a molten salt pool with an inert cover gas, as the UNF is dissolved, the actinides and some fission product elements form compounds with the salt (although they remain dissociated) and the uranium is electrotransported. The other fission product elements remain undissolved along with the fuel pin cladding, while volatile elements are released to the inert cover gas. The electrotransported uranium is recovered in a metallic form and removed, while the transuranic elements accumulate in the salt. The salt is processed separately to recover a metallic product that contains both uranium and the transuranic elements, with the remaining salt processed into a waste form. Another waste form consists of the remaining undissolved materials from the initial dissolution step, which are consolidated into a metallic waste form after removal of any adhering salt. The process is intended to recover the actinides as a group, although it is also possible to use pyroprocessing for further separation of the TRU if desired. 
Gaseous (Dry chlorination, Fluoride volatility, etc.) - Various gaseous processes for the treatment of LWR UNF have been developed. Dry chlorination of UNF powder involves high temperature oxidation of uranium-oxide-based UNF (voloxidation), where uranium oxide remains unreacted while most of the fission product oxides are transformed into chlorides and oxychlorides that are readily soluble in water. Phase equilibria predict that $\mathrm{Pu}$ and $\mathrm{Np}$ will remain as oxides while $\mathrm{Cm}$, Am and the lanthanide fission products will transform into oxychlorides and possibly chlorides. This information suggests the possibility that dry chlorination and water washing might be able to remove $\mathrm{Cs}, \mathrm{Sr}, \mathrm{Am}, \mathrm{Cm}$ and the rare earths; while leaving the U, Pu and $\mathrm{Np}$ oxides unreacted. Such a process would only easily separate these elements in groups, without the capability of further separation using this process.

Fluoride volatility uses high temperature flame fluorination of the fine powder produced by voloxidation of uranium-oxide-based UNF, which removes the uranium as $\mathrm{UF}_{6}$, leaving a fluoride ash that contains the bulk of the fission products and TRU. Selective trapping and distillation purifies the $\mathrm{UF}_{6}$ for reenrichment and recycle as fuel. $\mathrm{Pu}$ and $\mathrm{Np}$ can be removed in a secondary fluorination and be trapped together by a uranium-based material. The ashes left after both fluorination steps consist mostly of lanthanide fission product fluorides, as well as $\mathrm{Zr}, \mathrm{Cs}, \mathrm{Sr}, \mathrm{Am}$, and $\mathrm{Cm}$ fluorides. Zirconium fluoride is volatile at temperatures above $650^{\circ} \mathrm{C}$ and it could be separated during the flame fluorination or afterward if so desired. The ashes can be treated electrochemically as a molten fluoride to recover the Am and $\mathrm{Cm}$. Alternatively, washing of the ashes removes $\mathrm{Cs}$ and $\mathrm{Sr}$ (a major heat source), and leaching with $\mathrm{HNO}_{3}$ dissolves Am and Cm, leaving mostly rare earths. Depending on the process steps, it is possible to either recover elements or groups of elements with this approach.

Supercritical Fluids ( $\mathbf{C O}_{2}$, etc.) - The use of supercritical $\mathrm{CO}_{2}$ as a solvent for metal complexation and separations is well established. The process operates at pressures of $2000-3000$ psi and about $70^{\circ} \mathrm{C}$. Under these conditions $\mathrm{CO}_{2}$ becomes a supercritical fluid, able to penetrate deeply into porous materials, yet maintaining good mass transfer characteristics. It is thus an ideal solvent for extracting metals from solid materials, such as oxide powders, soil, fly ash, etc. Its use for the separation of metals from aqueous solutions, such as nitric acid, has also been demonstrated. Current research is also underway investigating the use of $\mathrm{CO}_{2}$ to partition metals from ionic liquids. Actinides such as $\mathrm{U}$ and Pu have been separated directly from mixed actinide/lanthanide oxide powders by extraction with a TBP/ $/ \mathrm{HNO}_{3}$ complex dissolved in the $\mathrm{CO}_{2}$ fluid. Dissolution of the oxides is not necessary. Separation of actinides from lanthanides is achieved by varying the pressure and temperature of the extraction. The advantages of the process include the generation of extremely small waste volumes. The product is collected as the organic/metal complex when the $\mathrm{CO}_{2}$ diluent is allowed to expand back to the gas phase. Fissile materials may be recovered in concentrated form in a small volume, requiring criticality controls.

Plasma (Archimedes process, etc.) - The Archimedes technology is based on a physical separation process of lighter (predominately stable) elements and heavier (predominately radioactive) elements. For the treatment of UNF, the fuel material needs to be dissolved in nitric acid as in aqueous-based processing. Uranium ( $>95 \%$ of the UNF mass, excluding cladding materials) would be removed by solvent extraction. The remainder is mixed with molten sodium hydroxide and injected into the plasma with an inductively-coupled plasma torch at $5000^{\circ} \mathrm{C}$, which vaporizes and injects the mixture. RF power supplied by two sets of helicon antennas ionizes the vapor. The heavier elements immediately exit the plasma onto a collector and the light elements remain in the plasma until they deposit at the chamber ends. Electric and magnetic fields combine to rotate the plasma. When the plasma rotates at high speeds, the magnetic and electric fields can be adjusted to create a "mass cutoff" that keeps lighter ions confined to the plasma while the heavy ions rotate instantly to the side wall collector. From published literature, the light/heavy phase cutoff appears to be adjustable, but $99.9 \%$ of the radionuclides report to the heavy fraction. The primary decay heat sources in UNF that may limit the amount of UNF or HLW that can be placed in a repository are plutonium and americium (long term) as well as cesium and strontium (short term). If all of the radionuclides are in the same fraction, as well as the substantial amount of lanthanides, 
then no effective separation has been achieved. This would not allow for effective recycle of transuranium elements into thermal or fast spectrum reactors without additional processing. It is theoretically possible to adjust the plasma filter to make the cutoff between fission products (including lanthanides) and actinide elements which would be useful in a recycle strategy.

Laser (AVLIS, MLIS, ...) - Atomic Vapor Laser Isotope Separation (AVLIS) process includes separators, lasers, and optical systems designed for uranium enrichment. The separations process uses finely tuned, high-power lasers to tag the fissile isotope of uranium by removing one of its electrons. The product stream is formed by collecting ${ }^{235} \mathrm{U}$ ions, as well as a portion of the ${ }^{238} \mathrm{U}$ material on charged plates. This process takes place in a vacuum chamber where the uranium is vaporized and exposed to the lasers. The product is removed as small nuggets of solid enriched uranium metal. The AVLIS process provides high energy efficiency comparable with gas centrifuges, high separation factor, and low volume of radioactive waste. Molecular Laser Isotope Separation (MLIS) separates molecules rather than atoms. In principle this technology could be applied to separation of UNF, and would be capable of separating by element or possibly by isotope.

Thermomechanical Processing - Dry processing of UNF by oxidation methods has been developed in several different variations. Process varieties are identified by the differences in the volatile fissions products removed or by the disposition of the fuel-bearing product. These processes are not for separation and recovery of elements or groups of elements, but are used more for reconstitution of UNF or for conditioning the UNF prior to processing. The primary process variations have been named. Voloxidation is a process where the uranium-oxide-based UNF is oxidized at moderate temperatures $\left(450-600^{\circ} \mathrm{C}\right)$ to convert it to $\mathrm{U}_{3} \mathrm{O}_{8}$ powder and release the tritium into the gaseous phase as tritiated water for recovery. Small, but radiologically significant, fractions of other volatile fission products are also released (e.g., iodine, carbon, krypton, and xenon). The process does not provide further separations of actinide elements, and would not result in a product that could be easily used in a recycle strategy without further processing. It is typically proposed as an initial step in processing UNF.

AIROX (AIR Oxidation) is similar to voloxidation, but with higher temperature oxidation of uraniumoxide-based UNF using air. Processing temperatures up to $1000^{\circ} \mathrm{C}$ are used to drive-off the volatile fission products (tritium, iodine, carbon dioxide, krypton, xenon) and some of the semi-volatile fission products (fractions of the cesium, technetium, and others) while most of the strontium, the rare earths, and transition metals remain with the actinides. The product powder can be blended with fresh mediumenriched uranium powder, and refabricated into fuel elements in a recycle strategy. Primary limitations of the process are that it requires significant amounts of uranium enriched to about $20 \%$ U-235 for blending to obtain sufficient fuel quality due to the presence of fission products and higher actinides in the recycled fuel. Fuel fabrication is a totally remote operation because the fuel remains highly radioactive. As with Voloxidation, the process does not provide separations of actinide elements, and could also be used as an initial processing step.

DUPIC (Direct Use of PWR UNF in CANDU reactors) is a process is similar to AIROX with the primary differences being that still higher processing temperatures are used to remove more of the volatile/semivolatile fission products and no enriched uranium is added to the fuel since the remaining materials are used in a heavy-water reactor for one additional irradiation, so DUPIC can only be considered for a limited recycle strategy. Processing temperatures up to $1200^{\circ} \mathrm{C}$ in the presence of air and/or oxygen are used to completely remove ${ }^{3} \mathrm{H}, \mathrm{I}, \mathrm{C}, \mathrm{Kr}, \mathrm{Xe}, \mathrm{Tc}$ and $\mathrm{Cs}$ (this is also sometimes called enhanced voloxidation). Operation of the process under reduced pressure improves the removal of cesium. Fuel fabrication is a totally remote operation because the fuel remains highly radioactive.

OREOX (Oxidation-Reduction-Oxidation) is a variation of DUPIC where the fuel is oxidized at about $500^{\circ} \mathrm{C}$ in air or oxygen to produce a powder and release some of the volatile fission products. The powder is then subjected to two or three cycles of reduction in low concentration hydrogen at $\sim 700^{\circ} \mathrm{C}$ 
followed by re-oxidation at $\sim 500^{\circ} \mathrm{C}$. Each cycle reduces the mean particle size and releases more of the volatile fission products. All the tritium is released, and $80-90 \%$ of the ${ }^{14} \mathrm{C}$ and ${ }^{85} \mathrm{Kr}$ are typically released. The process is complicated by the need for processing in multiple vessels or by the need to repeatedly exchange the processing atmosphere in one vessel. Other limitations are similar to those of DUPIC and this process would only be usable in a limited recycle strategy.

In summary, many processing options are available, aqueous and non-aqueous, capable of providing the desired separations. The choice of any option would be based on separations capabilities and waste production, while it appears that all separations processes have essentially the same proliferation risk. Some processes are more complex, or use more challenging environments, possibly increasing costs.

\subsection{Disposal Options for UNF and Radioactive Wastes}

In general, one or more disposal environments will always be needed for UNF, HLW, and LLW to provide the required disposal of hazardous radioactive materials regardless of the fuel cycle strategy. A wide variety of options have been suggested, and some have been extensively investigated, both in the U.S. and internationally.[31-33, 40] It is important to note that since interim storage basically performs a transmutation function to reduce radiation, radiotoxicity and decay heat, and does not perform a waste disposal function, it is not discussed in this section. However, interim storage may be used in combination with a waste disposal option to improve overall waste management performance.

\section{Disposal of UNF and HLW}

The disposal of UNF and HLW requires isolation for an extended time period (hundreds of thousands of years or more) which has prompted numerous proposals, almost all based on using 'deep geologic disposal' to provide nearly complete separation from the inhabited environment.

Mined Geologic Repositories - Repositories built using standard mining technology and designed for human access to facilitate placement and retrievability. The depth of such a repository is typically hundreds of meters below the surface, and long-term performance is based mainly on the stability of the environment and the behavior of water in the immediate vicinity of the repository. Isolation of the used fuel and waste can be supplemented by engineered isolation barriers if that is judged to be beneficial.

- Saturated environment

- Hard rock (granite, basalt, ...)

- Soft rock (sedimentary rocks, shale, ...)

- Clay layer

- Unsaturated environment (but not dry)

- Rock (volcanic tuff, alluvium, ...) - the proposed Yucca Mountain repository is volcanic tuff

- Dry environment

- Salt

- Island Disposal - a mined geologic repository in the freshwater 'lens' on an ocean island

Non-Retrievable Disposal- Disposal facilities built at depths not designed for human access or to allow retrievability, typically several kilometers below the surface and constructed with drilling technologies rather than mining technologies. Long-term performance is based on the greater level of isolation provided by greater depth as well as the stability of the environment. Isolation of the used fuel and waste can also be supplemented by engineered isolation barriers, although not necessarily to the same extent as in mined geologic repositories. 
- Deep Boreholes - extreme depth (thousands of meters) constructed using deep well drilling technology

- Seabed / Sub-seabed - placement in the sea floor

- Subduction Zone - placement at the junction of tectonic plates where one plate is moving under the adjacent plate; essentially deep boreholes placed in the subducting tectonic plate

- Rock-melt - similar to deep boreholes, but decay heat is required to melt the surrounding rock and the waste moves down into the earth

- Ocean Dilution - dilute wastes in the ocean to result in negligible dose rate

- Ice Sheet - place packaged waste on an ice sheet where decay heat melts waste to the bottom of ice sheet.

Extremely Remote Disposal - Disposal of used fuel and wastes that is so remote from the inhabited environment that there is no possibility of it ever posing an exposure hazard

- Space - launch packaged waste into space, put in long heliocentric orbit or into the sun.

\section{Disposal of LLW}

Given the low level of the hazard, the isolation requirements are much less stringent than for used fuel and HLW, resulting in less costly disposal approaches.

Near-surface disposal - typically placement in trenches, pits, or other shallow depressions, and then buried to prevent direct access, as is done today. Volume of LLW waste that might arise from nuclear power expansion and/or deployment of advanced fuel cycle technologies may require expanded capacity or new approaches to LLW disposal.

HLW disposal pathway - use of the same disposal pathway as for used fuel and HLW, although the large volumes for LLW typically preclude these pathways due to expense. This pathway may be more attractive when used in combination with approaches for LLW volume reduction such as incineration, dissolution / recovery, compaction, etc.

Development of Intermediate Isolation pathways - just as current LLW disposal capabilities have developed in response to past waste streams, advanced fuel cycle technologies may result in volumes of waste with activities that promote development of an intermediate isolation disposal capability, especially for the disposal of GTCC LLW. Examples include "Intermediate Level Waste" (ILW) categories used in some other countries, or a "Greater Confinement Disposal" pathway that has been suggested for certain legacy materials.

\section{Performance and Capabilities of Disposal Options}

The performance of the disposal options has been studied internationally for several decades as countries address the issues of UNF and nuclear wastes. Several countries, including the United States, have selected preferred disposal options and proposed a site for the disposal of UNF and HLW, although none have yet been licensed for construction and operation. The following discussions briefly review the current state of knowledge about the disposal options, including performance characteristics that are relevant for the AFCI Options Study. [31-33]

\section{Mined Geologic Repositories}

When considering performance of disposal options, most concern is generally directed towards UNF and HLW. While the quantities of low-level and transuranic waste may be larger than UNF and HLW, the 
long-term hazard is dominated by UNF and HLW as discussed in Section 2.2. Any comprehensive performance analysis of disposal options is beyond the scope of this document. However, representative technical issues (both advantages and disadvantages) of several commonly proposed disposal environments are discussed in this section. The representative geologic repository environments are unsaturated tuff, salt, clay, and granite. Some summary observations are excerpted from an OECD-NEA study on "Advanced Nuclear Fuel Cycles and Waste Management" (ISBN 92-64-02485-9), 2006.[33]

Unsaturated Tuff Repository - A typical unsaturated rock repository design proposal is mined emplacement galleries in unsaturated tuff. Corrosion resistant waste packages are placed in the openings. Water flow in the host rock may be either through fractures or connected porosity, but rock porosity tends to keep water from flowing freely into openings. Degradation of the waste package and waste form is limited by the amount of water contact. Eventual release of radionuclides is controlled by transport through the unsaturated host rock and down to the saturated zone. The proposed repository at Yucca Mountain is an example of this type of repository, where the repository is located about 300 meters below the surface, as shown in Figure 6.

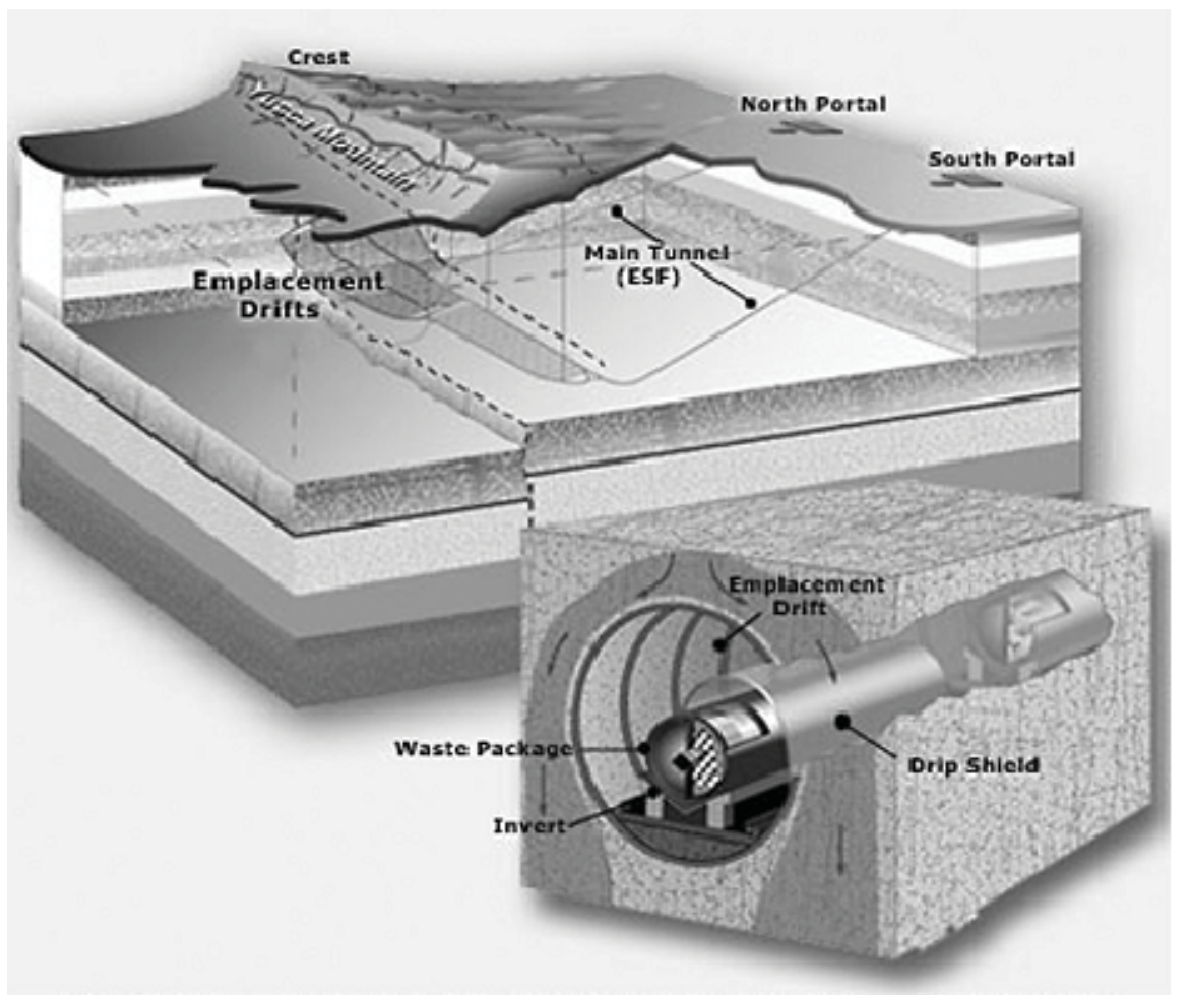

Figure 6. Cross section of a repository in unsaturated volcanic tuff.

Typical characteristics of this type of repository are that water flow in the volcanic tuff may be dominated by flow in fractures and be intermittent, with possible periods of relatively high flow depending on conditions at the surface. However, porosity also tends to keep water inside the rock, thus diverting flow around openings in the rock (drifts) such as would be made in constructing the repository. Natural and man-made examples exist for long-term preservation in unsaturated caves and mines with this geology. In the presence of water, the oxidizing chemical environment enables steel corrosion, requiring use of a corrosion resistant waste package. Some radionuclides have reduced solubility (Se), while others have increased solubility and mobility (Tc, Np) due to the chemistry of the ground water, as listed in Table 3 for normal (undisturbed) conditions. To ensure reliability of predictions of long-term performance, thermal limits are imposed to keep the host rock from altering. Limits could intentionally be imposed to 
force drying of local rock if desired, but such an effect is not sustainable as decay heat decreases with time. Upper temperature limits may also be imposed to permit free drainage around and away from the drifts. Analyses for the proposed repository at Yucca Mountain indicate that sufficient isolation for at least a million years may be possible, with estimated peak dose rates remaining well below regulatory limits.

Salt Repository - A typical salt repository design proposal is mined emplacement galleries in either thick bedded or dome salt, with steel waste packages placed in openings sized for thermal management as shown in Figure 7. Following emplacement the salt heats and slowly creeps thus sealing the emplacement opening. Degradation of the waste package and waste form is limited by water migration through the salt. Eventual release of radionuclides is limited by lack of transport pathways through the salt, with the dominant radionuclides listed in Table 3 for normal (undisturbed) conditions. A salt repository is being studied in Germany, where the proposed repository would be located almost 900 meters below the surface.

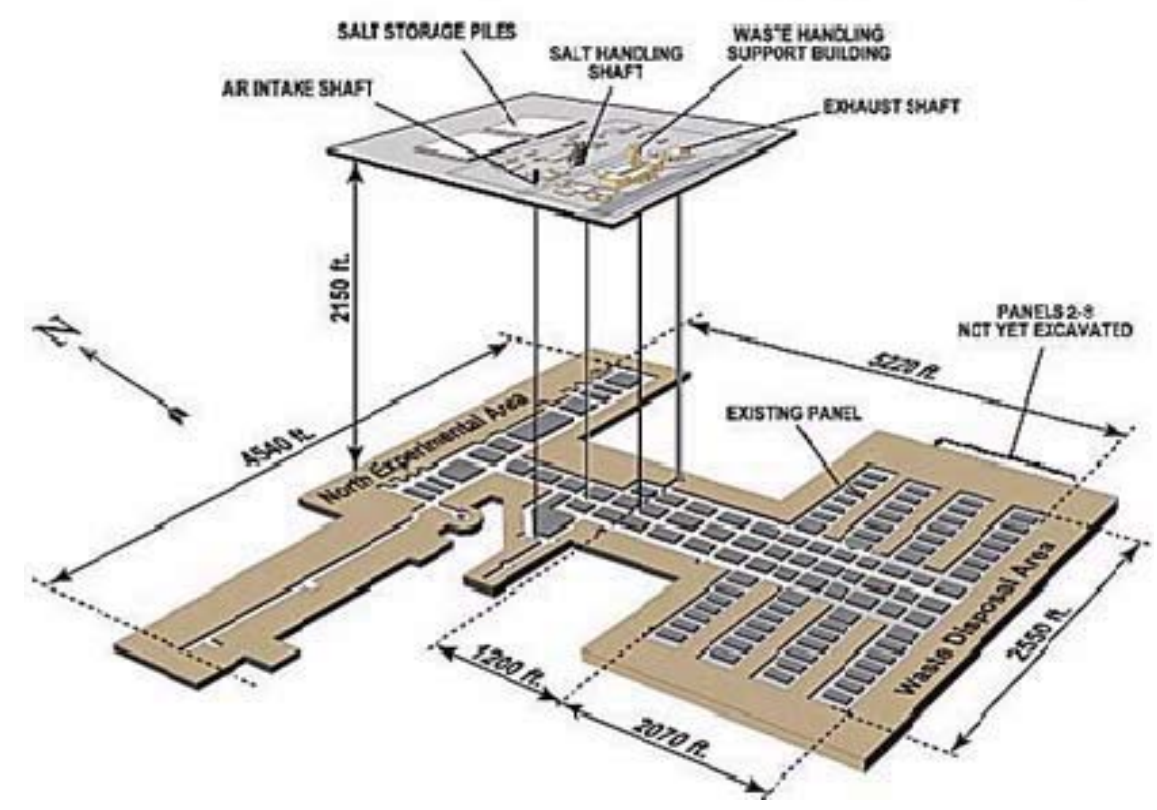

Figure 7. Diagram of a repository in a salt layer.

The long-term stability of ancient salt deposits is clear evidence of the lack of water migration pathways. However, there may be water containing voids or inclusions in the salt that may be an issue that affects long-term performance. The reducing chemical environment from the salt and dessicated conditions inhibits steel corrosion. Temperature limits may be applied to the repository, including minimum temperatures that need to be achieved to ensure salt creep and closure of all open spaces in the repository, and maximum temperatures that would be allowed to prevent uplift and rupture of the salt deposit. One issue for salt repositories is that any penetrations, either man-made or natural, that permits water infiltration will compromise the isolation integrity. The lack of free water is critical to long-term performance, since the introduction of water would result in aggressive corrosive conditions, rapid failure of the waste packages, and transport of radionuclides. Many thick salt formations are associated with potential natural resources trapped beneath them that may attract future drilling, potentially increasing the likelihood of human intrusion as compared to other repository concepts. 
Clay Repository - A typical clay repository design proposal has steel waste packages emplaced in galleries mined in a thick bed of saturated clay located several hundred meters below the surface, shown schematically in Figure 8. Following emplacement the clay creeps to seal the emplacement opening and any water flow pathways. Degradation of the waste package and waste form is limited by water and oxygen diffusion through the clay. Eventual release of radionuclides is limited by diffusive transport through the clay, with the dominant radionuclides listed in Table 3 for normal (undisturbed) conditions. The clay serves as both host and engineered isolation system.

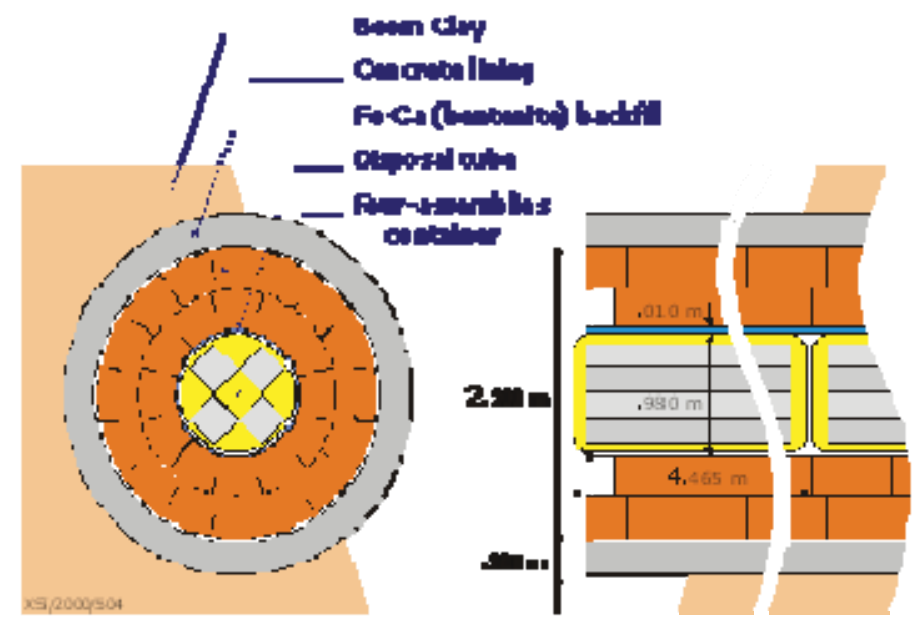

Figure 8. Cross-section detail of used fuel disposal in clay.

A typical characteristic for a repository in saturated clay is that there is typically little or no water flow through the clay. The reducing chemical environment from the clay inhibits steel corrosion, waste form dissolution and the solubility of many radionuclides, although some radionuclides may compromise clay integrity, either chemically or radio-chemically. The clay must be plastic enough to flow and seal fractures, but rigid enough to avoid excessive creep that could allow the waste package to sink through it. For this reason, thermal limits are imposed to keep the clay from locally drying out and cracking, a process that could result in rapid migration pathways. Analyses for a proposed repository in Belgium using this method indicate that releases from such a repository would be extremely slow under normal conditions and that dose would be dominated by fission products such as iodine-129. However, the risk may be dominated by off-normal events such as human intrusion, where the actinide elements can dominate the potential dose.

Granite Repository - A typical hard rock repository design proposal is mined emplacement galleries in saturated granite, typically located several hundred meters below the surface, with steel waste packages surrounded by compacted bentonite clay packing material, as shown in Figure 9. Following emplacement the clay absorbs groundwater and swells - thus sealing the emplacement opening and any flow pathways for water. In this sense, the isolation provided with the combined granite and clay approach is based on the same principles as for disposal in saturated clay alone. Degradation of the waste package and waste form is limited by water and oxygen diffusion through the clay. Eventual release of radionuclides is limited by diffusive transport through the clay. The granite serves as a mechanically and chemically stable host for this engineered isolation system.

Typical issues for a granite repository include the water flow in the host rock, which is dominated by flow in fractures. Water infiltration to the waste package is controlled by diffusion in the packing clay surrounding the waste packages. The reducing chemical environment from the granite and clay inhibits steel corrosion, waste form dissolution and the solubility of many radionuclides, as listed in Table 3 . The integrity of the bentonite clay is essential to long-term performance as it is for a saturated clay repository. 
If it fails, then radionuclide release and transport could be rapid. Therefore, it is likely that thermal limits would be imposed to keep the packing clay from drying out and cracking since that could result in more rapid migration pathways, both for the water reaching the waste packages and for any radionuclides that are released from the waste packages. Challenges for this approach are that some radionuclides may compromise clay integrity (chemically or radio-chemically), and the clay must be plastic enough to flow and seal fractures, but rigid enough to avoid creep that could allow the waste package to sink through it and contact the host granite.

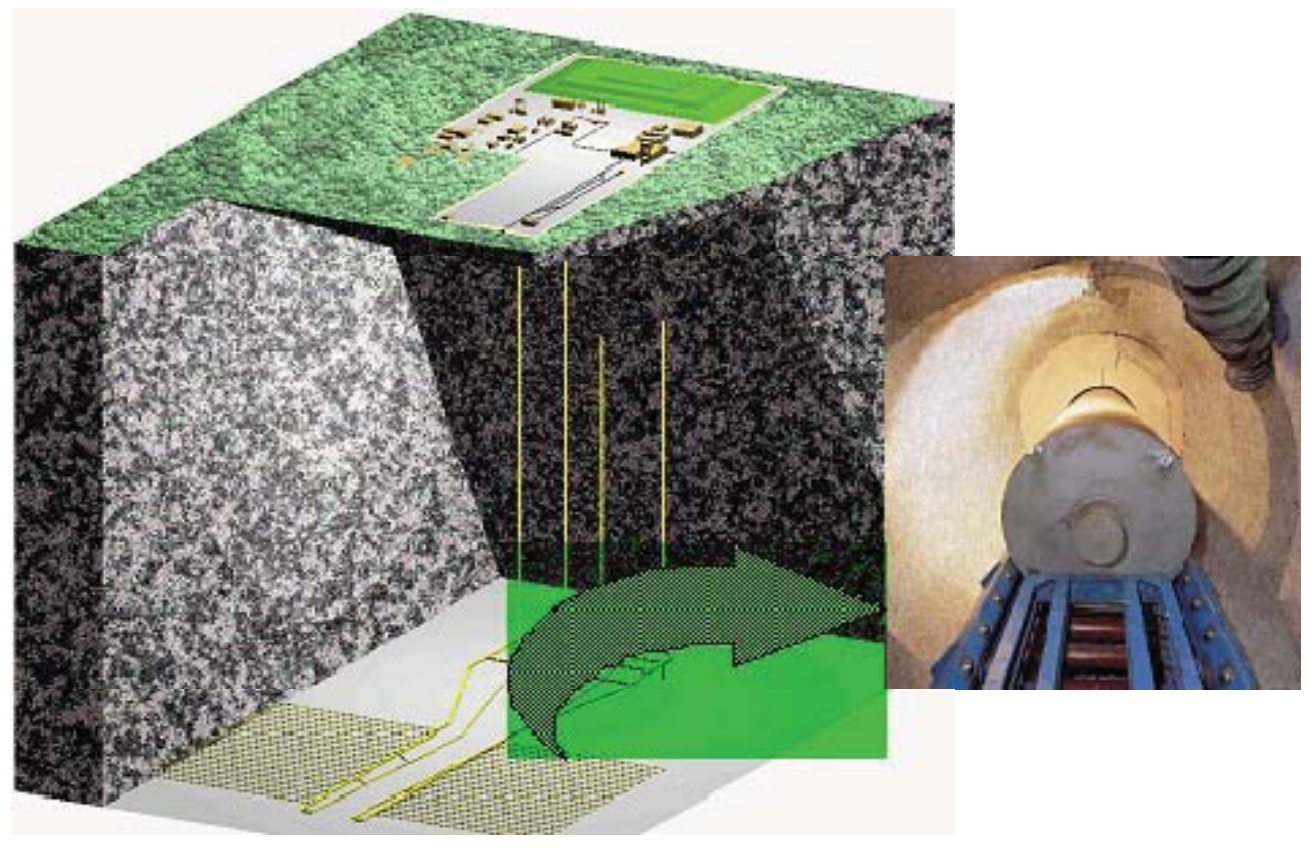

Figure 9. Cut-away view of a mined geologic repository in granite.

An example of a granite repository is the recently-announced repository at Forsmark in Sweden. The repository is located about 500 meters below the surface, in granite that has few fractures, high quartz content and high thermal conductivity, and with very little water content. Chemical analyses of the water indicate that the water has been isolated from the surface for at least 1.5 million years, indicating that there is little or no water flow through this region. The UNF is placed inside thick copper canisters with cast iron inserts. The waste packages are surrounded with clay after placement to inhibit contact with water, as in a clay repository, and one could consider this disposal approach to be essentially the same as disposal in clay. The repository is designed to isolate wastes for 100,000 years.

Island Disposal - Island disposal is a mined geologic repository located on a ocean island, typically in the freshwater lens of the island. The geology is likely to be similar to volcanic tuff or other hard rock repositories. The performance of a geologic repository located on an ocean island would rely on ocean dilution in that the ocean is the ultimate "sink" for radionuclides. Similarly, it might work technically, but declared unacceptable, or only applicable in limited locations, and would require changes in international law to be allowed. If ocean dilution were permitted, then it is likely that no radionuclide would be relevant to the estimated peak dose rate since the dilution is so extreme.

\section{Mined Repository Performance}

As an example of the issues discussed above, the dominant radionuclides contributing to potential human dose for several mined geologic repository environments are summarized from representative long-term 
isolation performance analyses for disposal of intact LWR fuel under normal, undisturbed conditions in the repository, listed in Table 3. It is important to recognize that the listed radionuclides are dominant only for normal conditions in the repository where the repository environment has not been disturbed by human or naturally-occurring events. When the repository is disturbed, the risk is determined by the radiotoxicity of the UNF and HLW, which in turn is dominated by long-lived isotopes of actinide elements, although some fission product isotopes still important.

Table 3: Important Radionuclides for Long-term Isolation Performance in Representative Disposal Environments for Normal (Undisturbed) Conditions

\begin{tabular}{|l|l|l|l|}
\hline Repository Option & 10,000 years & 100,000 years & $1,000,000$ years \\
\hline $\begin{array}{l}\text { Tuff repository, unsaturated, } \\
\text { oxidizing, steel packages }\end{array}$ & Tc-99, I-129 & Tc-99, I-129 & Tc-99, Th-229 \\
\hline $\begin{array}{l}\text { Salt repository, dome salt, reducing, } \\
\text { steel packages }\end{array}$ & I-129, Se-79 & $\begin{array}{l}\text { U/Ra + daughters. } \\
\text { Cs-135, }\end{array}$ & $\begin{array}{l}\text { Np + daughters, } \\
\text { U/Ra + daughters }\end{array}$ \\
\hline $\begin{array}{l}\text { Clay repository, saturated, reducing } \\
\text { conditions, steel waste packages, } \\
\text { clay packing }\end{array}$ & Se-79, I-129 & $\begin{array}{l}\text { Se-79, I-129, Tc-99, } \\
\text { Sn-126 }\end{array}$ & $\begin{array}{l}\text { Th-229, Sn-126, Se- } \\
79, \text { Tc-99 }\end{array}$ \\
\hline $\begin{array}{l}\text { Granite repository, saturated, } \\
\text { reducing conditions, steel waste } \\
\text { packages, bentonite clay packing }\end{array}$ & Se-79 & Se-79, Cs-135 & $\begin{array}{l}\text { Cs-135, Zr-93, Nb- } \\
\text { 93m, Th-229 }\end{array}$ \\
\hline
\end{tabular}

\section{Disposal Options other than Mined Geologic Repositories}

While mined geologic repositories are the most commonly proposed disposal pathways for HLW and UNF, other options have been considered in the past and are periodically re-considered. Some may have potential use for a wide range of wastes, and some may be better suited to high isolation disposal of specific problematic wastes. A wide range of disposal pathways have been evaluated by high level advisory panels [41,42] government programs and by international organizations [43], with the common result that a mined geologic repository represents the most practical approach. A brief survey of issues is provided here.

\section{Non-Retrievable Disposal}

Deep Borehole Disposal - The most practical approach in this category is the use of deep boreholes for high-isolation-value wastes. Deep borehole disposal was more recently considered for disposition of excess weapons $\mathrm{Pu}$ [44] and was found to be technically viable. The low heat generation and limited quantity of material contributed to this favorable result. This alternative was not pursued in the weapons $\mathrm{Pu}$ disposition study due to lack of process and interest in siting such a facility given preferences by Russia, the project partner. Recent studies continue to explore the extent to which deep boreholes can be used for the direct disposal of UNF. [46] Disposal in a subduction zone is essentially a deep borehole in the subducting tectonic plate, or is similar to subseabed disposal when the subducting plate is at the ocean floor.

Several of the other options have significant technical uncertainties or would require changes in international law and/or treaties.

Subseabed disposal - Previous project in the U.S. abandoned in 1996; more research required according to a 1998 NEA study. Approach is currently prohibited under the 1996 Protocol to the 1972 London Dumping Convention, which was signed by the United States on March 31, 1998, and entered into force March 24, 2006, but has not been ratified by the Senate. 
Rock-melt option - Uncertainties in process control, gaseous releases and geologic stability have been raised. Because it uses decay heat to facilitate deep burial, increased performance confidence is coupled with increased risk from higher waste concentrations and increased high-temperature process rates. Uncertainties about both operational safety and long-term isolation capability raise doubt about the acceptability of the approach. As this system has not been extensively studied, further R\&D would be required to verify the behavior of such a system to determine if these uncertainties can be resolved and to what extent unsolved technical details exist.

Ocean dilution - While dilution of waste into the world's oceans would probably be effective, it is prohibited by the London Convention, other international agreements, US policy, and brings serious public acceptance concerns.

Other disposal concepts studied by DOE and its predecessors include waste emplacement in polar ice sheets, subduction zones, and deep well injection of liquid waste. AEC's draft final environmental statement dismissed those alternatives as not viable, and they have since received relatively little attention.[45] Many of these approaches bring concerns of loss of control over uncertain process (ice melt, injection) or simply are too slow to be practicable (subduction).

\section{Extremely Remote Disposal}

The primary option here is launching materials into space. This option was extensively studied in the United States and was judged to be too risky and costly given the hazards and volumes of materials involved.[45] Energy requirements to actually send material into the sun are extremely high, and alternatives leave material circulating in the solar system in perpetuity.

\section{Disposal Options Summary}

Even though the future of the proposed Yucca Mountain is highly uncertain, it represents a suitable reference for evaluation of the change offered by other geologic disposal options or disposal approaches that may not utilize direct disposal of UNF.

UNF and HLW disposal must provide isolation for hundreds of thousands of years or more. Potential disposal options are usually deep underground, typically either in mined geologic repositories at depths up to about $1 \mathrm{~km}$ or in more remote, non-retrievable conditions with depths up to $4-5 \mathrm{~km}$ or greater. The risk from disposal of UNF and HLW in mined geologic repositories can be considered in two parts, one for the undisturbed, or normal evolution of the conditions in the repository and the other for situations where the repository environment is disturbed by either natural or man-made causes. For disposal environments studied to date, fission products are generally the major contributor to the risk for mined geologic repositories for normal evolution, while the actinide elements and a few of the fission products dominate the risk for disturbed conditions.

The relative importance of the actinide elements and the fission products is strongly affected by the probability of occurrence for disturbances as compared to normal evolution, probabilities that are highly uncertain since there are no fundamental scientific principles that can be applied. Similarly, estimation of the risk for normal evolution is strongly affected by details of the repository environment that are also not well known and can be highly variable within and near the repository, contributing to a high level of uncertainty. Experience has demonstrated that it may be possible to show that a repository will be able to provide sufficient isolation of the radioactive materials with a high degree of probability under normal circumstances, while for disturbed conditions such isolation may be difficult to show convincingly unless the repository contents are relatively low.

More remote disposal such as placement 4-5 km down in deep boreholes lessens the likelihood that any of the disposed materials will be released to the inhabited environment due to the extreme depths of waste 
placement. Such approaches reduce the importance of uncertainties about details of the disposal environment and greatly reduce the probability of human intrusion events. However, the constraints on loading of disposal sites such as deep boreholes may be more severe due to anticipated system temperatures, as well as higher risks from the placement operations, as is discussed above.

Table 4. Dominant Risk and Performance Contributors for UNF / HLW Disposal

\begin{tabular}{|c|c|c|c|c|c|}
\hline & \multicolumn{2}{|c|}{ Performance / Risks } & \multicolumn{2}{|l|}{ Capacity Issues } & \multirow{2}{*}{$\begin{array}{l}\text { Economic } \\
\text { Impact } \\
\text { Costs }\end{array}$} \\
\hline & $\begin{array}{l}\text { Normal } \\
\text { evolution }\end{array}$ & $\begin{array}{l}\text { Disturbed } \\
\text { conditions }\end{array}$ & $\begin{array}{l}\text { Importance of decay } \\
\text { heat }\end{array}$ & $\begin{array}{l}\text { Importance } \\
\text { of Volume }\end{array}$ & \\
\hline \multicolumn{6}{|c|}{ Mined geologic disposal } \\
\hline Volcanic tuff & $\begin{array}{l}\text { Fission } \\
\text { products and } \\
\text { actinides }\end{array}$ & Actinides & $\begin{array}{l}\text { Actinide decay heat } \\
\text { limits loading }\end{array}$ & Low & Reference \\
\hline Salt & None & $\begin{array}{l}\text { Actinides and } \\
\text { fission products }\end{array}$ & $\begin{array}{l}\text { Beneficial in sealing } \\
\text { the repository }\end{array}$ & Low & $\begin{array}{l}\text { Same as } \\
\text { reference }\end{array}$ \\
\hline Saturated clay & $\begin{array}{l}\text { Fission } \\
\text { products }\end{array}$ & $\begin{array}{l}\text { Actinides and some } \\
\text { fission products }\end{array}$ & $\begin{array}{l}\text { Fission product } \\
\text { decay heat limits } \\
\text { loading }\end{array}$ & Low & $\begin{array}{l}\text { Same as } \\
\text { reference }\end{array}$ \\
\hline $\begin{array}{r}\text { Granite } \\
\text { (clay/granite) }\end{array}$ & $\begin{array}{l}\text { Fission } \\
\text { products }\end{array}$ & $\begin{array}{l}\text { Actinides and some } \\
\text { fission products }\end{array}$ & $\begin{array}{l}\text { Fission product } \\
\text { decay heat limits } \\
\text { loading }\end{array}$ & Low & $\begin{array}{l}\text { Same as } \\
\text { reference }\end{array}$ \\
\hline $\begin{array}{r}\text { Island Disposal } \\
\text { (illegal) }\end{array}$ & $\begin{array}{l}\text { Fission } \\
\text { products and } \\
\text { actinides }\end{array}$ & $\begin{array}{l}\text { Actinides and } \\
\text { fission products }\end{array}$ & $\begin{array}{l}\text { Actinide and/or } \\
\text { fission product decay } \\
\text { heat limits loading }\end{array}$ & Low & Unknown \\
\hline \multicolumn{6}{|c|}{ Non-retrievable Disposal } \\
\hline $\begin{array}{l}\text { Deep Borehole } \\
\text { Disposal }\end{array}$ & None & $\begin{array}{l}\text { Disturbance not } \\
\text { likely }\end{array}$ & $\begin{array}{l}\text { Decay heat limits } \\
\text { loading }\end{array}$ & High & Unknown \\
\hline $\begin{array}{l}\text { Seabed / Sub- } \\
\text { seabed }\end{array}$ & None & $\begin{array}{l}\text { Disturbance not } \\
\text { likely }\end{array}$ & $\begin{array}{l}\text { Decay heat limits } \\
\text { loading }\end{array}$ & High & Unknown \\
\hline $\begin{array}{l}\text { Subduction } \\
\text { Zone }\end{array}$ & None & $\begin{array}{l}\text { Actinides and } \\
\text { fission products }\end{array}$ & $\begin{array}{l}\text { Decay heat limits } \\
\text { loading }\end{array}$ & High & Unknown \\
\hline Rock melt & None & $\begin{array}{l}\text { Disturbance not } \\
\text { likely }\end{array}$ & $\begin{array}{l}\text { Sufficient decay heat } \\
\text { required }\end{array}$ & High & Unknown \\
\hline $\begin{array}{l}\text { Ocean dilution } \\
\text { (illegal) }\end{array}$ & None & $\begin{array}{l}\text { Actinides and } \\
\text { fission products }\end{array}$ & None & None & Unknown \\
\hline \multicolumn{6}{|c|}{ Extremely Remote Disposal } \\
\hline Outer Space & None & $\begin{array}{l}\text { Actinides and } \\
\text { fission products } \\
\text { (launch accidents) }\end{array}$ & $\begin{array}{l}\text { Weight and decay } \\
\text { heat limits loading }\end{array}$ & High & Unknown \\
\hline
\end{tabular}

The disposal options are intended to address waste management issues sufficient to eliminate concern. Whether this succeeds in practice is the subject of continuing debate, with the proposed repository at Yucca Mountain having submitted a license application. NRC review will determine if this approach is ultimately judged to be technically acceptable.

The proliferation risk from mined geologic repositories is the future availability of SNM in UNF with little radiation protection, offering an attractive source of materials for nuclear weapon purposes. There is no distinction between the disposal options in their ability to address this concern, although for continuous recycle options, the HLW does not contain significant amounts of SNM, eliminating this concern. Similarly, non-retrievable disposal and extremely remote disposal essentially prevent access to the SNM materials, lowering the proliferation risk from disposal. There is insufficient SNM in LLW to pose any proliferation risk. 
Safety and security of the geologic disposal options will depend on the operations at the disposal sites and the long-term performance of the repository. Licensing review will address these concerns, although in principle all of the geologic disposal options can satisfy regulatory requirements and this is not a discriminator between options.

Sustainability in this case is simply a matter of having adequate disposal space for the UNF and HLW, something that becomes easier with lower UNF and HLW amounts. There is a significant, i.e., order of magnitude, change in this requirement only for continuous recycle options, or for nearly-complete consumption with a once-through strategy, and only for actinide content. Fission product content is unaffected, and if that is determining disposal space requirements, no alternative strategy or technology option can affect the required disposal space.

\section{LLW Disposal}

Low level radioactive waste (LLW) is a wide range of mildly contaminated or activated materials that represent modest hazard. They are categorized into classes A, B and C and GTCC wastes based on content, and are typically disposed of via shallow land burial. LLW disposal is a commercial process, and regulation is the responsibility of each state. Several LLW disposal sites exist, mostly operated by DOE for government use, and there is a process for "compacts" of states to develop new sites as needed. However, capacity at existing sites is limited, and no new facilities have been successfully developed by states or compacts.

Wastes that exceed the activity and/or activity lifetime limits for LLW, but do not meet the definition of HLW, fall into a category of 'greater than class C' (GTCC). There is currently no commercial disposal pathway for GTCC. In most countries with recycle fuel cycles, this type of higher activity waste is often referred to as 'intermediate level waste' (ILW). A recycle fuel cycle is likely to create sufficient GTCC or ILW to force the creation of a disposal pathway. Disposal options include: intermediate depth burial, co-disposal with HLW, and high-confinement engineered surface/near-surface storage.

The major issue for LLW disposal is the availability of suitable disposal sites and the LLW volume. It is expected that continued use of the once-through fuel cycle option will continue to create LLW at a rate similar to that occurring today, on an energy generated basis, unless there are significant developments in volume reduction technologies. Nuclear fuel cycles involving recycle will increase the amount of LLW, with the increase dependent on the technologies used, the amount of material recycled, and the ability to limit LLW generation in reprocessing facilities, fuel fabrication facilities, and the irradiation facilities. Estimates of the increased LLW indicate that the LLW from an advanced nuclear fuel cycle, even with recycle, may not necessarily be the major contributor to total LLW disposal when all other sources of LLW are considered, including medical and industrial uses. Experience has shown that the main issue for LLW disposal may be siting sufficient disposal capacity, given that such operations may face strong local opposition.

\section{Decision Framework}

In this study, the nuclear fuel cycle strategies and the component technology options have been considered with respect to the ability to address the root causes of the nuclear power issues identified in Section 2.1, potentially leading to resolution of the issues. The decision framework that identifies the decisions to be made is based on this same approach, where the impact of a decision on the issues is apparent. The clear connection between the decisions and the impacts should allow selection of the appropriate research and development directions based on the desired impact on, or resolution of, the issues. 


\subsection{Nuclear Fuel Cycle Strategies}

Based on consideration of the root causes of the nuclear power issues, a decision on the type of nuclear fuel strategy would appear to be the first logical step in the decision-making process, since the selection of a fuel cycle strategy has a profound effect on the ability of an advanced nuclear fuel cycle to successfully address the issues as discussed in Chapter 3 and will determine what technology options could be beneficial. As a result, the following observations can be made.

As summarized in Table 1, there appears to be little opportunity for alternative once-through fuel cycles to significantly change the fundamental characteristics of nuclear power systems as compared to the current implementation. Of course, incremental improvements can be achieved, and depending on the issue, it may be determined that such incremental changes are all that is required, or that implementation of a strategy with incremental improvements is a logical part of the process leading to one or more systems that provide the significant changes desired.. As discussed in Chapter 4, alternative once-through fuel cycles using advanced technologies would only offer the potential for significant change if one could achieve essentially complete burnup of the nuclear fuel without processing, or if one were able to locate and site geologic repositories with sufficient disposal space, performance characteristics and predictability that would result in the necessary scientific, public and political support, although direct disposal of UNF requires significant disposal capability. A decision to continue pursuit of a once-through fuel cycle strategy would necessarily focus efforts on these areas, although a review of the available technologies and the technical difficulties as discussed in Chapter 4 would not suggest that success is likely for achieving essentially complete burnup without processing. The issue of geologic disposal will need to be resolved regardless of the nuclear fuel cycle strategy.

Limited recycle uses UNF processing to allow recycle one or more times, but the number of recycles is limited, after which there is disposal of the remaining UNF. Due to the UNF disposal, it would appear to be difficult for limited recycle to significantly change the waste characteristics when both UNF and HLW are considered as summarized in Table 1. As with once-through, incremental improvements are certainly possible, since limited recycle can be used to reduce SNM inventory, to lower the radiotoxicity of the UNF and HLW, or to increase utilization of fuel resources. However, results from previous studies indicate that the potential gains are less than an order of magnitude difference, and in many cases can be substantially less. On the negative side, UNF processing has the potential to generate substantially more LLW, although this may be mitigated by the processing technology choice and details of the specific design and operational goals. UNF processing may also be viewed as a source of increased proliferation risk, although in practice, commercial UNF processing activities may have little effect on proliferation risk, depending on the processing technologies being used, the availability of uranium enrichment, and other activities such as UNF diversion and clandestine processing can be employed. In light of these observations, it may not be reasonable to expect a limited recycle nuclear fuel cycle strategy to offer much improvement overall in terms of being able to address the root causes of the nuclear power issues, regardless of the advanced technologies being used.

Of the three general categories of nuclear fuel cycle strategies, a continuous recycle strategy appears to offer the greatest opportunity for advanced technologies to make a significant impact on nuclear power issues. However, realizing significant gains will strongly depend on what is being recycled and the technologies used to support continuous recycle. For waste management, continuous TRU recycle, including plutonium, neptunium, americium, and curium, appears to be necessary to reduce radiotoxicity and the long-term hazards from HLW disposal. However, as with limited recycle, UNF processing has the potential to significantly increase LLW amounts. UNF processing may also be viewed as representing an increased proliferation risk, although as discussed in the previous paragraph, this may only be a perception. It should be emphasized that not all continuous recycle strategies will result in significant improvements. If a significant favorable impact on the nuclear power issues is desired, a decision to pursue continuous recycle fuel cycle strategies should be limited to those specific strategy options, i.e., 
TRU recycle, processing and fuel fabrication technologies that meet the goals for TRU losses, etc., that can provide these results.

\subsection{Technology Options}

Any decision on technology options should be made following a decision on which nuclear fuel cycle strategies to utilize, since the choice will determine which advanced technologies could be used and which technologies may be available since not all technologies are equally applicable to all fuel cycle strategies. For these reasons, in the following the technology decisions are provided for each of the fuel cycle strategies. Technology choices can be made from the options described in Chapter 4, recognizing the advantages and limitation for each of the options as discussed there.

\section{Once-Through Nuclear Fuel Cycle Strategy}

If the once-through fuel cycle strategy is selected, there are a limited number of choices that can be made regarding advanced nuclear technologies given the simplicity of the system shown schematically in Figure 1. The corresponding decision framework is shown in Figure 10, where it must be stressed that the order in which decisions are made is not unique, as indicated by the bi-directional arrows, and is only intended to provide an example of a usable framework. In reality, the decision process would be integrated over all parts of the fuel cycle for optimum fuel cycle performance.

For the type of nuclear fuel, either uranium-based or thorium-based fuel can be chosen, although one could propose to use both, recognizing the increased infrastructure that would be required. However, the discussion in Chapter 4 summarizing the performance characteristics showed that there was no difference in natural uranium requirement with the use of thorium-based fuel due to the need to supply substantial enriched uranium to support the once-through use of thorium. This in turn results in UNF that has radiotoxicity and decay heat characteristics very similar to that for uranium-based fuel due to the presence of the uranium in the fuel, so that the waste management issues are unaffected by the choice of fuel type. The need for enriched uranium means that there is no significant change in proliferation risk, although plutonium production is lower by about a factor of two to three compared to the use of uranium-based fuel. The use of fuel designs other than solid fuel clad with metal or ceramic offer no advantages in the once-through cycle.

The next choice concerns the selection of the desired reactor or irradiation environment. Both thermal and fast reactors can be used in the once-through approach. Externally-driven sub-critical systems are likely to be uncompetitive economically due to the additional size and complexity required. More than one reactor or irradiation system type can be used, but the benefit of doing so would have to be balanced against any resulting increased costs from the larger infrastructure needed to support each system. All systems would produce fission products in proportion to the power produced, although TRU production decreases with increasing burnup on a per unit energy generated basis. As a result, higher burnup fuel would have UNF with the same fission product content and lower TRU content per unit of energy generated, although not significantly lower until one approaches the extreme case of nearly complete burnup where the UNF is almost entirely fission products with the very small remainder being mostly TRU.

The use of interim storage can have a beneficial impact by lowering the radiation and decay heat of the UNF, although this may increase proliferation risk by raising the material attractiveness of the SNM. Lower decay heat will allow better utilization of geologic disposal space and may improve the relative potential of options such as deep borehole disposal where decay heat can be a significant limiting factor.

Geologic disposal performance is dependent on both fission product and actinide content in the UNF, so the emphasis would be on selecting one or more disposal options that provide isolation for both fission 
products and TRU, as is the case with LWR UNF today. If nearly complete burnup can be achieved, the fission products still require long-term isolation, but the residual TRU may represent only a minor part of the overall risk. As a consequence, the decision on disposal options is essentially unaffected by the choice of fuel type or burnup and can be made independently of the fuel choice.

The decision choices and the implications are shown in Figure 10. It must be emphasized that the purpose of the figure is only to identify those technology choices that make a significant difference in addressing the issues, and that choices do not necessarily have to be made on that basis. In that case, one should expect conditions that are similar to the reference fuel cycle representing today's implementation of nuclear power.

\section{DECISION FRAMEWORK FOR ONCE-THROUGH NUCLEAR FUEL CYCLE STRATEGIES}

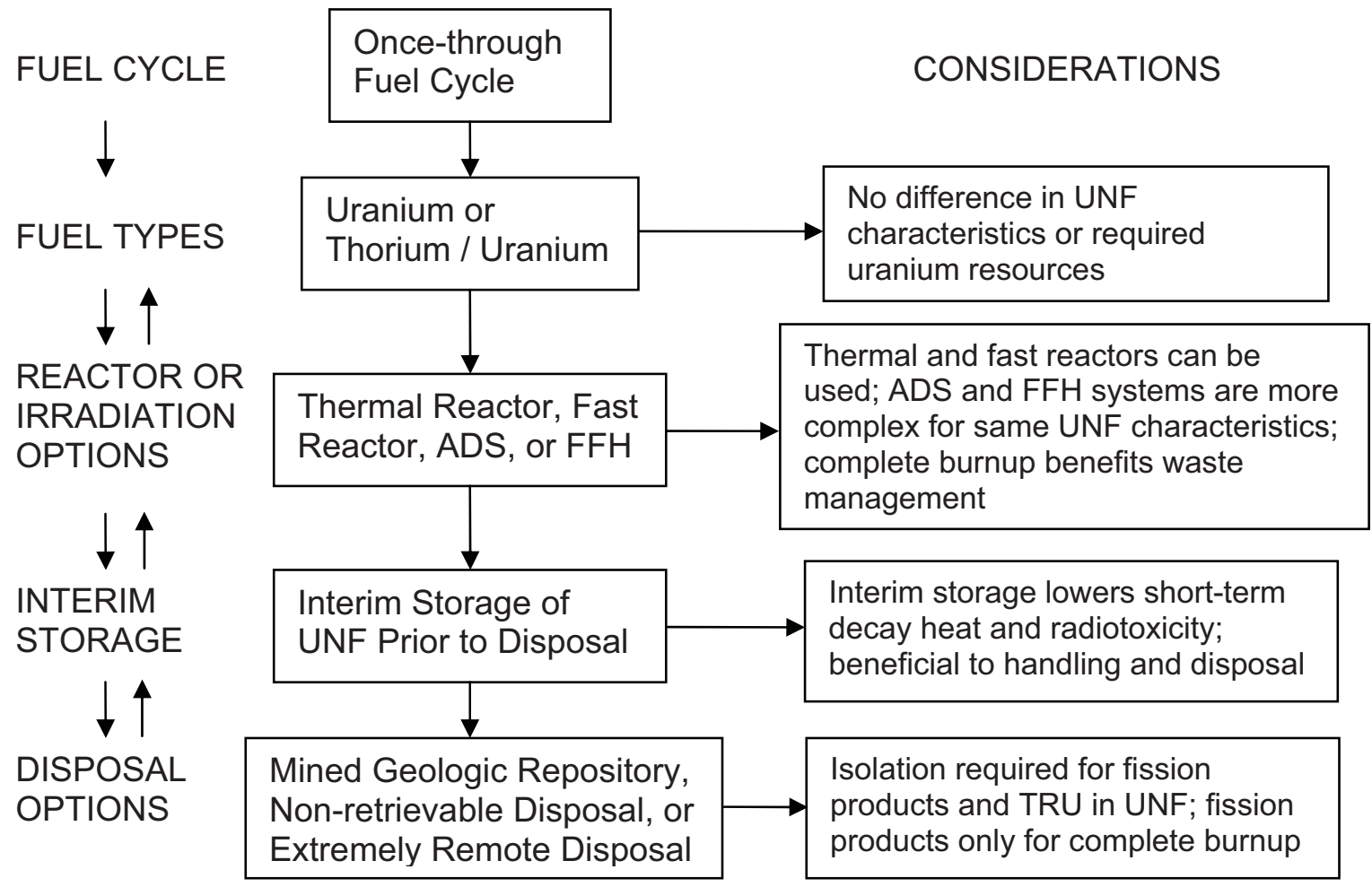

Figure 10. Decision Framework for Once-through Nuclear Fuel Cycle Strategies

\section{Limited Recycle Nuclear Fuel Cycle Strategy}

For the limited recycle nuclear fuel cycle strategy, there are more options to use advanced technologies given the more complex system shown schematically in Figure 2. However, as discussed in Chapter 3, there are no significant benefits due to the eventual disposal of UNF, and the changes with respect to the reference nuclear fuel cycle are incremental in nature. The only exception would be in the case where complete burnup was achieved, the same as for the once-through nuclear fuel cycle strategy. The decision framework for the limited recycle strategy is shown in Figure 11, where it must be stressed again that the order in which decisions are made is not unique, but only an example of a usable framework. In reality, the decision process would be integrated over all parts of the fuel cycle for optimum fuel cycle performance, and in this case requires careful coordination between incoming fuel and recycle fuel for irradiation and recycle, ultimately leading to disposal of some UNF. 


\section{DECISION FRAMEWORK FOR LIMITED RECYCLE NUCLEAR FUEL CYCLE STRATEGIES}

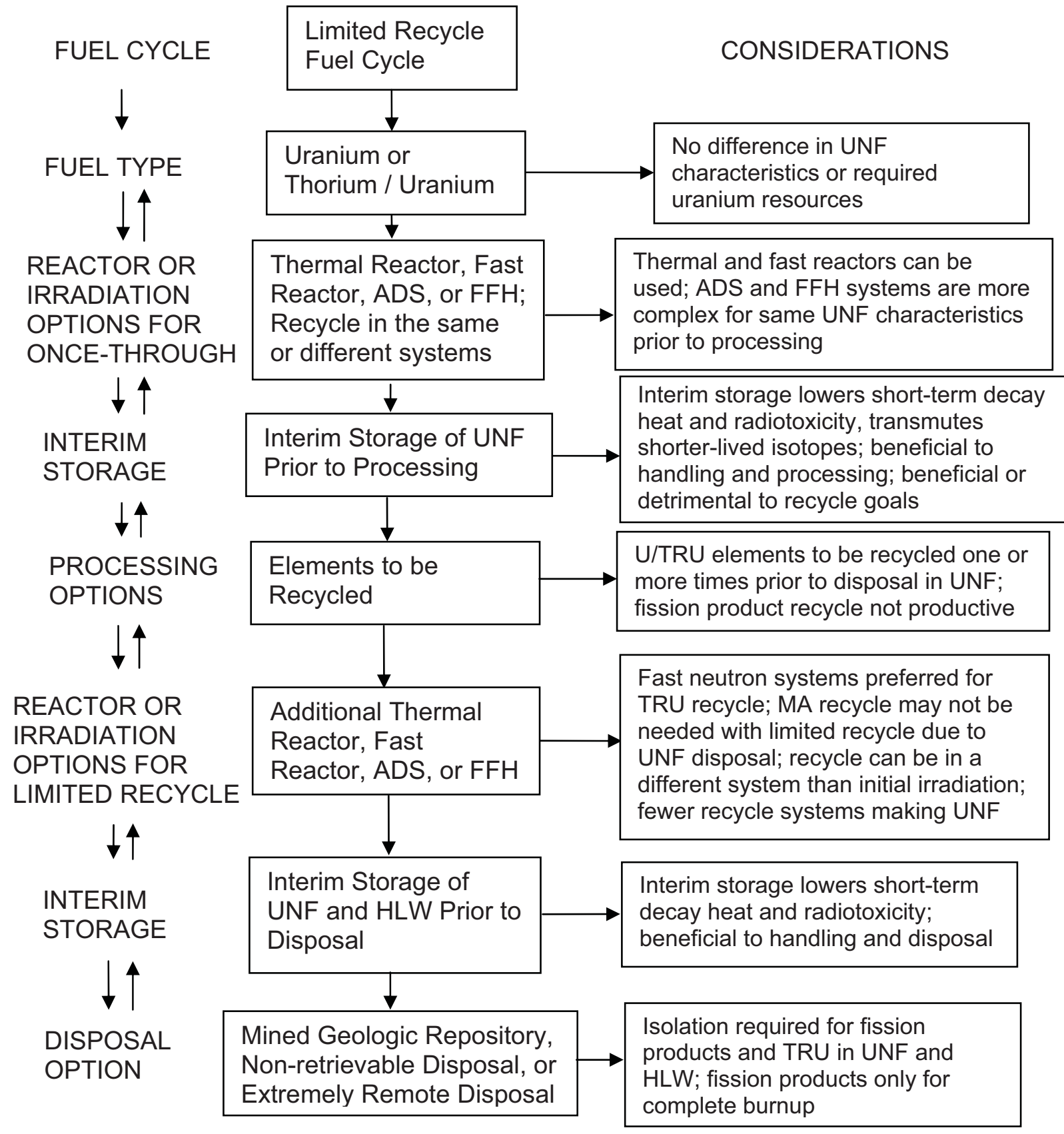

Figure 11. Decision Framework for Limited Recycle Nuclear Fuel Cycle Strategies

The first decision is the choice between uranium and thorium-uranium fuel, although both could be used, recognizing the increased infrastructure that would be needed. As with the once-through strategy, the uranium requirements are expected to be about the same with either fuel, although there is the possibility that some of the uranium may be offset by the breeding and recycle of U-233 if that choice is selected and the recycle fuel is used in the same irradiation system as the input fuel. The difference in uranium resource requirement is only expected to be an incremental change rather than a significant difference, i.e., not as large as an order of magnitude. As with the once-through option, if the same systems are used 
for both input fuel and recycle fuel, the ADS and FFH will be at a disadvantage due to the complexity of the systems but resulting in the same UNF characteristics.

A decision needs to be made about using the same or different reactors and irradiation options for the input fuel and the recycle fuel. There are advantages to either approach, and one can also consider using multiple system types for irradiation. Recycle in the same system allows using the recovered fissile fuel to offset new fuel needs. Using only one system simplifies the infrastructure. On the other hand, using multiple systems may allow designing the recycle systems for more effective recycle, especially if specific elements are targeted for transmutation prior to disposal, potentially reducing the number of recycle systems that are required. Combined approaches can be used, where part of the system is using a once-through approach where the UNF is processed and recycled once or a few times in the limited recycling part of the system. Both thermal and fast reactors are suitable for either once-through or recycle use, and it is possible that externally-driven sub-critical systems may have application for transmutation of certain materials such as minor actinides due to the relatively small amounts of these materials in UNF.

Interim storage can be used prior to processing to lower radiation and decay heat of the UNF, facilitating handling and easing processing requirements, but adding costs to the system. The radioactive decay also transmutes shorter-lived isotopes which may or may not be beneficial, depending on the specific recycle being pursued, i.e., are isotopes transmuting into something that will be recycled, or are they transmuting into other problematic isotopes. For example, the decay of $\mathrm{Pu}-241$ to Am-241 reduces the value of the plutonium as a fuel, so that more fuel from another source is required for the recycle fuel. Depending on the interim storage time, it may also be possible to enable recycle options that would not be attractive without interim storage. An example of this is the possible use of LWRs for TRU recycle, which becomes more attractive with longer interim storage due to the decay of higher actinide isotopes, limiting the subsequent buildup of these isotopes with TRU recycle in an LWR. However, if extended interim storage is used, the storage capacity will have to be large to accommodate the accumulation of UNF. Some interim storage will be required to allow the decay heat to decrease sufficiently to allow transport to the processing facility if centralized or regional processing facilities are used.

The processing requirements are driven entirely by the elements selected for recycle. As discussed in Section 4.3, most reprocessing technologies can be adapted to provide the required separations, either by altering the conditions or by adding additional processing steps specifically to recover the desired elements. However, the type of fuel will also affect the choice of processing technologies, since a given processing technology may not be suitable for every fuel type. In principle, there appears to be no significant difference between processing technologies with respect to proliferation risk, and most processing technologies can be implemented with minimal waste generation, although any distinction in this regard would be determined by design features. Economics will be determined by process complexity and the number of facilities required, offset by any reductions in disposal requirements for UNF and HLW disposal. The recycle fuel is fabricated, irradiated and then stored after discharge, awaiting either additional processing or disposal. At the point where the UNF is destined for disposal, interim storage can be used again to reduce radiation and decay heat, easing handling and disposal requirements.

As in the case of the once-through nuclear fuel cycle, geologic disposal performance is dependent on both fission product and actinide content in the UNF, and additionally dependent on the HLW content. The emphasis is again on selecting disposal options that provide isolation for both fission products and TRU, as is the case with LWR UNF today. If nearly complete burnup can be achieved for the UNF prior to disposal, the fission products still require long-term isolation, but the residual TRU may represent only a minor part of the overall risk. As a consequence, the decision on disposal options is unaffected by the choice of fuel type or burnup, can be made independently of the fuel choice, and is only incrementally affected by the selection of elements for recycle. 


\section{Continuous Recycle Nuclear Fuel Cycle}

For a continuous recycle nuclear fuel cycle strategy, there is a wide range of options to use advanced technologies given the complex system shown schematically in Figures 3 and 4. As discussed in Chapter 3 , there are opportunities to significantly impact the issues with nuclear power, but only for certain variations of a continuous recycle strategy as noted on Figure 12 which shows the decision framework. With continuous recycle, the burnup of the fuel is only relevant in that it determines the frequency of processing, and losses during processing including fabrication of recycle fuel are the only paths for TRU to be included in HLW. It is most important in this case to emphasize that the order in which decisions are made is not unique, and that the decision process will require iteration over all parts of the fuel cycle strategy to achieve optimum fuel cycle performance. Careful coordination between incoming fuel and recycle fuel for irradiation and recycle is essential, especially in recognition that multiple reactor types or irradiation options can be beneficial to overall system performance in addressing the issues with nuclear power. The continuous recycle strategy can also include components of the once-through strategy. For example, the UNF from once-through reactors can be processed and the recovered TRU recycled in other parts of the system that are using a continuous recycle so that only HLW is sent to geologic disposal. It is important to recognize the flexibility in constructing continuous recycle strategies, since such a combined approach will be needed during any transition from the current once-through strategy to an advanced continuous fuel cycle strategy and may have other benefits as well.

As with the other recycle strategies, the first decision is the choice between uranium and thorium / uranium fuel, although both could be used, recognizing the increased infrastructure that would be needed. With continuous recycle, there is the potential for the thorium/U-233 option to reduce or eventually eliminate the need for additional uranium resources if sufficient U-233 were bred in the system. Thorium resources would be required instead. Similarly, one could use the uranium/Pu-239 option to reduce uranium resource requirements, but both approaches have essentially identical proliferation concerns.

A decision needs to be made about using the same or different reactors and irradiation options for the input fuel and the recycle fuel. There are advantages to either approach, and one can also consider using multiple system types for irradiation. In particular, fast neutron irradiation for recycle fuel would be preferred over thermal neutron irradiation for continuous recycle, as discussed in Chapter 4. Recycle in the same system allows using the recovered fissile fuel to offset new fuel needs, possibly encouraging consideration of integrated fuel cycles that rely entirely systems designed for enhanced resource utilization. In addition, using only one system simplifies the infrastructure. On the other hand, using multiple systems may allow designing the recycle systems for more effective recycle, especially if specific elements are targeted for transmutation prior to disposal, potentially reducing the number of recycle systems that are required. ADS and FFH may offer potential in such roles. In addition, the liquid-fueled systems and some fast reactor options directly integrate irradiation and processing into a single facility. Any proposed integrated fuel cycle needs to be evaluated in its entirety before making any conclusions about the desirability of particular technology options.

Interim storage can be used prior to processing to lower radiation and decay heat of the UNF, facilitating handling and easing processing requirements, but providing interim storage adds costs as well. The radioactive decay transmutes shorter-lived isotopes, a process which may or may not be beneficial, depending on the specific recycle being pursued, i.e., are isotopes transmuting into something that will be recycled, or are they transmuting into other problematic isotopes. As with limited recycle, depending on the interim storage time, it may also be possible to enable recycle options that would not be attractive without interim storage. An example of this is the possible use of LWRs for TRU recycle, which may become more attractive with longer interim storage due to the decay of higher actinide isotopes, limiting the subsequent buildup of these isotopes with TRU recycle in an LWR. However, if extended interim storage is used, the storage capacity will have to be large to accommodate the accumulation of UNF. It should be recognized that some interim storage would be required to allow the decay heat to decrease 
sufficiently to allow transport to the processing facility if centralized or regional processing facilities are used.

\section{DECISION FRAMEWORK FOR CONTINUOUS RECYCLE NUCLEAR FUEL CYCLE STRATEGIES}

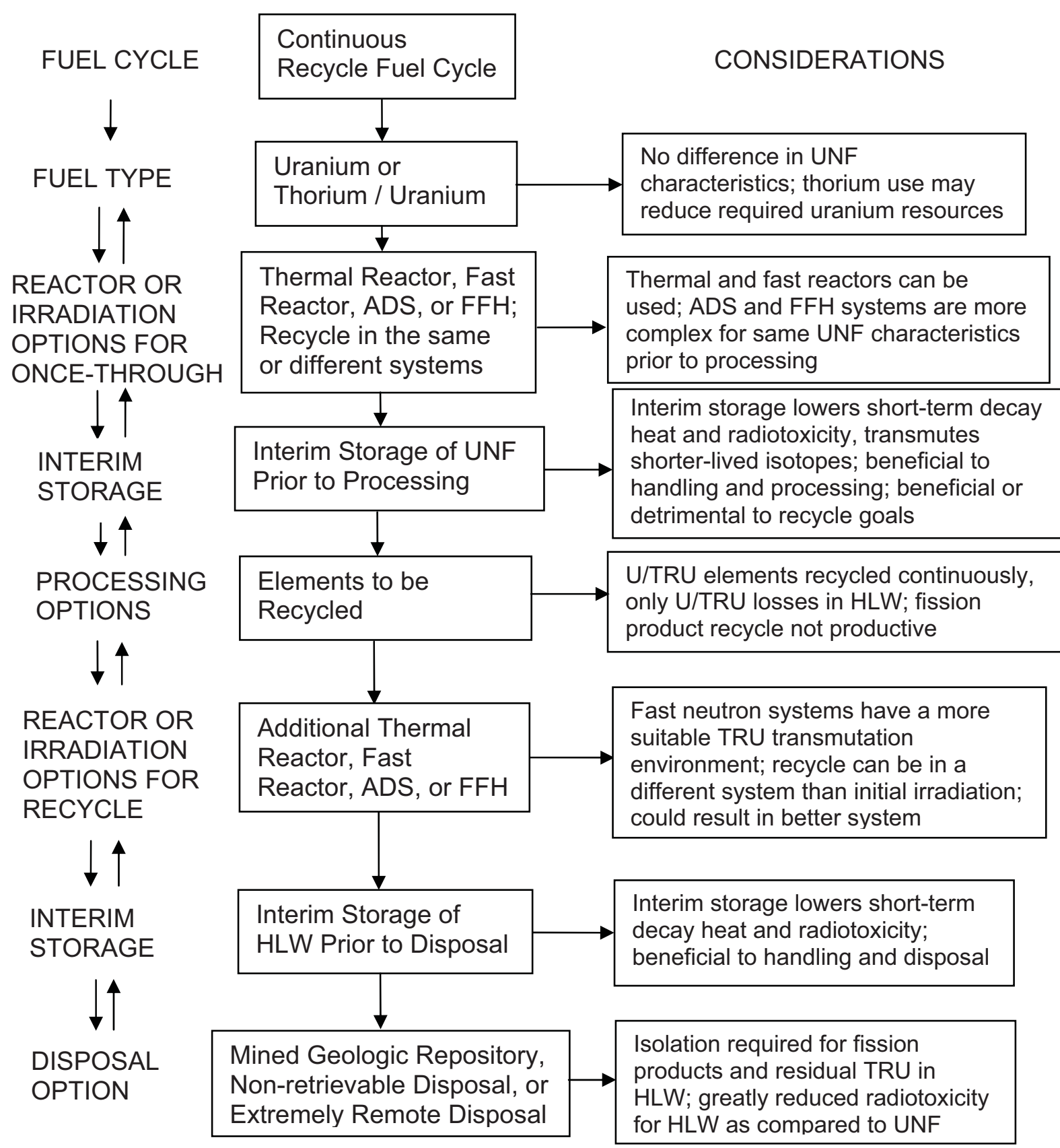

Figure 12. Decision Framework for Continuous Recycle Nuclear Fuel Cycle Strategies

The processing requirements are driven entirely by the elements selected for recycle. As discussed in Section 4.3, most reprocessing technologies can be adapted to provide the required separations, either by altering the conditions or by including additional processing steps specifically to recover the desired 
elements. However, the type of fuel will also affect the choice of processing technologies, since a given processing technology may not be suitable for every fuel type. With continuous recycle, the processing losses of TRU, both from UNF processing and fuel fabrication, are extremely important, since only HLW is generated. Technologies that have very low TRU losses would be advantageous in that the residual TRU content in the HLW has a direct impact on the TRU hazard from the HLW. In principle, there appears to be no significant difference between processing technologies for proliferation risk, and the contribution from processing activities to proliferation risk may not necessarily be significant, most processing technologies can be implemented with minimal waste generation, although any distinction in this regard would be determined by design features. Economics will be determined by process complexity and the number of facilities required, offset by any reductions in disposal requirements for HLW disposal.

The recycle fuel is fabricated, irradiated and then stored after discharge, awaiting additional processing. In the case where the recycle fuel is irradiated in different reactor types or irradiation facilities, it is recognized that different processing could be used on the recycle UNF as for the processing of the initial UNF. At the point where the HLW is destined for disposal, interim storage can be used again to reduce radiation and decay heat, easing handling and disposal requirements.

With continuous recycle, geologic disposal performance is dependent mainly on the fission product content of the HLW. Regardless, the emphasis is on selecting disposal options that provide isolation for both fission products and TRU, as is the case with LWR UNF today, unless the residual TRU content in the HLW can be nearly completely eliminated. The decision on disposal options is unaffected by the choice of fuel type or burnup, can be made independently of the fuel choice, but may be affected by the selection of elements for recycle as that determines the HLW content.

\section{Summary}

To date, the AFCI Options Study has examined the issues with the current use of nuclear power and collected and summarized the extensive results from previous studies for identifying the issues, the root causes, and the evaluation measures to be used for alternative fuel cycle and technology options. The importance of the fuel cycle strategy is discussed, as this directly affects the ability of an alternative fuel cycle to address the issues with nuclear power. The technology options are reviewed for the four major technology areas, fuel type (form and content), reactors and irradiation, processing, and disposal. The general capabilities for each option are summarized with respect to the potential effect that the option could have in addressing the nuclear power issues. The report concludes with a discussion of the decision framework for both nuclear fuel cycle strategies and the associated technology options, recognizing the overall advantages and limitations of various choices.

A number of observations can be made at this stage of the AFCI Options Study. It is seen that the only fuel cycle strategy that can have a significant impact, i.e., an order of magnitude or more change, with respect to the nuclear power issues is continuous recycle of all TRU elements. There may be a special case for near-complete burnup of UNF that could also result in significant impact on the issues, making once-through and limited recycle strategies more attractive, since such an approach is essentially equivalent to a continuous recycle strategy where all TRU is recycled. However, after a review of the technical issues as discussed in Chapter 4 , this possibility is considered impractical, maybe even impossible. Deciding on the fuel cycle strategy before discussing technology options is considered the important first step in considering alternative nuclear fuel cycle systems.

In considering the technology options for fuel type, either uranium-based or thorium-based, it is only in the case of continuous recycle where these two fuel types exhibit different characteristics, and it is important to emphasize that this difference only exists for a fissile breeder strategy. The comparison between the thorium/U-233 and uranium/Pu-239 option shows that the thorium option would have lower, 
but probably not significantly lower, TRU inventory and disposal requirements, both having essentially equivalent proliferation risks. For these reasons, the choice between uranium-based fuel and thoriumbased fuels is seen basically as one of preference, with no fundamental difference in addressing the nuclear power issues. Since no infrastructure currently exists in the U.S. for thorium-based fuels, and processing of thorium-based fuels is at a lower level of technical maturity when compared to processing of uranium-based fuels, costs and RD\&D requirements for using thorium are anticipated to be higher. The availability and utilization of thorium-based fuels along with the uranium fuel technology in the U.S. would however make available more nuclear fuel resources for future nuclear expansion.

For reactor or irradiation options, both thermal and fast reactors are suitable for use in a once-through strategy. Externally-driven sub-critical systems are likely to be generally uncompetitive economically due to the additional size and complexity required. The same is likely to be true for the limited recycle strategy, since UNF disposal is part of the integrated system. In both cases, incremental improvements such as higher UNF burnup can be used to reduce the volume of UNF requiring geologic disposal, but with little impact on disposal issues. The selected reactor systems can be mature technologies or a more innovative approach with higher technical risk. Cost has not been a major discriminator between thermal reactor options to date, with the developers of all approaches aiming for lower overall costs.

However, with continuous recycle of TRU, fast neutron irradiation may be preferable due to the more favorable transmutation environment, i.e., more surplus neutrons, less disturbance to the system due to the introduction of additional TRU, etc. as discussed in Chapter 4, resulting in essentially complete burnup. Either fast neutron reactors or externally-driven sub-critical systems could be used, but due to the increased size, complexity and cost of the latter, any deployment would likely be limited to specialized applications such as minor actinide transmutation. Fast reactors are capable of continuous TRU recycle for transmutation, and although sodium-cooled fast reactor technology is mature, it is not without technical risk. Other fast reactor options are at a lower level of development with significant technical issues remaining and have higher development risk. Liquid-fueled systems such as the MSR provide an alternative to the solid fuels approach that can operate with thermal or fast neutrons where the on-line processing could also potentially allow complete burnup. Accelerator-driven sub-critical systems and fusion-fission hybrid systems also rely on fission reactor technology, both thermal and fast, which adds to the technical risk associated with the external neutron source, requiring truly major development efforts to develop and integrate the external neutron source with neutron fission technologies.

Processing is usually only associated with recycle strategies, although it could also be considered for once-through use if the benefit of having HLW instead of UNF was high enough to offset all of the added costs. At this time, this does not seem likely, so the discussion of processing is confined to recycle strategies in this report. Applicable processing options in any given fuel cycle strategy will be determined by the separations and recovery goals, the types and characteristics of the fuel being processed, relative proliferation risk, and economics. At this time, aqueous-based methods are more technically mature with low technical risk, although some of the alternatives such as electro-chemical processing are also at a stage of development where technical risk should be relatively low. A related issue is the possibility for on-site processing as compared to centralized processing with the capability to greatly reduce the impacts of storage and transportation.

It is essential to recognize that waste disposal remains a common element for all nuclear fuel cycle strategies, being required for the disposal of highly radioactive materials, whether from fission products alone or including long-lived TRU. All UNF and HLW disposal options face the same issue of demonstrating the required isolation for these materials. There are also non-technical issues such as political and public acceptance that can dominate the decision-making process for siting and licensing such facilities. Continuous recycle appears to be the only practical fuel cycle strategy that can significantly affect waste management issues for UNF and HLW, but only if all of the TRU is recycled, leaving only fission products and residual amounts of TRU in the HLW. 


\section{Future Work}

The AFCI Options Study has reviewed the issues and root causes with the current approach to nuclear power. Initial evaluations of the fuel cycle strategies and technologies have been performed based on existing information, suitable to provide initial suggestions for options that may have the ability to significantly affect the issues. A decision strategy has been suggested, where the fuel cycle strategy is decided first, followed by consideration of technology options. At this stage of the study, many of the evaluations have only been qualitative, while for others information was sparse or lacking. The next phase of the study needs to be a comprehensive review of the capabilities of specific options in the context of the fuel cycle strategies identified. Such review would benefit from a decision on the fuel cycle strategy and overall goals for an advanced fuel cycle in that it would focus the analyses on relevant options. It is likely that new analyses on specific options will be required to fully inform the decisionmaking process, especially for novel or innovative technologies. The result of the next phase would be a more detailed, more quantified, assessment of advanced fuel cycles and technologies that would aid in providing direction for nuclear energy research and development.

\section{References}

1. "Nuclear Proliferation and Civilian Nuclear Power - Report of the Nonproliferation Alternative Systems Assessment Program,” DOE/NE-0001/9, June 1980.

2. "Nuclear Wastes-Technologies for Separations and Transmutation", National Research Council, National Academy Press, 1996.

3. “A Roadmap for Developing Accelerator Transmutation of Waste (ATW) Technology", DOE/RW0519, DOE, 1999.

4. "Final Report of the Panel to Review the Spent Fuel Standard for Disposition of Excess Weapons Plutonium, Committee on International Security and Arms Control," National Academy of Sciences, Washington, DC, 2000.

5. "Annex: Attributes of Proliferation Resistance for Civilian Nuclear Power Systems," Nuclear Energy Research Advisory Committee (NERAC), October 2000.

6. "Technological Opportunities to Increase the Proliferation Resistance of Global Civilian Nuclear Power Systems (TOPS)," Report by the TOPS Task Force of the Nuclear Energy Research Advisory Committee.

7. "Report to Congress - The Advanced Accelerator Applications Program Plan," March, 2001.

8. “A Report to Congress on Electrometallurgical Treatment Waste Forms," March 2001.

9. Candidate Approaches for an Integrated Nuclear Waste Management Strategy - Scoping Evaluations," AAA Program Report, LA-UR-01-5572, November 2001.

10. A Technology Roadmap for Generation IV Nuclear Energy Systems, GIF-002-00, USDOE, December 2002.

11. "Report to Congress on Advanced Fuel Cycle Initiative: The Future Path for Advanced Spent Fuel Treatment and Transmutation Research," U.S. Department of Energy, Office of Nuclear Energy, Science and Technology, January 2003.

12. "The U.S. Generation IV Implementation Strategy," U.S. Department of Energy Report, September 2003.

13. “Advanced Fuel Cycle Initiative (AFCI) Comparison Report, FY 2003,” U.S. Department of Energy, Office of Nuclear Energy, Science and Technology, October 2003. 
14. “Advanced Fuel Cycle Initiative (AFCI) Comparison Report, FY2004,” U.S. Department of Energy, Office of Nuclear Energy, Science and Technology, September 2004.

15. Generation IV Nuclear Energy Systems Ten-Year Program Plan,” Volume II: Appendices, DOE Office of Nuclear Energy, Science and Technology, March 2005.

16. “Advanced Fuel Cycle Initiative (AFCI) Comparison Report, FY 2005," U.S. Department of Energy, Office of Nuclear Energy, Science and Technology, May 2005.

17. "Report to Congress - Advanced Fuel Cycle Initiative: Objectives, Approach, and Technology Summary," U.S. Department of Energy, Office of Nuclear Energy, Science, and Technology, May 2005.

18. "Report to Congress: Spent Nuclear Fuel Recycling Program Plan," U.S. Department of Energy, May 2006.

19. “Advanced Fuel Cycle Initiative (AFCI) Comparison Report, FY 2006 Update,” U.S. Department of Energy, Office of Nuclear Energy, July 2006.

20. The Proliferation Resistance and Physical Protection Evaluation Methodology Expert Group of the Generation IV International Forum, Evaluation Methodology for Proliferation Resistance and Physical Protection of Generation IV Nuclear Energy Systems, GIF/PRPPWG/2006/005, Revision 5, November 30, 2006.

21. National Academy of Sciences, "Going the Distance - The Safe Transport of Spent Nuclear Fuel and High-Level Radioactive Waste in the United States," Committee on Transportation of Radioactive Waste, National Research Council, 2006.

22. National Academy of Sciences, "Safety and Security of Commercial Spent Nuclear Fuel Storage: Public Report," Committee on Transportation of Radioactive Waste, National Research Council, 2006.

23. Global Nuclear Energy Partnership Technology Development Plan, GNEP-TECH-TR-PP-200700020, Rev. 0, July 25, 2007.

24. Global Nuclear Energy Partnership Statement of Principles, September 16, 2007; http://www.gnep.energy.gov/pdfs/GNEP_SOP.pdf.

25. U.S. Committee on the Internationalization of the Civilian Nuclear Fuel Cycle; Committee on International Security and Arms Control, Policy and Global Affairs; National Academy of Sciences and National Research Council, "Internationalization of the Nuclear Fuel Cycle: Goals, Strategies, and Challenges," 2008.

26. M. B. Nikitin, J. M. Parillo, S. Squassoni, A. Andrews, M. Holt, "CRS Report for Congress Managing the Nuclear Fuel Cycle: Policy Implications of Expanding Global Access to Nuclear Power," Congressional Research Service, March 7, 2008.

27. "Global Nuclear Energy Partnership Technology Roadmap Phase I," GNEP-TIO-PMO-MI-DV-2008000295 Rev. 0, August 30, 2008.

28. R. Bari, "Proliferation Resistance and Physical Protection (PR\&PP) Evaluation Methodology: Objectives, Accomplishments, and Future Directions", Proceedings of Global 2009, pg.2431, September, 2009.

29. C. Bathke et al., "The Attractiveness of Materials in Advanced Nuclear Fuel Cycles for Various Proliferation and Theft Scenarios," Proceedings of Global 2009, Paris, France, September 6-11, 2009. 
30. D. Greneche and L. Boucher, "A Status of Methodology Developments in France for Assessing Proliferation Resistance of Nuclear Energy Systems," Proceedings of Global 2009, Paris, France, September 6-11, 2009.

31. "Total System Performance Assessment Model/Analysis for the License Application", MDL-WISPA-000005 Rev 00, U.S. Department of Energy Office of Civilian Radioactive Waste Management, January 2008.

32. "Red Impact - Impact of Partitioning, Transmutation, and Waste Reduction Technologies on the Final Nuclear Waste Disposal - Synthesis Report," Forschungszentrum Jülich, GmbH, FP6 Contract No: F16W-CT-2004-002408, September 2007.

33. "Advanced Nuclear Fuel Cycles and Waste Management," OECD/NEA No. 590 (ISBN 92-64-024859), 2006.

34. "Trends in the Nuclear Fuel Cycle: Economic, Environmental and Social Aspects" (OECD-NEA, 2001).

35. E. Johnson, et al, "Design Concept for a 900-MWe Scale-Up of the 60-MWe Shippingport LWBR", WAPD-TM-1380, Bettis Atomic Power Laboratory, October 1982.

36. U.S. Department of Energy, Nuclear Proliferation and Civilian Nuclear Power: Report of the Nonproliferation Alternative Systems Assessment Program (NASAP), DOE/NE-0001/1-9

37. R. Skjoldebrand, The International Nuclear Fuel Cycle Evaluation, IAEA Bulletin-Vol.22,No.2, International Atomic Energy Agency

38. C. W. Forsberg, et al, "Definition of Weapons-Usable Uranium-233", ORNL/TM-13517,Oak Ridge National Laboratory, March 1998

39. A. Andrews, "Nuclear Fuel Reprocessing: U.S. Policy Development," CRS Report for Congress, Order Code RS22542, March 27, 2008.

40. "Final Environmental Impact Statement - Management of Commercially Generated Radioactive Waste - Volume 1", U.S. Department of Energy, DOE/EIS-0046F, October, 1980.

41. "The Disposal of Radioactive Waste on Land", NAS-NRC (National Academy of Sciences - National Research Council), Publication 519, 1957.

42. "Disposition of High-Level Waste and Spent Nuclear Fuel: The Continuing Societal and Technical Challenges", National Academy of Sciences - National Research Council, ISBN-10: 0-309-07317-0, 2001.

43. International Atomic Energy Agency. The Principles of Radioactive Waste Management. Safety Series No. 111-5, 1995.

44. "Deep Borehole Disposal Facility PEIS Data Input Report for Immobilized Disposal," UCRL-ID119735, and "Deep Borehole Disposal Facility PEIS Data Input Report for Direct Disposal," UCRLID-119481, Lawrence Livermore National Laboratory, Livermore, CA. 94550, April, 1995.

45. "Final Environmental Impact Statement - Management of Commercially Generated Radioactive Waste - Volume 1", U.S. Department of Energy, DOE/EIS-0046F, October, 1980.

46. B. Sapiie and M. Driscoll, "A Review of Geology-Related Aspects of Deep Borehole Disposal of Nuclear Wastes," Massachusetts Institute of Technology, MIT-NFC-TR-109, August 2009. 